\title{
Prenatal stress and adult psychopathology
}

Citation for published version (APA):

van den Hove, D. L. A. (2006). Prenatal stress and adult psychopathology. [Doctoral Thesis, Maastricht University]. Maastricht University. https://doi.org/10.26481/dis.20060427dh

Document status and date:

Published: 01/01/2006

DOI:

$10.26481 /$ dis.20060427dh

Document Version:

Publisher's PDF, also known as Version of record

\section{Please check the document version of this publication:}

- A submitted manuscript is the version of the article upon submission and before peer-review. There can be important differences between the submitted version and the official published version of record.

People interested in the research are advised to contact the author for the final version of the publication, or visit the DOI to the publisher's website.

- The final author version and the galley proof are versions of the publication after peer review.

- The final published version features the final layout of the paper including the volume, issue and page numbers.

Link to publication

\footnotetext{
General rights rights.

- You may freely distribute the URL identifying the publication in the public portal. please follow below link for the End User Agreement:

www.umlib.nl/taverne-license

Take down policy

If you believe that this document breaches copyright please contact us at:

repository@maastrichtuniversity.nl

providing details and we will investigate your claim.
}

Copyright and moral rights for the publications made accessible in the public portal are retained by the authors and/or other copyright owners and it is a condition of accessing publications that users recognise and abide by the legal requirements associated with these

- Users may download and print one copy of any publication from the public portal for the purpose of private study or research.

- You may not further distribute the material or use it for any profit-making activity or commercial gain

If the publication is distributed under the terms of Article $25 \mathrm{fa}$ of the Dutch Copyright Act, indicated by the "Taverne" license above, 


\title{
Prenatal stress and adult psychopathology
}

\author{
Daniël L.A. Van den Hove
}


(c) Daniel L.A. Van den Hove, Maastricht, 2006

Coverdesign by fan de Vente

'Tlypesettung by Michal Slawiński

ISBN-10: 90-9020569-1

ISBN-13:978-90-9020569-4

Printed in Poland 


\section{Prenatal stress and adult psychopathology}

\section{Proefschrift}

ter verkrijging van de graad van doctor

aan de Universiteit Maastricht

op gezag van de Rector Magnificus, Prof. Mr. G.P.M.F. Mols

volgens het besluit van het College van Decanen

in het openbaar te verdedigen

op donderdag 27 april 2006 om 16:00 uur

door

Daniël L.A. Van den Hove 


\section{Promotores:}

Prof. Dr. H.WM. Steinbusch

Prof. Dr. C.E. Blanco

\section{Co-promotores:}

Dr. I. Prickaerts

Dr. A. Scheepens (University of Auckland, New-Zealand)

\section{Beoordelingscommissie:}

Prof. Dr. J. Van Os (voorzitter)

Prof. Dr. J.M. Lauder (University of North Carolina, USA)

Prof, Dr. B.E. Leonard

Prof. Dr. G.H.A. Visser (Universiteit Utrecht)

Prol. Dr. L. J. I. Zimmerman 


\section{Contents}

Chapter 1 General Introduction: Prenatal stress and adult psychopathology 9

Chapter 2 Prenatal stress and neonatal rat brain development

Chapter 3 Prenatal stress reduces S100B in the neonatal rat hippocampus in a sexually divergent manner

Chapter 4 Prenatal stress in the rat alters $5-\mathrm{HT}_{1 \mathrm{~A}}$ receptor binding in the ventral hippocampus

Chapter 5 Prenatal restraint stress and long-term affective consequences

Chapter 6 Prenatal stress and behavior in the rat; the implications of a subsequent exposure to stress

Chapter 7 Prenatal stress produces anxiety- and depression-related behavior particularly in male Sprague-Dawley rats

Chapter 8 Maternal paroxetine treatment and neonatal mortality in the rat; a preliminary investigation

Chapter 9 General Discussion: Prenatal stress and adult psychopathology 119

Summary

Samenvatting

Curriculum Vitae

Acknowledgements/Dankwoord

Publications 



\section{Abbreviations}

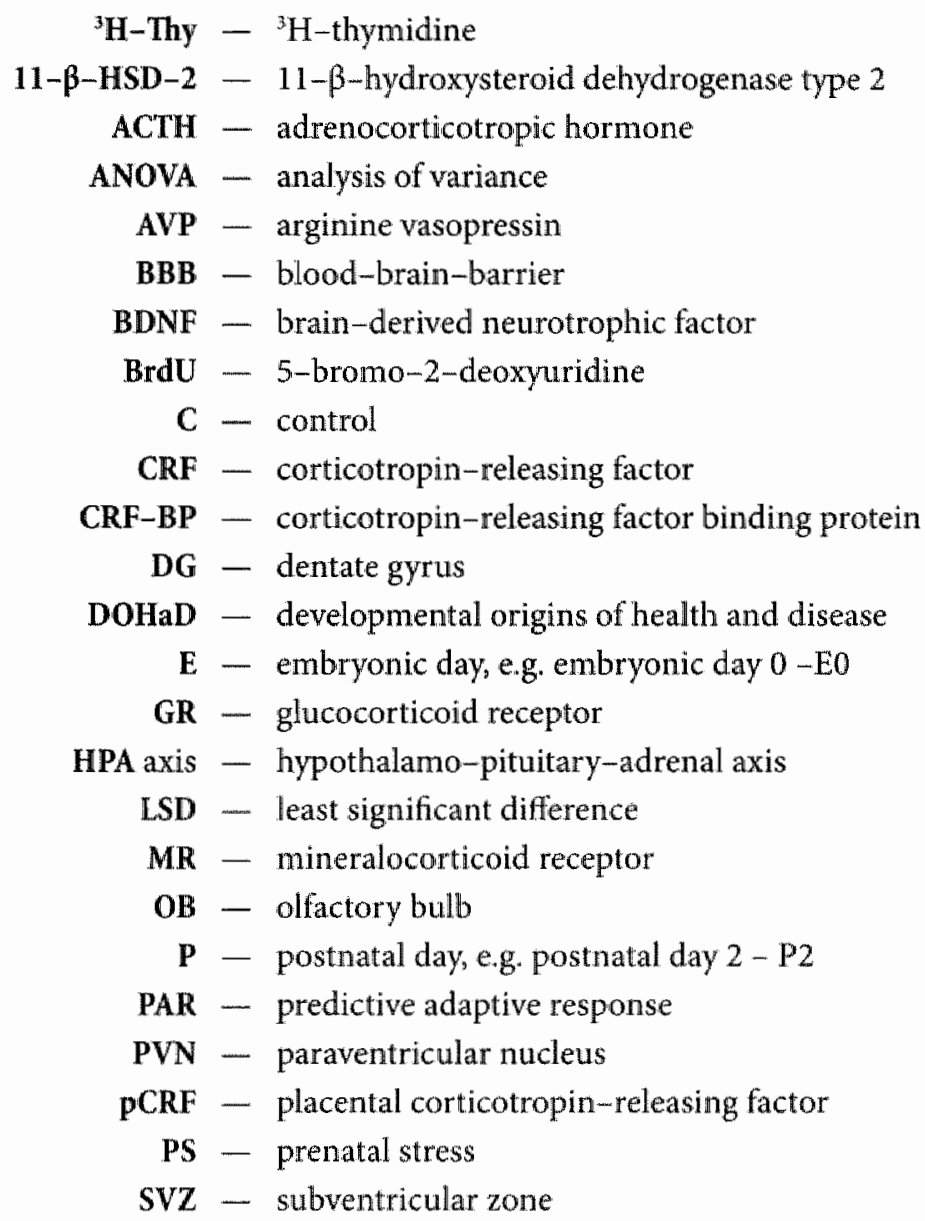





\section{Chapter 1}

\section{General Introduction}

\section{Prenatal stress and adult psychopathology}

Van den Hove DLA 


\section{Introduction}

In approximately 400 B.C. Hippocrates reported that the emotional state of a pregnant woman may affect the child she carries. Amost two millennia later Leonardo da Vinci wrote in his Quaderni: "... one fear that the mother has, or mental pain, has more power over the child than over the mother, since frequently the child loses its life thereby."

Nowadays, it has become increasingly clear that adverse events experienced by the pregnant mother, be they physical or emotional, may be reflected upon the developing fetus and adversely affect its physical and mental wellbeing in later life.

It is difficult to give an estimate of the number of people that are affected by prenatal stress (PS) in adult life, given for example, the extended period of time between the actual stress and the appearance of clinical symptoms in the affected offspring. Yet, its clinical relevance is evident, considering for example several retrospective clinical studies which report a higher incidence of behavioral abnormalities in offspring exposed to PS. Well-documented examples of maternal stress during pregnancy concern familial and marital discord (Stott, 1973), threat of impending war (Meijer, 1985), actual loss of the husband in the Second World War (Huttunen and Niskanen, 1978), and surviving a severe earthquake (Watson et al., 1999). Maternal depression and anxiety can also be regarded as maternal stress. Depression and anxiety affect $13.5 \%$ and $4.7 \%$ of reproductive-aged. women, respectively (Robins and Regier, 1991, Kessler et al., 1993).

In humans, PS has been associated with an increased incidence of cranial neural-crest malformations (Hansen et al., 2000), preterm delivery, and lower birth weight (Stein et al., 1987, Pagel et al., 1990, Hedegaard et al., 1993, Wadhwa et al., 1993, Lou et al., 1994, Copper et al., 1996, Hedegaard et al., 1996, Ruiz et al., 2002, Rondo et al., 2003). Moreover, when corrected for binth weight, PS is also related to a reduced head circumference (Lou et al., 1994). Further, PS has been related to impaired physical development (Jones and Tauscher, 1978, Knipschild et al., 1981, Lou et al., 1994), hyperactivity attention deficit disorder (Clements, 1992), Gilles de la Tourette's syndrome (Pasamanick and Kawi, 1956) as well as various learning, behavioral and/or psychiatric disorders in later life including schizophrenia, anxiety and depression (Stott, 1973, Huttunen and Niskanen, 1978, Meijer, 1985, Ward, 1991, van Os and Selten, 1998, Watson et al., 1999).

In animal studies PS has been associated with reduced birth weight as well as increased preweaning morbidity and mortality (e.g. Cabrera et al., 1999, Tuchscherer et al., 2002). In addition, PS has been linked to hyperglycaemia and glucose intolerance (Lesage et al., 2004), an altered immune response (Coe and Lubach, 2005), and disturbances in the hypothalamopituitary-adrenal (HPA) axis (see review by Weinstock, 2005). Further, PS may lead to impaired sexual function (Ward and Reed, 1985), learning and memory deficits (Hayashi et al., 1998, Vallee et al, 1999, Szuran et al., 2000, Gue et al., 2004), increased anxiety (Archer and Blackman, 1971, Fride and Weinstock, 1988, Wakshlak and Weinstock, 1990, Vallee et al., 1997, Griffin et al,, 2003, Rimondini et al., 2003, Dickerson et al., 2005, Estanislau and Morato, 2005), paradoxical sleep alterations (Dugovic et al., 1999, Rao et al., 1999), and increased 
depression-related behavior in later life (Secoli and Teixeira, 1998, Alonso et al, 1999, Morley-Fletcher et al, 2003a, Morley-Fletcher et al, 2003b, Morley-Fletcher et al., 2004).

Investigations on the putative mechanisms involved have primarily focused on the HPA axis. The regulation of its response to stress is thought to be impaired in PS subjects. As a result, PS offspring may be unable to react appropriately to stressfull life events lt has been suggested that PS may lead to a situation in which the brain is permanently hypersensitized to subsequent stressful situations (Weinstock, 1997, Weinstock, 2005). Besides HPA axis alterations, reductions in uteroplacental blood flow, reducing nutrient and oxygen supply to the fetus, received major interest as factors involved in PS-related psychopathology (Huizink et al., 2004).

The purpose of this chapter is to stress the importance of the prenatal environment and to highlight some of the primary and secondary mechanisms that contribute to the pathophysiological changes observed in PS offspring. Discussed are the long-term effects of impaired fetal growth associated with PS, the organization of both the maternal and fetal HPA axis during pregnancy, and the role of placental blood flow in mediating the effects of PS. Further discussed is the serotonin (5-HT) system, brain cell proliferation and cell death, and the role of neurotrophic factors in these events. Finally, this chapter highlights the aims and outline of this thesis.

\section{Developmental origins of adult health and disease}

A growing body of evidence indicates that alterations in the fetal environment can have longterm consequences on metabolic and endocrine functioning in later life. The developmental origins of health and disease' (DOHaD) concept (Gillman, 2005) states that the risk of disease in adulthood partly depends upon variations in the prenatal environment, which are often reflected in weight/size at birth (Barker, 1995). Fetal undernutrition, for example, resulting in impaired fetal growth and reduced birth weight, predisposes individuals to the development of e.g. cardiovascular disease and non-insulin-dependent (or type 2) diabetes mellitus in later life (Curhan et al., 1996, Barker et al., 2002). Recently, reduced birth weight has also been linked to an increased susceptibility to stress (Nilsson et al., 2001) and an in* creased risk for depression in adulthood (Thompson et al., 2001, Gale and Martyn, 2004). Of note, the relationship between fetal growth and disease risk in later life reflects the sensitivity of fetal growth to adverse intrauterine influences and does not imply a causal role of being born small (Gluckman and Hanson, 2004b). In this respect, low birth weight is regarded as a marker for impaired fetal development rather than a contributory factor.

The predictive adaptive response" (PAR) hypothesis recently proposed (Gluckman and Hanson, 2004b, Gluckman and Hanson, 2004a) states that a growing fetus tries to predict the environment it is likely to live in after birth to have an optimal chance of survival in that particular environment. In reaction to nutritional and hormonal cues it receives from its mother -environmental perception by the mammalian embryo/fetus largely depends on the mother 
and the placenta- the fetus adjusts its physiology using developmentally plastic processes, based upon the current and thus predicted conditions.

Though developmental adaptations usually favor outcome , the persistemce of PARs after birth can also have detrimental consequences in adult life, i.e, if the predicted and the actual enviromment do not match. This may lead to an increased risk of disease in later life. In view of the PAR liypothesis, the relation between birth weight and disease risk in adulthood may be explained by a mismatch in pre- and postnatal nutritional status. That is, for example, if a fetus responds to an adverse intrauterine environment by reducing its growth and making $\mathrm{PARs}$ in expectance of a nutritionally-deprived postnatal environment, but ends up in a nutrition-rich postnatal environment. In line with this, those who are born smallest and gain weight fastest after birth, i.e., fast catch-up growth, are at greatest risk for disease in later life (Barker et al., 2002, Gluckman and Hanson, 2004b). Of note, epigenetic changes, i.e., DNA methylation patterns, are thought to be crucial in exerting the effects of envirommental cues on the developing fetus and therefore in the regulation of PARs (Gluckman and Hanson, 2004b, Gluckman and Hanson, 2004a).

\section{Primary mechanisms}

\section{Hormonal response to stress}

\section{The hypothalamo-pituitary-adrenal axis}

The maintenance of a stable internal enviromment or homeostasis, an essential process for the survival of living organisms, is constantly being challenged by intrinsic and extrinsic, real and perceived adverse forces or stressors. In this respect, stress is defined as a state of (perceived) threatened homeostasis and represents both the subjective experience induced. by a stressor, as well as the adaptive neurochemical and behavioral response to it, in order to preserve homeostasis (Charmandari et al., 2005).

\footnotetext{
"Developnental adaptations (PARs) of fetall endocrine netabolic mechanisms in reaction to an adverse intraterine milieu regularly primantly support surwival in the short torm. A well-studied example of how PAks based on an adverse prenatal environment may yield a surval ad vantage is that of the snowshoe hare, a rabitulike mammal. In case of scarce food popuarion. density of snowsho hares declines due to starvation. The few thares that survive now oppose an additional threat, i.e., that of natural predarors (the individual chance of being canght increases). As a result, pregnant lenale hares have thigh cortisol levels during pregnancy which reach the fetus, thus altering the sensitivity of the fetal HPA axis (see: Gestational stress and the HPA uxisy. Consequently, oftspring ate more responsive to stress, i.e., more vigilant from early life onwards. This incteased alertness makes then mote aware of the greater threat of predators, by which they are more likely to survive unill food supplies improve. Predator population densiky decreases, $i$, , the envirommental challenge lessens and as a result pregnant hares are less stressed and their oftspritg in turn show reduced HPA axis reactiwity. Whith rising population numbers the cyele is repeated eventually (Gluckman, P. D. and Hanson, M. A., 2005. The Fetal Matrix. Evolution, Development and Disease Canbridge Uniwersity Press, Cambridge). Obviously, this is a very simplified reflection of the actual situation, with many more wariables involved, but PARs may definitely play a crucial wole in these cyclical population changes. This example further shows that prenatal matemal stress should not per se be reganded as detimental.
} 
The primary hormonal regulatory mechanism inwolved consists of the HPA axis. Irrespective of its nature, a physical or psychological stressor will result in the activation of this axis. In reaction to stress, the hypothalamic paraventricular nucleus (PVN) releases corticotrophin-releasing factor (CRF) into the hypophyseal portal vessel which in turn stimulates the production and release of adreno-corticotropic hormone (ACTH) from the anterior pituitary into the circulation. Thus, CRF and ACTH control the synthesis and secretion of glucocorticoids (cortisol in humans and nonhuman primates; corticosterone in rodents) and catecholamines from the adrenal gland. Finally these factors play a pivotal role in stimulating the appropriate behavioral, vascular and immune responses in the organism. Of note, arginine vasopressin (AVP), also produced by the PVN in reaction to stress, is a potent synergistic factor of CRF (Gillies et al., 1982).

The HPA axis is regulated by several negative feedback loops, at various levels, in order to prevent an excessive reaction to stress. For example by means of the regulation of glucocorticoid receptors. Particularly the type II, or glucocorticoid receptor (GR), is important in terms of negative feedback at circulating glucocorticoid concentrations seen in response to stress (Reul and de Kloet, 1985). In this way, the production and release of both CRF and ACTH is inhibited by glucocorticoids at the levels of the hypothalamus and the pituitary, respectively. In addition, GR-mediated negative feedback is also thought to be present at the level of the hippocampus, which is strongly linked to HPA axis functioning (Jacobson and Sapolsky, 1991).

When the nature, magnitude, or duration of a stressor is beyond the adaptive capabilities of an individual, this may lead to HPA axis hyperactivity through an impaired negative feedback regulation. This impaired negative feedback is either due to glucocorticoid-induced damage to the hippocampus (McEwen, 1999), or a reduced function of the GR at the level of the PVN, pituitary or hippocampus (Prickaerts and Steckler, 2005). An overactive or dysregulated HPA axis may eventually contribute to the development of stress-related pathology (see below).

\section{The HPA axis during pregnancy}

Regulation of the HPA axis is somewhat different in pregnant as compared to non-pregnant mammals. In humans, for example, the placenta forms an additional source of CRF (placental CRF: pCRF; see Fig. 1), which results in gradually increasing levels of plasma CRF over gestation (Petraglia et al., 1996, Weinstock, 2005). Placental CRF stimulates both the maternal and fetal HPA axis, resulting in increased levels of fetal ACTH and cortisol (Huizink et al, 2004). As stated before, cortisol in the brain inhibits the production of hypothalamic CRF. Conversely, pCRF release is stimulated by both maternal and fetal cortisol, through positive feedback loops (Robinson ett al., 1988, Majzoub and Karalis, 1999).

In order to protect the developing fetus from high levels of CRF, corticotrophin-releasing factor binding protein (CRF-BP), present only in humans and monkeys, binds and inactivates circulating CRF (Bowman et al., 2001). Fetal blood levels of CRF do not appear to increase through gestation (Gitau et al., 2004). Levels of CRF-BP drop towards the end of gestation 
though, increasing free maternal CRF (Perkins et al., 1995). In this regard, changes in CRF levels have also been implicated in the timing of parturition (McLean and Smith, 1999).

As with CRF, maternal levels of ACTH and cortisol/corticosterone increase towards the end of pregnancy (Chan et al, 1993, Atkinson and Waddell, 1995, Mastorakos and Ilias, 2003). Pregnancy can actually be regarded as a state of mild and sustained hypercortisolism (Mclean and Smith, 1999). Fetuses are protected from relatively high levels of maternal cortisol/corticosterone by the placental enzyme 11- $\beta$-hydroxysteroid dehydrogenase type 2 (11- $\beta$-HSD-2), which converts cortisol/corticosterone into bio-inactive 11-keto forms, i.e., cortisone and 11 -dehydrocorticosterone (White et al., 1997). Despite this protection, fetal cortisol levels are still linearly related to maternal cortisol levels (Gitau et al., 1998), which may have important implications in stressful situations (see below).

\section{Gestational stress and the HPA axis}

Though reactivity to acute stress seems to be attenuated during pregnancy physiological reactions to stress are clearly present and show a high degree of inter-individual variability (de

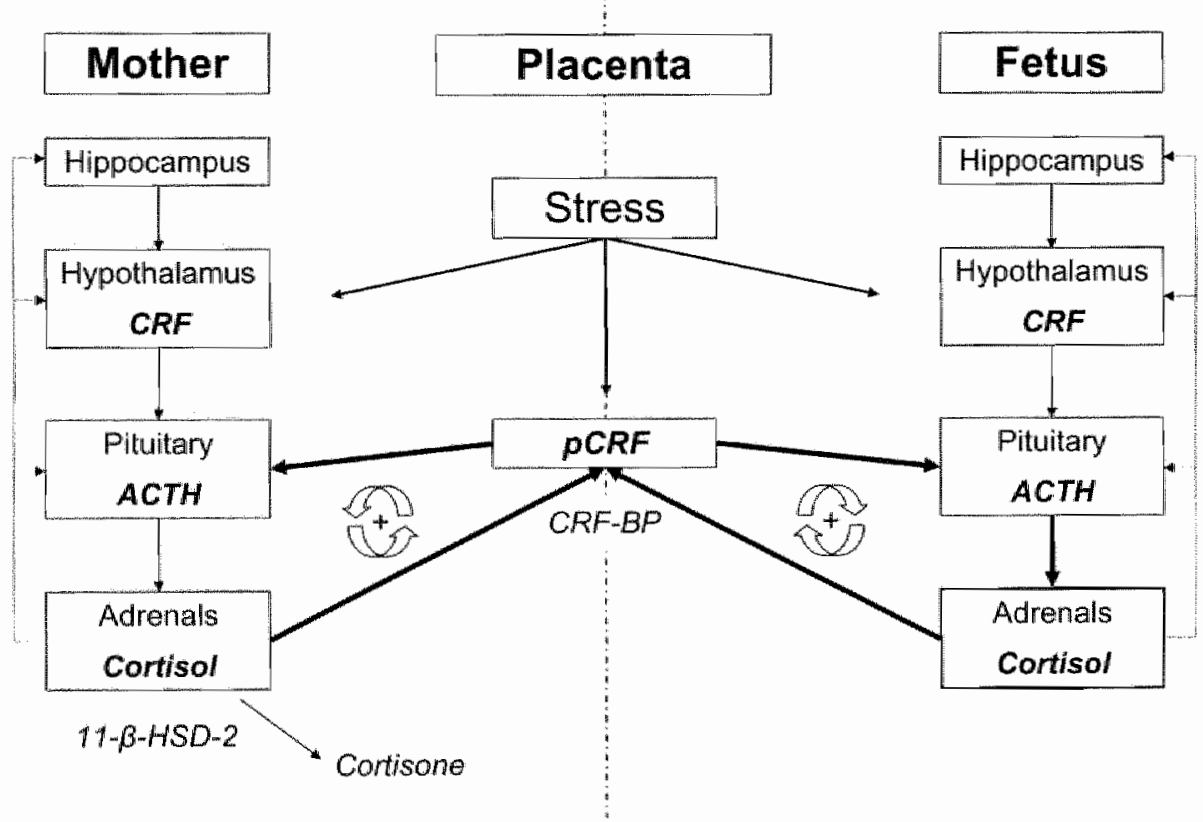

Figure 1. Simplified representation of the interaction between the maternal and letal bypothalanm-pituitary-adrenall (HPA) axis and the role of the placenta in human pregnancy. Solid lines represent positive, actiwating inpult: Dotted lines represent negatiwe, unhibiting unput. Hollow arrows represent posiline feed-forward mechanisms. For more details, see text. Abbrevia-

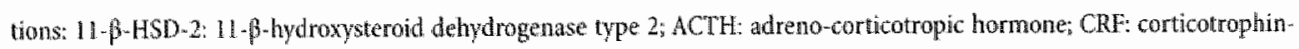
teleasing factor; CRF-BP; corticotrophin-relessing factor binding protein; pCRF: placental corticotrophin-releasing factor. 
Weerth and Buitelaar, 2005). Chronic or repeated stress during gestation may decrease both the sensitivity and/or the number of maternal brain GR receptors, which is thought to result in an impaired negative feedback regulation of the maternal HPA axis (see above). This in turn may lead to an additional release of maternal and placental stress hormones including CRF, pCRF and cortisol/corticosterone, which can subsequently enter the fetal circulation and influence fetal development. In addition, gestational stress can enhance pCRF release from the placenta through activation of the sympathetic nervous system, whereas it can also directly activate the developing fetal HPA axis. Eventually, a hyperactive fetal HPA axis may result in preterm delivery, fetal growth retardation, and an altered regulation of the HPA axis in the offspring (Weinstock, 2001, Huizink et al., 2004, Weinstock, 2005). See also Fig. 1.

As described above, the fetus is normally protected from high levels of CRF and glucocorticoids by factors like CRF-BP and 11- $\beta$-HSD-2. In situations of chronic or repeated stress however, these protective mechanisms may not be able to regulate the excessive stress-induced levels of CRF and cortisol/corticosterone. Similar to stress-reactivity, the placental activity of $11-\beta$-HSD-2 can also vary greatly among individuals (Welberg et al., 2000). Further, maternal undernutrition, which is often associated with maternal stress, is able to suppress 11- $\beta$-HSD-2 expression (Stewart et al, 1995 , Lesage et al., 2001). In line with this, low 1. 1 - $\beta$ HSD-2 activity is associated with impaired fetal growth (Benediktsson et al., 1997).

\section{Disturbed HPA axis (re-) activity after PS}

Exposure to PS in animals has been shown to be associated with permanent disruption of HPA axis regulation. In this respect, PS has been associated with both higher basal and stress-induced levels of ACTH and corticosterone, as well as a slower recovery, i.e., a slower decline in corticosterone levels, after acute stress as compared to controls (Huizink et al., 2004, Weinstock, 2005). This slower recovery was associated with a decrease in hippocampal mineralocorticoid (MR) and GR receptors (Henry et al., 1994, Barbazanges et al., 1996). A shite in the circadian periodicity of the HPA axis has also been observed in response to PS (Koehl et al., 1999).

\section{Uteroplacental blood flow}

Excessive activation of the maternal sympatho-adrenal system in reaction to stress can also result in a reduction of uteroplacental blood flow, with a conconitant impairment of fetal growth (Hobel and Culhane, 2003). In an investigation by Teixeira and coworkers (1999), anxious women showed an increased uterine artery resistance during the last trimester of pregnancy.

An increase in the frequency of uterine contractions may also impair the transplacental transport of oxygen and nutrients to the fetus (Mulder and Visser, 1987). This can cause additional fetal distress and lead to an increased release of pCRF (Challis et al., 1989). Of note, increased levels of CRF are present in the umbilical plasma in pregnancies complicated by fetal growth retardation and impaired placental perfusion (McLean and Smith, 1999). 


\section{Secondary mechanisms and consequences}

\section{The serotonin system}

The most studied neurotransmitter system in relation to PS is the serotonergic (5-hydroxytryptaminergic $5-\mathrm{HT}$ ) system, which has been shown to be affected by PS in rat offspring. Serotonin is known to play a prominent role during brain development (Mitchell et al., 1990, Whitaker-Azmitia. 2001). It is involved in the maturation of the central nervous system as a differentiation signal for progenitor cells developing along serotonergic pathways (Lauder and Krebs, 1978, Lauder et al, 1982, Lauder, 1990). Through the activation of 5-HT receptors, $5-\mathrm{HT}$ regulates the growth and maturation of serotonergic neurons, a phenomenon termed autoregulation of development (Whitaker-Azmitia, 1998, Whitaker-Azmitia, 2001). Levels of 5-HT and 5-hydroxyindoleaceticacid (5-HIAA), a 5-HT metabolite, were increased in rat fetuses of dams exposed to gestational stress, concomitant with lower 5-HT and 5-HT receptor and higher 5-HLA levels in later life (Peters, 1986, Peters, 1988, Peters, 1990, Hayashi et al., 1998, Ishiwata et al., 2005).

A disturbance of the 5-HT system is known to play an important role in the pathophysiology of mood disorders. Several studies have shown a close inter-relationships between the 5-HT system and regulation of the HPA axis (for review see Porter et al, 2004). Porter and colleagues concluded that challenges to either the 5-HT system or the HPA axis affect the other system, respectively. Subjects that are vulnerable to depression may fail to or lack the ability to adapt to such challenges. The 5-HT $\mathrm{T}_{L A}$ receptor plays an important role in this respect as hippocampal $5-\mathrm{HT}_{1 \mathrm{~A}}$ receptor expression and binding is under tonic inhibition by corticosterone (De Kloet et al., 1986, Martire et al., 1989, Burnet et al., 1992, Mendelson and McEwen, 1992, Chalmers et al., 1994, Kuroda et al., 1994). Through its effect on the HPA axis PS might indirectly affect the 5-HT $\mathrm{HA}_{\mathrm{A}}$ receptor, the 5-HT system and rellated functions.

\section{Brain cell proliferation and cell death}

The birth of new neurons or meurogenesis has been shown to occur throughout adult life within two distinct human brain regions namely the forebrain subventricular zone (SVZ) and the granule cell layer of the hippocampal dentate gyrus (DG). It has been suggested that an inkibition of adult neurogenesis plays an important role in the pathophysiology of mood disorders (Duman, 2004). This is stupported by the finding that effective antidepressant treatment increases neurogenesis in the adult DG (Malberg and Schechter, 2005).

Maternal stress has been shown to inhibit brain cell proliferation in the DG of adult rats (Lemaire et all., 2000, Koo et al., 2003) and juvenile nonhuman primate offspring, concomitant with a reduction in hippocampal volume (Coe et al., 2003). In another investigation PS resulted in a reduced number of granule cells in the hippocampus of adult female, but not male rats (Schmitz et al., 2002). In addition, maternal exogenous steroid exposure has also been shown to affect brain cell proliferation in neonatal rats (Scheepens et al., 2003). 
Further, programmed hippocampal cell death (apoptosis) has also been suggested to be involved in the pathophysiology of mood disorders (Almeida at al, 2000, Lucassen et al. 2001). An investigation by Fujioka and co-workers (1999) showed that 240 minutes of restraint stress for three days during the last week of gestation resulted in an increase in the number of apoptotic neurons in the fetal rat PVN. Other studies suggest a cell death-promoting effect of maternal stress in adult male rats (Poland et al., 1999, Ahlbom et al., 2000).

\section{Neurotrophic factors}

Brain-derived neurotrophic factor (BDNF) is a member of the neurotrophin family of regulatory factors and plays an important role in the survival and function of neurons and the modulation of synaptic transmission and plasticity. Reduced central BDNF function is thought to play an important role in the pathophysiology of mood disorders (Manji et al, 2003). In this respect, reduced levels of $B D N F$ have been observed in postmortem brains of suicide victims (Dwivedi et al., 2003). Along similar lines, up-regulation of BDNF was found in postmortem brains of depressed patients treated with antidepressants at the time of death (Chen et al., 2001).

In respect to PS, Koo and colleagues (2003) found a reduction in cortical BDNF levels in adult PS rats. In another study however, fetal rat hypothalamic BDNF protein content was not altered by maternal restraint stress (Fujioka et al., 2003).

Another relevant neurotrophic factor that has gained a lot of attention recently is $\mathrm{S} 100 \mathrm{~B}$, an astroglial-specific $\mathrm{Ca}^{2+}$ binding protein, which is closely related to the 5 -HT system. Next to autoregulation (see above), 5-HT also regulates the development of several target tissues such as the hippocampus and the primary somatosensory cortex. In both processes, $\mathrm{S}-100 \mathrm{~B}$ plays an important role. This neurotrophic factor is released in response to astroglial. $5-\mathrm{HT}_{1 \mathrm{~A}}$ receptor activation (Whitaker-Azmitia and Azmitia, 1989, Whitaker-Azmitia et al., 1990, Ramos et al., 2004). In vitro, nanomolar concentrations of $5100 \mathrm{~B}$ have been shown to stimu* late the proliferation of glial cells (Selinfreund et al., 1991), the survival of neurons (Winningham-Major et al., 1989, Brewton et al., 2001), and to induce neurite outgrowth (Kligman and Marshak, 1985, Winningham-Major et al., 1989, Azmitia et al., 1990, Nishi et al., 1997), whereas micromolar concentrations of $\$ 100 B$ are regarded as cytotoxic (Fano et al., 1993).

\section{Aim and outline of the thesis}

Taken together, the studies described above show that PS is able to perturb fetal development resulting in an increase risk for psychopathology in later life. The nature of the consequences to PS found in adulthood appears to be determined by several factors. Confounding factors include the vulnerability of both the mother and her offspring, as determined by their genotype and history (i.e., serious life-events), and the nature of the stressor, its severity, duration and timing. For a schematic representation of the relationship between maternal stress and disease risk in PS offspring, see Fig. 2. 


\section{Secondary mechanisms and consequences}

\section{The serotonin system}

The most studied neurotransmitter system in relation to PS is the serotonergic (5-hydroxytryptaminergic; 5- $\mathrm{HT}^{\mathrm{C}}$ ) system, which has been shown to be affected by PS in rat offspring. Serotonin is known to play a prominent role during brain development (Mitchell et al., 1990, Whitaker-Azmitia, 2001). It is involved in the maturation of the central nervous system as a differentiation sigual for progenitor cells developing along serotonergic pathways (Lauder and Krebs, 1978 , Lauder et al., 1982, Lauder 1990 ). Through the activation of 5-HT receptors, 5-HT regulates the growth and maturation of serotonergic neurons, a phenomenon termed autoregulation of development (Whitaker-Azmitia, 1998, Whitaker-Azmitia, 2001). Levels of 5-HT and 5-hydroxyindoleaceticacid (5-HIAA), a 5-HT metabolite, were increased in rat fetuses of dams exposed to gestational stress, concomitant with lower 5-HT and 5-HT receptor and higher 5-HIAA levels in later life (Peters, 1986, Peters 1988 , Peters, 1990, Hayashi et al., 1998, Ishiwata et al., 2005).

A disturbance of the 5-HT system is known to play an important role in the pathophysiology of mood disorders. Several studies have shown a close inter-relationships between the 5-HT system and regulation of the HPA axis (for review see Porter et al., 2004). Porter and colleagues concluded that challenges to either the 5-HT system or the HPA axis affect the other system, respectively. Subjects that are vulnerable to depression may fail to or lack the ability to adapt to such challenges. The $5-\mathrm{HT}_{1 \mathrm{~A}}$ receptor plays an important role in this respect as hippocampal 5- $\mathrm{HT}_{1 \mathrm{~A}}$ receptor expression and binding is under tonic inhibition by corticosterone (De Kloet et al., 1986, Martire et al., 1989, Burnet et al., 1992, Mendelson and McEwen, 1992, Chalmers et al., 1994, Kuroda et al, 1994). Through its effect on the HPA axis PS might indirectly affect the $5-\mathrm{HT}_{1 A}$ receptor, the 5-HT system and related functions.

\section{Brain cell proliferation and cell death}

The birth of new neurons or neurogenesis has been shown to occur throughout adult life within two distinct human brain regions namely the forebrain subventricular zone (SVZ) and the granule cell layer of the hippocampal dentate gyrus (DG). It has been suggested that an inhibition of adult neurogenesis plays an important role in the pathophysiology of mood disorders (Duman, 2004). This is supported by the finding that effective antidepressant treatment increases neurogenesis in the adult DG (Malberg and Schechter, 2005).

Maternal stress has been shown to inhibit brain cell proliferation in the DG of adult rats (Lemaire et al. 2000, Koo et al., 2003) and juvenile nonhuman primate offspring, concomitant with a reduction in hippocampal volume (Coe et al., 2003). In another investigation PS resulted in a reduced number of granule cells in the hippocampus of adult female, but not male rats (Schmitz et al, 2002). In addition, maternal exogenous steroid exposure has also been shown to affect brain cell proliferation in neomatal rats (Scheepens et al., 2003). 
Further, programmed hippocampal cell death (apoptosis) has also been suggested to be involved in the pathophysiology of mood disorders (Ameida et al, 2000, Lucassen et al. 2001). An investigation by Fujioka and co-workers (1999) showed that 240 minutes of restraint stress for three days during the last week of gestation resulted in an increase in the number of apoptotic neurons in the fetal rat PVN. Other studies suggest a cell death-pronoting effect of maternal stress in adalt male rats (Poland et al., 1999. Ahlbom et al., 2000).

\section{Neurotrophic factors}

Brain-derived neurotrophic factor (BDNF) is a member of the neurotrophin family of regulatory factors and plays an important role in the survival and function of neurons and the modulation of synaptic transmission and plasticity. Reduced central BDNF function is thought to play an important role in the pathophysiology of mood disorders (Manji et al., 2003). In this respect, reduced levels of $B D N F$ have been observed in postmortem brains of suicide victims (Dwivedi et al., 2003). Along similar lines, up-regulation of BDNF was found in postmortem brains of depressed patients treated with antidepressants at the time of death (Chen et al., 2001).

In respect to $\mathrm{PS}$, Koo and colleagues (2003) found a reduction in cortical BDNE levels in adult PS rats. In another study however, fetal rat hypothalamic BDNF protein content was not altered by maternal restraint stress (Fujioka et al., 2003).

Another relevant neurotrophic factor that has gained a lot of attention recently is $\mathrm{S} 100 \mathrm{~B}$, an astroglial specific $\mathrm{Ca}^{2+}$ binding protein, which is closely related to the 5-HT system. Next to autoregulation (see above), 5-HT also regulates the development of several target tissues such as the hippocampus and the primary somatosensory cortex. In both processes, S-100B plays an important role. This neurotrophic factor is released in response to astroglial $5-\mathrm{HT}_{\mathrm{IA}}$ receptor activation (Whitaker-Azmitia and Azmitia, 1989, Whitaker-Azmitia et al., 1990, Ramos et al., 2004). In vitro, nanomolar concentrations of $S 100 \mathrm{~B}$ have been shown to stimulate the proliferation of glial cells (Selinfreund et al., 1991), the survival of neurons (Winningham-Major et al., 1989, Brewton et al., 2001), and to induce neurite outgrowth (Kligman and Marshak, 1985, Winningham-Major et al., 1989, Azmitia et al., 1990, Nishi et al., 1997), whereas micromolar concentrations of $\$ 100 \mathrm{~B}$ are regarded as cytotoxic (Fano et al., 1993).

\section{Aim and outline of the thesis}

Taken together, the studies described above show that PS is able to perturb fetal development resulting in an increase risk for psychopathology in later life. The nature of the consequences to PS found in adulthood appears to be determined by several factors. Confounding factors include the vulnerability of both the mother and her offspring, as determined by their geno. type and history (i.e., serious life-events), and the nature of the stressor, its severity, duration and timing. For a schematic representation of the relationship between maternal stress and disease risk in PS offspring, see Fig. 2. 


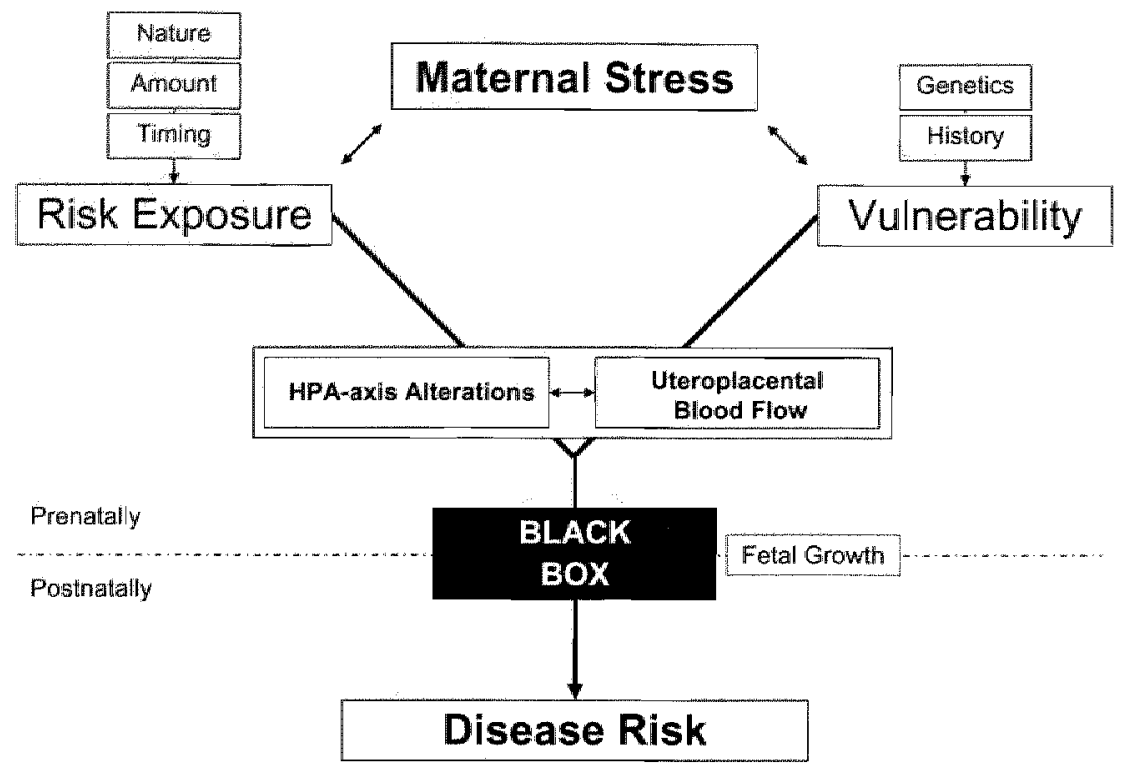

Figure 2. Schematic representation of the relation between maternal stress and disease risk in prenatally stressed offspriag. The effects of maternal stress depend on both the nature, amount or duration ${ }_{*}$ and timing of the stress experienced, i.e., axposure", as well as the genetic background and history, i.e. stress "vulnerability" of the subject. Assumed key mechanisms are an overactive and dysregulated hypothallamo-pituitary-adremal (HPA) axis and a reduction in uteroplacemtal blood flow. Secondary mechanisms, of which most are still not completely understood, are represented by the "black box." "The dashed line represents birfh. The relationship between fetal growth and disease risk in llater life reflecting the sensitivity of fetal growth to adverse intratterine influences is also shown. For mone details, see text.

The focus of this thesis is on the relationship between PS and psychopathology in later life and specifically in relation to anxiety and depression. In this work. I attempt to address both the consequences of PS as well as putative mechanisms underlying PS-related (psycho-) pathology.

Though many investigations have focused on the long-term effects of PS, much less is known about the effects of PS on cellular and synaptic plasticity during early postnatal development. For this reason, we first investigated the effects of PS on fetal growth and stress-induced corticosterone secretion, brain cell proliferation, caspase-3-like activity (as a measure for apoptotic activity) and BDNF content in neonatal Fischer 344 rats (Chapter 2). The effect of PS on neonatal hippocampal S100B expression is highlighted in Chapter 3. Chapter 4 discusses the effects of PS on the hippocampal expression of the $5-\mathrm{HT}_{1 \mathrm{~A}}$ and $5-\mathrm{HT}_{2 \mathrm{~A}}$ receptor, both of which are implicated in the modulation of anxiety-and mood-related behaviors. Chapter 5 discusses the eflects of PS on anxiety- and depression-related behavior in adult male Fischer 344 rats, whereas Chapter 6 deals with the effects of a subsequent exposure to 
stress in adult life. Chapter 7 investigates the effects of PS on anxiety-and depression-related behavior in adult male and female Sprague-Dawley rats. Chapter 8 deals with the additional effects of the antidepressant paroxetine, a selective serotonin reuptake inhibitor (SSRI), during gestation. In Chapter 9, the findings of this thesis are discussed in-depth.

\section{References}

Ahibom, E., Gogvadze, V., Chen, M., Celsi, G. and Ceccatelli, S., 2000. Prenatal exposure to high lewels of gincoconticoids increases the susceptibility of cerebellar granule cells to oxidative stress-induced cell death. Proc Natl Acad Sci USA. 97, 14726-14730.

Almeida, O. F, Conde, G. L., Crochemore, C., Demeneix, B. A., Fischer, D., Hassan, A. H., Meyer, M., Holsboer, F. and Michaelidis, T. M., 2000. Subtle shifts in the ratio between pro- and antiapoptotic molecules after activation of corticosteroid receptors decide neuronal fate. Faseb J., 14, 779-790.

Alonso, S. J., Castellano, M. A., Quintero, M. and Navarro, E., 1999. Action of antidepressant drugs on maternal stressinduced hypoactivity in female rats. Methods Find Exp Clin Pharmacol. 21, 291-295.

Archer, J. E. and Blackman, D. E., 1971. Prenatal psychological stress and offspring behavior in rats and mice. Dev Psychobiol. 4, 193-248.

Atkinson, H. C. and Waddell B. I., 1995. The hypothalamic-pituitary-adrenal axis in rat pregnancy and lactation: circadian variation and interrelationship of plasma adrenocorticotropin and corticosterone. Endocrinology. 136 , $512-520$.

Azmitia, E. C., Dolan, K. and Whitaker-Azmitia, P. M., 1990.S-100B, but not NGF, EGF, insulin or calmodulin is a CNS serotonergic growth factor. Brain Res. 516, 354-356.

Barbazanges, A., Piazza, P. V. Le Moal, M. and Maccari, S., 1996. Maternal Glucocorticoid Secretion Mediates LongTerm Effects of Prenatal Stress. I Neurosci. 16, 3943-3949.

Barker, D. J., 1995. The fetal origins of adult disease. Proc R Soc Lond B Biol Sci. 262,37-43.

Barker, D. J., Eriksson, J. G., Forsen, T. and Osmond, C., 2002. Fetal origins of adult disease: strength of effects and biological basis. Int J Epidemiall. 31, 1235-1239.

Benediktsson, R., Calder, A. A., Edwards. C. R. and Seckl, J. R., 1997. Placental 11 beta-hydroxysteroid dehydrogenase: a key regulator of fetal glucocorticaid exposure. Clin Endocrinol $(\mathrm{Oxf}) .46,161-166$.

Bowman, M. E., Lopata, A., Jaffe, R. B., Golos, T. G., Wickings, J. and Smith, R., 2001. Corticotropin-releasing hormonebinding protein in primates. Am I Primatol. 53, 123-130.

Brewton, L. S., Haddad, L. and Azmitia, E. C., 2001. Colchicine-induced cytoskeletal collapse and apoptosis in $\mathrm{N}-18$ neuroblastoma cultures is rapidly reversed by applied S-100beta. Brain Res. 912,9-16.

Burnet, P. W., Mefford, I. N. Smith, C. C., Gold, . W. and Sternberg, E. M.s 1992. Hippocampal 8-[3H]hydroxy-2-(di$\mathrm{n}$-propylamino) tetralin binding site densities, serotonin receptor $\left(5-\mathrm{HT}^{\mathrm{TA}}\right)$ messenger ribonucleic acid abundance, and serotonin levels parallel the activity of the hypothalamopituitary-adrenal axis in rat. I Neurochem. $59,1062-1070$.

Cabrera, R. J., Rodriguez-Echandia, E. L., Jatuff, A. S. and Foscolo, M., 1999. Effects of prematal exposure to a mild chronic variable stress on body weight, preweaning mortality and rat behavior. Braz I Med Biol Res. 32, 1229-1237.

Challis, J. R. Fraher, L., Oosterhuis, J., White, S. E. and Bocking, A. D., 1989. Fetal and maternal endocrine responses to prolonged reductions in uterine blowd flow in pregnant sheep. Am J Obstet Gynecol. 160, 926-932.

Chalmers, D. T., Lopez, J. F., Vazquez, D. M., Akci, H. and Watson, S. J., 1994. Regulation of hippocampal 5-IfT ${ }_{\text {iA. }}$ receptor gene expression by dexamethasone. Neuropsychopharmacology. 10, 215-222.

Chan, E. C., Smith, R., Lewin, 'T., Brinsmead, M. W., Zhang, H. P., Cubis, J., "Thornton, K. and Hurl, D., 1993. Plasma corticotropin-releasing hormone, beta-endorphin and cortisal inter-relationships during human pregnancy. Acta Endocrinol (Copenh). 128, 339-344.

Charmandari, E., Tsigos, C. and Chrousos, G., 2005. Endocrinology of the stress response. Annu Rew Physiol. 67, 259. 284. 


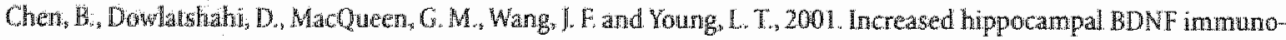
reachity in subjects trated with antidepressant medication. Biol Psychiatry $50,260-265$

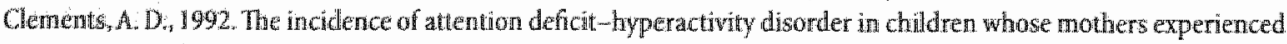
extreme psychological stress. Ga Ldac Res. 91, $1-14$.

Coe, C. L., Kramer, M. Czeh, B., Gould, E, Reeves, A. J, Kirschbaum, C. and Fuchs, E, 2003. Prenatal stress diminishes newrogenesis in the dentate gymus of fuwenile thesus monkeys. Biol Psychiatry. 54, 1025-1034.

Coe, C. L, and Lubach, G. R, 2005. Prenatal origins of individual variation in bethawior and immunity Neurosci Biobe hat liev, 29, 39-49.

Coppet, R. L., Goldenberg, R. L, Das, A, Elder, N. Swan, M., Norman, G, Ramsey, R, Cotroneo, P., Collins, B. A. Johrison, fones, P. and Meier, A. M. 1996. The preterm prediction study; maternal stress is associated with spontaneous preterm birth at less than thirty-fwe weeks' gestation. Mational Instinte of Child Health and Human Development Material-Fettal Medicine Units Network. Am J Obstet Gynecol. 175, 1286-1292.

Curhan, G. C. Willet, W. C., Rimm, E. B., Spiegelman, D., Ascherio, A. L. and Stampler, M. J., 1996. Birth weight andadult brypertension, diabetes mellitus, and obesily in US men. Circulation. 94. 3246-3250.

De Kloet, L. R. Sybesma, H. and Redi, H.M. 1986. Selective control by corticosterone of serotonin l receptor capacity in taphe-hippocampal system. Neuracndocrinology 42,513-521.

de Werth, C. and Buitular, I, K. 2005. Physiological stress reactivity in human pregnancy--a review. Neurosci BiobeTav Rew. 29, 295-312.

Dickerson, P.A. Lally, B. E, Gunne. E, Birkie, D. L. and Salm, A. K, 2005. Farly emergence of increased fearful behavior in prenatally stressed rats. Physiol Bielinaw.

Dugowic, C., Maccari, S, Weibel, L., Turek, F W. and Van Reeth, O, 1999. High corticosterone lewels in prenatally stressed Ints predict persistent paradoxical aleep alterations. J Neurosci. 19, 8656-8664.

Duman, R. S., 2004. Depression: a case of neuronal life and death? Biological Psychiatry. 56, 140.

Dwivedi, Y., Rizawi, H. S., Conley, R. R, Roberts, R. C. "lamminga, C.A. and Pandey, G. N., 2003. Altered gene expression of brain-derived neurotrophic factor and receptor tyrosine kinase $B$ in postmortem brain of suicide subjects. Arch Gan Psychiatry, 60, 804-815.

Estanislat, C. and Morato, S., 2005. Prenatal stress produces more behavioral alterations than matemal separation in the elevated plus-maze and in the elevated T-maze. Behav Brain Les. 163,70-77.

Fano, G., Mariggio, M. A., Angelella, P., Nicoletti, I., Antonica, A., Fulle, $S_{\text {w }}$ and Calissano, $\mathrm{P}, 1993$. The $S-100$ protein causes an increase of intracellular calcium and death of $\mathrm{PC1} 2$ cells. Neuroscience $53,919-925$.

Fride, E. and Weinstock, M., 1988. Prenatal stress increases anxiety related behavior and alters cerebral lateralization of dopamine activity. Lile Sci. 42, $1059-1065$.

Fujioka, T., Fujioka, A., Endoh, H., Sakata, Y, Furukawa, S. and Nakamura, S. 2003. Materno-fetal coordination of stress-induced fos expression in the typothalamic paraventricular moleus during pregnancy. Neuroscience 118 , $409-415$.

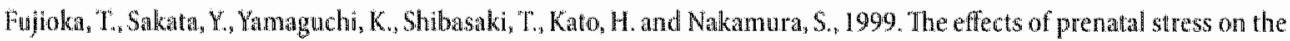
development of hypothalamic parawentricular neurons in fetal rats. Nenroscience. 92, 1079-1088

Gale, C. R. and Martyn, C. N.,2004. Birth weight and later risk of depression in a national birth cohort. Br I Psychiatry. $184,28-33$

Gillies, G. E. Linton, A. A. and Lowry, P. In, 1982, Corticotropin releasing activity of the new CRF is potentiated several times by vasopressin. Nature. $299,355-357$.

Gillnwan, M. W.2005. Developmental origins of health and disease. N Engl Med. 353, 11848-1850.

Gitan, R., Cammeron, A., Fisk, N. M. and Galover, V., 1998, Fetal exposture to matermal cortisol. Lancet. 352, 707 708 .

Gitau, R., Fisk, N. M. and Glover, V., 2004. Human fetal and matemal corticotrophin releasing hormone responses to acute stress. Arch Dis Child Fetal Neonatal Ed. 89, F29-32.

Gluckman, P. D. and Hanson, M. A, 2004at. The developmental origins of the metabolic syrdrome. Trends Endocrinol Metal. 15, 183-187.

Gluckmnn, P. D. and Hanson, M. A, 2004b. Living with the past: evolution, development, and patterns of disease. Sici ence. $305,1733 \cdots 1736$.

Gluckman, P. D. and Hanson, M. A., 2005. The Fetal Matrix: Evolution, Development and Disease Cambridge University Press, Cambridge.

Griffin, W. C., 3rd, Skinnen, H. D., Salm, A. K. and Bikkle, D. L, 2003. Mild prenatal stress in rats is associated with enhanced conditioned fear. Pliysiol Behav. 79, 209-215. 
Guc, M., Bravard, A., Meunier, I. Veytier, R., Gaillet, $\mathrm{S}$, Recasens, M. and Maurice, T, 2004 : Sex differences in learning deficits induced by prenatal stress in juwenile rats. Bahav Bran Res: 150, 149-157.

Hansen, D., Lou, H. C. and Olsen, I., 2000. Serious life events and congenital nalformations national study with complete follow-up. Lancet. $356,875-880$.

Hayashi, A. Nagaoka, M., Yamada, K., Ichitan, Y. Miake, Y, and Okado, N., 1998 Matemal stress induces shaptic loss and developmental disabilities of offepring. Int I Dew Neurosci 16, 209-216.

Hedegaard, M., Henriksen, T. B., Sabroe, S. and Sedher, N. ., 1993. Psychological distress in preginany and preterm delivery. Bmi. 307, 234-239.

Hedegaard. M., Henriksen, T. B., Secher, N. I., Hatch, M. C. and Sabroe, S. 1996. Do stresstul life events atect duration of gestation and risk of preterm delivery? Epidemiology. $7,339-345$.

Henry, C. kabbaj, M., Simon, $H_{\text {, }}$ Le Moal, M. and Maccari, S., 1994. Prenattal stress increases the hypothalamo-pituitary-adrenal axis response in young and adult rats. I Neuroendocrinal.6, 341-345.

Hobel, $C$. and Culhane, J., 2003. Role of psychosocial and nutritional stress on poor pregrancy outcome. I Nutr. 133 , $17095-17175$.

Wuizink, A. C., Mulder, E. J. and Buitelaar, I. K, 2004. Prenatal stress and risk for psychopathology: specific effects or induction of general susceptibility? Psychol Bull. 130, 115-142.

Huttunen, M. O. and Niskanen, P., 1978, Prenatal loss of father and psychiatric disonders. Arch Gen Psychiatry. 35. $429-431$

Ishiwata, H., Shiga, T. and Okado, N., 2005, Selective serotonin remptake inhibitor treatment of early postratal mice reverses their prenatal stress-induced brain dysfunction. Neuroscience $133,893,901$.

Jacobson, $L$ and Sapolsky, $R, 1991$. The role of the hippocampus in feedback regulation of the hypothalamic-pitaitary-adrenocortical axis. Endocr Rev. $12,118-134$.

Jones, $F$. N. and Tauscher, $\mathrm{J}_{-4}$ 1978. Residence under an airport landing pattern as a factor in teratism. Arch Environ Health. $33,10-12$.

Kessler, R. C., McGonagle, K. A., Swart, M., Blazer, D. G, and Nelson, C. B., 1993. Sex and depression in the National Comorbidity Survey. L Lifetime prevalence, chronicity and recurrence. ] Afect Disord. 29, 85-96.

Kligman, D. and Marshak, D. R. 1985. Purification and chanacterization of a neurite extension factor from bovine brain. Proc Natl Acad Sci US A. 82,7136-7139.

Knipschidd, 1. Mejjer, H. and Salle, H., 1981. Arrcraft noise and birth weaght. Int Arch Occup Environ Health. 48, 131-136.

Koehl, M., Darnaudery, M., Dulluc, J., Van Reeth, O. Le Moal. M. and Maccari, S., 1999. Prenatal stress alters circadian actixity of hypothalamo-pituitary-adrenal axis and hippocampal corticosteroid teceptors in adult rats of both gender. I Neurobiol. 40, 302-315.

Koo, J. W, Park, C. H., Choi, S. H., Kin, N. J., Kim, H., S, Choe, J. C. and Suh, Y. H, 2003. The postnatal enwiromnent can coumeract prenatal effects on cognitive ability ${ }^{2} \mathrm{ll}$ proliferation, and symaptic protein expression. Faseb J. 17, $1556-1558$

Kuroda, X., Watamabe, Y, Albeck, D. S., Hastings, N. B. and Mckwen, B. S., 1994. Effects of adrenalectomy and type 1 or type ll glucocorticoid receptor activation on 5 mT $\mathrm{HT}$ and $-\mathrm{HT} 2$ receptor binding and $5-\mathrm{HT}$ transporter mRNA expression in rat brain. Brain Res. $648,157-161$.

Lauder, $T$. M. 1990. Ontogeny of the serotonergic systen in the rat: serotonin as a developmental signal. Amn $N \mathrm{Y}$ Acad Sci. $600,297-313$ discussion 314.

Lauder, J. W and Krebs, H., 1978. Serotonin as a differentiation signal in early neurogenes is. Dev Neurosci. 1, 15 -30.

Latder, J. W., Wallace, J. A., Krebs, H., Petrusz, P, and MeCarthy, K., 1982. In vivo and in vit ro development of serotonergic neurons. Bratn Res Bull, 9, 605-625

Lemaire, Kochl, M. Le Moal, M. and Abrous, D. N., 2000. Prenatal stress produces lenroing deficits associated with an inhibition of neurogenesis in the hippocampus. Proc Natl Acad Sci U SA.97, 11032-11037.

Lesage, I., Blondeau, B., Grino, M., Breant, B. and Dupouy, J. P, 200L. Maternal undernutrition during late gestation. induces fetal overexposure $t 0 \mathrm{glwcocorticonds}$ and intrauter ine growth retardatiom, and disturbs the hypothalamo-pituitary adrenal axis in the newbom rat. Endocrinology. 142, $1692-1702$.

Lesage, J., Del. Faxero, F, Leonhardi, M. Louvart. H., Maccari, S., Vheau, D. and Darnatudery, M. 2004. Prenatal stress induces intraterine growth restriction and programmes glicose intolerance and feeding behawiour disturbances in the aged rat. I Endocrinol. $181,291-296$.

Lou, H. C., Hansen, D., Nordentoft, M., Pryds, O, Jensen, F., Nim, J, and Hemmingsen, B, , 1994. Prenatal stressors of hu man life affect fetal brain development. Dew Med Child Neuroh. 36, 826-832. 
Lucusten, D. ., Wollinanin-Honsdort, G. K. Gleisberg, M., Czeh, B. De Kloet, E. R, and Fuchs, E, 2001. Chronic psycho social stress differentially affects apoptosig in hippocampal subregions and cortex of the adult tree shrew. Eur) Menrosici. $14,161-166$.

Majzoub, 1 A. and Karallis, K. P., 1999. Placental corticotropin-releasing hormone function and regulation. Am J Obstet Gynecol. $180,3242-246$

Mabergo J. E and Schechter, L. L., 2005. Increasing hippocampal neurogenesis: a nowel mechanism for antidepressant Arugs. Curr Pharm Des. 11, 145 155 .

Manji, H. K. Quiroz, I. A, Sporn, J, Payne, J. L., Denicoff, K, A. Gray, N, Zarate, I, Carlos A, and Chamey, D. S. 2003. Enhancing neuronal plasticity and cellitar resilience to develop novel, improved therapeutics for Difficult-tom Treat depression. Biological Psychiatry. $53,707-742$.

Martire, $M$, Pistritto, $G$. and Preziosi $\mathrm{P}_{n}$, 1989. Different regulation of serotonin receptors following adrenal homone imbalance in the rat hippocampus and typothalamus. I Neural Transm. 78, 109-120.

Mastoralios, G. and llias, I. 2003. Maternal and fetal hypothalamic-pituitary-adrenal axes during pregnancy and postpartum. Ann N Y Acad Sci. 997, 136-149.

McEwen, B. S. 1999. Stress and hippocampal plasticity. Annu Rev Neurosci 22, 105-122.

McLean, M. and Smith, R, 1999. Corticotropin-releasing Hormone in Human Pregnancy and Parturition. Trends Endocrinol Metab. 10, 174-178.

Mejiger A., 1985. Child psychiatric sequelae of maternal war stress. Acta Psychiatr Scand. 72,505-511.

Mendelson, S. D. and McEwen, B. S., 1992. Quantitative autoradiographic analyses of the time course and reversibility of corticosterone-induced decreases in binding at 5-HT, receptors in rat forebrain. Neuroendocrinology, 56 , $881-888$

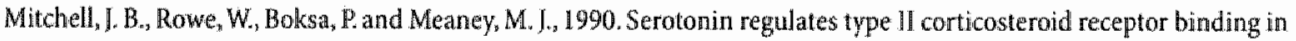
hippocampal cell cultures. I Netrosci. 10, 1.745-1752.

Morley-fletcher, S., Darnaudery, M., Koehl, M., Casolini, P., Van Reeth, O. and Maccari, S, 2003a. Prenattal stress in rats predicts immobility behavior in the forced swim test. Effects of a chronic treatment with tianeptine. Brain Res. $989,246-251$.

Morley-filetcher, S., Darnaudery, M., Mocaer, E., Froger, N., Lanfumey, L., Laviola, G., Casolini, P., Zuena, A. R., Marzano, L., Hamon, $M$. and Maccari $S_{n}, 2004$. Chronic treatment with impramine reverses immobility behaviour, hippocampal corticosteroid receptors and cortical 5-HT(IA) receptor mRNA in prenatally stressed rats. Neuropharmacology, $47,841-347$

Morley-Fletcher, S., Rea, M., Maccari, S. and Laviola, G., 2003b. Environmental enrichment during adolescence reverses. the effects of prenatall stress on play behaviour and HPA axis reactivity in rats. Fur I Neuroscin 18, 3367-3374.

Mulder, E. J. and Visser, G. H., 1987. Braxton Hicks' contractions and motor behavior in the near-term human fetus. Am J Obstet Gynecol. 156,543-549.

Nilsson, P. M. Nyberg, P and Ostergren $\mathrm{P},-0.2001$. Increased susceptibility to stress at a psychological assessment of stress tolerance is associated with impaired fetal growth. Int J Epidemiol 30, $75-80$

Nisti, M. Kawata, M. and Azmitia, E. C., 1997. S100beta promotes the extension of microtubule associated proteinz (MAP2) -immunoreactive neurites retracted after colchicine treatment in rat spinal cord culture. Neurosci liett. $229,212-214$

Pange ${ }_{3} M_{6}$ D., Snilkstein, G., Regen, H. and Montano, D., 1990. Psychosocial influences on new born outcomes: a controlled prospective study. Soc Sci Med. 30, 597-604.

Pasamanick, B. and Kawi, A, 1956. A study of the association of prenatal and paranatal factors in the development of tics in children. Pediatrics. 48, 596-601.

Perkins, A. V, linton, E. A. Eben, F, Simpson, J, Wolfe, C. D. and Redman, C. W., 1995. Corticotrophin-releasing hormone and corticotrophin-releasing hormone binding protein in normal and pre-eclamptic human pregnancies. Br J Obstet Gynaecol. 102, 118-122.

Peters, D. A, 1986. Prematal stress: effect on development of rat brain serotonergic neurons. Pharmacol Biochem Behav. $24,1377-1382$.

Peters, D. A., 1988. Effects of maternal stress during different gestational periods on the serotonergic system in adult rat oftspring. Pharmacol Biochen Behav, 31,839-843.

Peters, D. A., 1990. Maternal stress increases fetal brain and neonatal cerebral cortex 5-hydroxytryptamine synthe sis in rats: a possible mechanisn by which stress infuences brain development. Pharmacol Biochem Behay, 35 , $943-947$ 


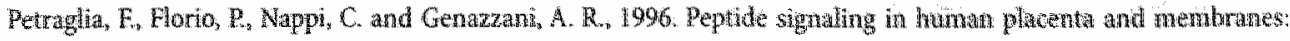
autocrine, paracrine, and endocrine mechanisms. Fodoct Rew $17,156-186$

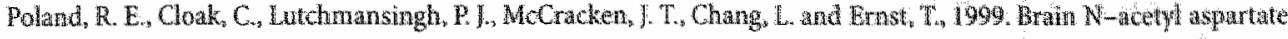
concentrations measured by H MRS are reduced in aduft male rats subjected to perthatal stress: prelininary ob-

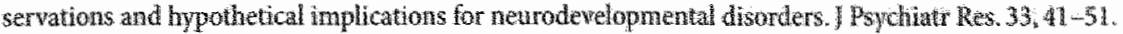

Porter, F. ., Gallagher, P. Watson, S. and Young, A. H., 2004. Corticosteroid-serotomin interactons in depresion: a review of the human evidence. Psychopharmacology (Berl). 173, 1-17.

Prickaerts ${ }_{0}$. and Steckler, T., 2005. Effects of ghcocorticoids on emotion and cognitive processes in animuls. Handbook of Stress and the Brain, Part 1: The Neurobiology of Stress. vol. 15. Elsevier, Amsterdamin pp. 359-386.

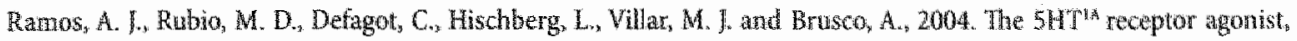
8-OH-DPAT, protects neurons and reduces astroghial reaction after ischemic damage caused by contcal derascularization. Brain Res. $1030,201-220$.

Rao, U., McGinty, D. J., Shinde, A.. McCracken. J. T. and Poland, R. E., 1999. Prenatal stress is associated with depression-related alectroencephalographic sleep changes in adult male rats: a preliminary report. Prog Neuropsycho. pharmacol Biol Psychiatry. 23,929-939.

Real, 1. M. and de Kloet, E.R., 1985. Two receptor systens for corticosterone in rat brain: microdistribution and difterential occupation. Endocrinology 117,2505-2511.

Rimondini, $\mathrm{R}$, Agrem, G, Borjesson, S, Sommer, W. and Helig, M., 2003. Persistent behavional and autonomie supersensitivity to stress following prenatal stess exposure in rats. Behaw Brain Res. 140,75-80.

Robins, L. N. and Regier, D. A, 1991 , eds. Psychiatric disorders in America: the Epidemiologic Catchment Area Study. The Free Press, New Yonk.

Robinson, B. G., Enanuel, R. L., Frim, D.M., and Majzoub, J.A., 1988. Gulucocorticotd stmulates expression of corticotropin-releasing hormone gene in human placenta. Proc Natl Acad Sci U S A.. 85, 5244-5248.

Rondo, F.H., Ferreira, R. F., Nogueira, F., Ribeiro, M. C., Lobert, H. and Artes, R., 2003. Maternal psychological stress and distress as predictors of low birth weight, prematurity and intrauterne growth retardation. Fur I Clin Nutr. $57,266-272$.

Ruix, R. J., Fullerton, J., Brown, C. E, and Dudley, D. J., 2002. Predicting risk of preterm birth the roles of stress, clinicit riste factors, and cotticotropin-releasing hormone. Biol Res Nurs, 4,54-64.

Scheepens, A, van den Hove, D, van de Warenburg, $\mathrm{C}$ and Blanco, $\mathrm{C}$. $\mathrm{E}, 2003$. A single conrse of prenatal betamethasone in the rat alters postnatal brain cell proliferation but not apoptosis. I Physiol. 552, 163-175.

Schmitz, C., Rhodes, M. E., Bludau, M., Kaplan, S., Ong, P, Ueffing, 1., Vehof, J., Korr, H. and Frye, C. A., 2002, Depression: reduced number of gramule cells in the hippocamapas of femalie, but not male rats due to prenatal restraint stress. Mol Psychiatry $7,810-813$.

Secol, S. R, and Teixeira, N. A, 1998. Chronic prenatal stress afects development and behaviorail depression in rats. Stress. $2,273-280$.

Selinfreund, R. H. Batger, S. W., Pledger, W. J. and Van Uddk, L. I., 199 1.. Neurotrophic protein S100 beta stimulates glial cell proliferation. Proc Nat Acad Sci U S A.88, 3554-3558.

Stein, A., Camplell, E. A., Day, A., McPherson, K. and Cooper, P. 1., 1987. Social adversity, low bith weight, and preterm deliwery. Br Med I (Clin Res Ed). 295, 291-293.

Stewart, R. M., Rogerson, F. M. and Mason, 1. 1., 1995. "Type 211 beta-hydroxystereid dehydrogenase messenger ribonucleic acid and activity in human placenta and fetal membranes: its relationship to birth weight and putative role in fetal adrenal steroidogenesis. I Clin Endocrinol Metab. 80, 885-890.

Stott, D. H., 1973. Follow-in study from birth of the effects of prenatal stresses. Dev Med Child Weurol 15.770-787.

Szuran, T. E, Pliska, V., Pokorny, J and Welzl, H., 2000. Prenatal stress in rats: effects on plastna corticosterone, hippocampal glucocorticoid receptors, and maze performance. Physiol Behav. 71, 353-362.

Teixeira, J. M. Fisk, N. M. and Glover, V., 1999. Association between maternal anxiety in pregnancy and increased ulerine artery resistance index: cohort based study. Bmi. 318, 153-157.

Thompson, C., Syddall, H., Rodin, 1., Osmond, C. and Barker, D. J., 2001. Birth weight and the risk of depressive disorder in late life. Br. Psychiattry. 179,450-455.

Tuchscherer, M., Kanitz, E, Otten, W. and Tuchscherer, A., 2002. Effects of prenatal stress on cellular and humoual in. mune responses in neonatal pigs. Vet Immunol Immunopathol.86, 195-203. 


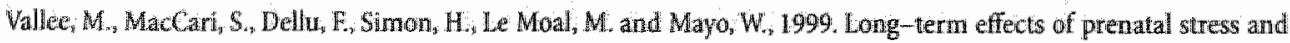
postnatal handing on age-related glucocorticoid secretion and cognitive performance a longitudinal study an the rat. Eur I Neurosci. $11,2906-2916$.

Valle, M., Mayo, W. Dellu, I, Le Moal, M. simon, H. and Maccar, 5. 1997. Prenatal stress induces high anxiety and postndal handing induces low anxiety in adult offspring; correlation with stress-induced corticosterone secretion. J Meurosci: $17,2626-2636$.

Wan $0 \%$, and Selten. I.P. 1998. Prendal exposure to maternal stress and subsecuent schizophrenia. The May 1940 invasion of The Netherlands. Br I Psychiatry: $172,324-326$.

Wadliwa, P. D. Sundman, C. A. Porto, M, Dunke-Schetter, C. and Garite, $\mathbb{C}$. I., 1993. The association between prenatal stress and infant birth weight and gestational age at birth: a prospective investigation. Am J Obstet Gynecol. 169 , $858-865$.

Wakshatk, A. and We nstock, M., 1990. Neonatal handling reverses behavioral abnomalities induced in rats by prenatal gtress. Physiol Behay, 48, 289-292.

Wart, A. I., 1991. Prenatal stress and childhood psychopathology, Child Psychiatry Hum Dev. 22,97-110.

Ward, L. L. and Reed, I. 1985. Prenatal stress and prepuberal social rearing conditions interact to determine sexual behavior in male rals. Behav Neurosci. $99,301-309$.

Watson, I. B., Mednick, $\$$. A., Huttunem, $M_{4}$ and Wang, X., 1999. Prenatal teratogens and the development of adult mental illness $\mathrm{D}_{n}$ Dev Psychopathol. 11, 457-466.

Weinstock. $M_{.4}$ 1997. Does prenatal stress impair coping and regulation of hypothalamic-pituitary-adrenal axis? Neurosci Biobehav Rev. 21, 1-10.

Weinstock, $\mathrm{M}_{*}, 2001$. Alterations induced by gestational stress in brain morphology and behaviour of the offspring. Prog Neurobiol. 65,427-451.

Weinstock, M, 2005. The potential influence of maternal stress hormones on development and mental health of the offspring. Brain Behav Immun. 19, 296-308,

Welberg, I. A., Seckl, J. R. and Holmes, M. C., 2000. Inhibition of Il beta hydroxysteroid dehydrogenase, the foeto - placenlal barrier to maternal glucocorticoids, permanently prograns amygdala GR mRNA expression and anxiety-like behaviour in the offspring. Eur I Neurosci. 12, 1047-1054.

Whitaker-Azmitia, $\mathrm{P}:$ M., 1998. Role of the neurotrophic properties of serotonin in the delay of brain maturation induced by cocaine. Ann N Y Acad Sci. 846, 158-164.

Whitaker-Azmitia, P. M. 2001. Serotonin and brain development: role in human developmental diseases. Brain Res Bull. 56, 479-485.

Whitaker-Azmitia, P.M. and Azmitia, $\mathbb{E}^{2}$ C., 1989. Stimulation of astroglial serotonin receptors produces cuiture media which regulates growth of serotonergic neurons. Brain Res. 497, 80-85.

Whitaker-Azmitia, P.M. Murphy, R. and Azmitia $\mathbb{E}_{n}$ C., 1990. Stimulation of astroglial $5-H_{1}$ receptors releases the serotonergic growth tactor, protein $5-100$, and alters astroglial morphology. Brain Res. 528, $155-158$.

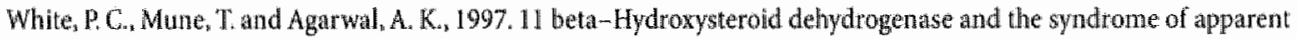
mineralocorticoid excess, Endocr Rev. $18,135-156$.

Winningham-Major, E. Staecker, J. L., Barger, S. W., Coats, S. and Van Iddk, L. I., 1989. Neurite extension and neuronal suivival activities of recombinant $\$ 100$ bela proteins that differ in the content and position of cysteine residues. J Cell Biol. 1.09, 3063-3071. 


\title{
Chapter 2
}

\section{Prenatal stress and neonatal rat brain development}

\author{
Van den Hove DLA ${ }^{1 / 2}$, Steinbusch $\mathrm{HWM}^{2}$, Scheepens $\mathrm{A}^{\mathrm{1} / 3}$, \\ Van de Berg WDJ ${ }^{1 / 4}$, Kooiman LAM $^{2}$, Boosten BJG ${ }^{2}$, Prickaerts $I^{2}$, Blanco CE
}

'Department of Pediatrics, Maastricht University, Maastricht, The Netherlands

2Department of Psychiatry and Neuropsychology,

Maastricht University, Maastricht, The Netherlands.

${ }^{3}$ Liggins Institute, University of AuckJand, Auckland, New Zealand.

${ }^{4}$ Department of Anatomy, Vrije Universiteil Medical

Center, Amsterdam, The Netherlands

Neuroscience 137: 145-55 (2006) 


\section{Abstract}

Chronic or repeated stress during human fetal brain development has been associated with various learning, behavioral, and mood disorders, including depression in later life. The mechanisms accounting for these effects of prenatal stress are not fully understood. The aim of this study was to investigate the effects of prenatal stress on early postnatal brain development, a disturbance of which may contribute to this increased vulnerability to psychopathology. We studied the effects of prenatal stress on fetal growth, stress-induced corticosterone secretion, brain cell proliferation, caspase-3-like activity and brain-derived neurotrophic factor protein content in newborn Fischer 344 rats. In addition to a slight reduction in birth weight, prenatal stress was associated with elevated corticosterone levels (33.8\%) after 1 hour of maternal deprivation on postnatal day 1 , whereas by postnatal day 8 this pattern was reversed $(-46,5 \%)$. Further, prenatal stress resulted in an approximately $50 \%$ decrease in brain cell proliferation just after birth in both genders with a concomitant increase in caspase-3like activity within the hippocampus at postnatal day $1(36.1 \%$ ) and at postnatal 5 (females only; 20.1\%). Finally, brain-derived neurotrophic factor protein content was reduced in both the olfactory bulbs $(-24.6 \%)$ and hippocampus $(-28.2 \%)$ of prenatally stressed male offspring at postnatal day 1 and 5 , respectively. These detrimental central changes observed may partly explain the increased susceptibility of prenatally stressed subjects to mood disorders, including depression, in later life.

\section{Introduction}

Accumulating evidence suggests that exposure of a pregnant woman to physical and/or psychological stress (prenatal stress; PS) might affect her offspring by promoting the development of warious learning, behavioral and mood disorders in later life (Stott, 1973, Huttunen and Niskanen, 1978, Meijer. 1985, Ward, 1991, Watson et al., 1999). In animal studies PS has been associated with reduced birth weight and increased preweaning mortality (Cabrera et al., 1999), disturbances in the hypothalamo-pituitary-adrenal (HPA) axis (Koehl et al., 1999, Szuran et al., 2000, Welberg and Seckl,2001), increased anxiety (Archer and Blackman, 1971, Vallee et al., 1997), persistent paradoxical sleep alterations (Dugovic et al., 1999), learning and memory deficits (Hayashi et al., 1998, Vallee et al., 1999, Szuran et al., 2000, Gue et al., 2004), and increased depression-related behavior in later life (Secoli and Teixeira, 1998, Alonso et al., 1999, Morley-Fletcher et $a_{r, 2}$ 2003). The mechanisms accounting for the impact of PS on postnatal life are not fully understood.

Investigations on the putative mechanisms involved have focused primarily on the HPA axis, the regulation of which is thought to be impaired in PS subjects. As a result, PS offspring may be unable to react appropriately to stressfull life events. In other words, PS may lead to a brain being permanently sensitized to subsequent stressful situations. "This disturbed reactivity of the HPA axis following PS is probably due to an enhanced release of maternal and 
placental stress hormones such as corticotropin-releasing factor (CRF) and cortisol/corticosterone, which subsequently enter the fetal circulation (Weinstock, 2001, Huzink et al, 2004) and influence fetal development.

PS may also have an impact on cellulam and synaptic plasticity. For example, PS has been shown to inhibit cell proliferation in the dentate gyrus (DG) of adult rats (Lemaire et al, 2000, Koo et aL, 2003) and juvenile nonhuman primates (Coe et al., 2003). In the latter investigation, PS rhesus monkeys also showed a reduced hippocampal volume. Other investigators have shown a reduced number of granule cells in the hippocampus of adult female, but not male, rats due to prematal restraint stress (Schmitz et al., 2002). PS resulted in a decrease in synaptic density in both the hippocampus and cortex of adult rats, whereas brain-derived neurotrophic factor (BDNE) protein content was diminished in the cortex, but not in the hippocampus (Koo et all., 2003).

However, little is known about the effect of PS on cellular and synaptic plasticity during early postnatal brain development. We therefore examined the effects of PS on fetal growth and stress-induced corticosterone secretion, brain cell proliferation, caspase-3-like activity, and BDNF content in neonatal. Fischer 344 rats.

\section{Experimental procedures}

\section{Animals and procedures}

These animal studies were all approved by the Animal Ethics Board of the University of Maastricht, The Netherlands. Acclimatized time-pregnant normal Fischer 344 rats (Charles River, The Netherlands) were used because the Fischer 344 strain is a pure breeding inbred strain with low heterogeneity and is known to be reasonably stress responsive (Izumi et al., 1997). The animals were housed individually within a temperature-controlled environment $\left(21 \pm 1^{\circ} \mathrm{C}\right)$ with $12 \mathrm{hr}$ light/ $12 \mathrm{hr}$ dark and had access to standard rat chow and water ad libitum. Pregnancy was determined by the presence of vaginal plugs (embryonic day $0-\mathbb{E} 0$ ). PS was performed daily during the last week of pregnancy (E14-E21). Pregnant femalle rats $(n=15)$ were individually restrained three times a day (at approximately 9:00 AM, 1:00 PM, and 5:00 PM) for 45 minutes in transparent plastic cylinders (Instrument Development Engineering \& Evaluation, Maastricht, The Netherlands) whilst being exposed to bright light (Ward and Weisz, 1984). Control pregnant females $(n=16)$ were left undisturbed in their home cages. Day of birth was defined as postnatal (P) day 0 and as soon as the last pup of a litter had been born, litter size was defined and pup gender and individual body weights were determined. Only litters of 8 or more pups were included in this study. No more than 2 male and/or 2 female pups per litter were examined at each particular time point to prevent litter effects (Chapman and Stern, 1978). Body weight of the dams was measured at E0, E21, and postpartum day 21 (weaning). For each grotup 7-8 pups were investigated per gender and per age. 
To determine the degree of cell proliferation we used the ${ }^{3} \mathrm{H}$-thymidine ( ${ }^{3} \mathrm{H}$-Thy) incorporation method (see below). For this purpose, on the assigned day, either P1, P2, P5, P8 or $\mathrm{P} 15$, the pups received a single dose of ${ }^{3} \mathrm{H}-$ Thy $(5 \mathrm{mCi} / \mathrm{gm}$ body weight) by subcutaneous injection into the nape of the neck with an ultrafine ( 30 gauge, fine-tipped, Teflon coated) needle to minimize injury and discomfort. Following ${ }^{3} \mathrm{H}$-Thy infusion the pups were placed. in a pediatric incubator set at $34^{\circ} \mathrm{C}$ and $75 \%$ humidity to prevent heat loss. Exactly 1 hour after ${ }^{3} \mathrm{H}$-Thy infusion the pups were decapitated and a blood sample was taken from the neck sturmp for corticosterone determination by radioimmunoassay. The brains were then carefully removed and microdissected using the method of Wagner and colleagues (Wagner et al., 1999). We isolated the olfactory bulb (OB), the cerebellum, the hippocampus, and the subventricular zone (SVZ) contained within the rostral forebrain. The microdissected regions were weighed, quickly snap frozen in liquid nitrogen and stored at $-75^{\circ} \mathrm{C}$ until further analysis. All dissections were performed by the same investigator (D.L.A. van den Hove) to preserve consistency.

For the purpose of a control experiment (see below) an extra group of 16 pregnant dams were delivered to our department at E4. At P1 and P8 PS and control offspring were either decapitated immediately after taking them away from their mother or injected with $0.9 \%$ $\mathrm{NaCl}$ instead of ${ }^{3} \mathrm{H}$-Thy and placed in a pediatric incubator for one hour beforehand, as described above. Blood was taken from the neck stump and plasma was subsequently used for corticosterone determination.

\section{Cell proliferation rate}

The dissected brain regions were homogenized using a Bead Beater (Biospec products, $O K$, USA) for $3 \times 30$ seconds in $350 \mathrm{ml}$ (for $\mathrm{OB}$ and hippocampus) or $1 \mathrm{ml}$ (for cerebellum and SVZ) of ice-cold lysis buffer (137 mM NaCl, $20 \mathrm{mM}$ Tris-HCl (pH 8.0), 1\% NP-40,10\% glycerol and a complete protease inhibitor tablet; Roche, The Netherlands).

The ${ }^{3} \mathrm{H}-$ Thy incorporation method, as described previously (Tao et al., 1997, Wagner et all., 1999, Scheepens et al., 2003a), uses the DNA synthesis rate in specific brain regions as an index of mitotic activity. Briefly, an aliquot of the homogenate was used to extract all cellular DNA using a standard tri-chloracetic acid precipitation protocol in order to determine the amount of ${ }^{3} \mathrm{H}$-Thy which was taken up by proliferating cells and incorporated into newly synthesized DNA during the 1 hour exposure. Essentially, this measure represents the product of the number of S phase cells within the sample times the DNA synthetic rate of these $S$ phase cells.

However, the incorporation of ${ }^{3} \mathrm{H}$-Thy into DNA depends on the amount of precursor taken up by the tissue. As a consequence, differences in e.g. blood flow between experimental groups might result in differences in ${ }^{3} \mathrm{H}$-Thy incorporation which do not reflect differences in mitotic activity. For this purpose, another aliquot was used to measure total amount of radioactivity in the tissue fraction. 
Homogenized DNA and tissue samples were solubilized in $1 \mathrm{ml}$ Solwene-350 (Packard Instruments, The Netherlands) at $50^{\circ} \mathrm{C}$ for $2-24 \mathrm{hrs}$ until the samples were completely dissolved. After this, $5 \mathrm{ml}$ of Hionic-Fluor scintillation cocktail (Packard Instruments, The Netherlands) was added and the samples were read for 20 minutes on a Wallac WinSpectral 1414 liquid scintillation counter. To convert the sample c.p.m. to d.p.m. the approprate quench curves were produced by adding tritiun standards to homogenized brain tissue before reading. The d.p.m. measures were corrected for the wet weight of tissue ( $\mathrm{mg}$ ) and the percentage of ${ }^{3} \mathrm{H}$-Thy incorporated into DNA relative to the total amount of radioactivity counted in the appropriate tissue was calcullated.

\section{Caspase-3-like activity}

Caspase-3-like activity was measured using the method as described previously (Puka-Sundvall et al, 2000, Scheepens et al., 2003a). In short, aliquots of homogenized brain samples $(30 \mathrm{mll})$ were mixed on a 96 well microtiter plate (Dynex, USA) with $70 \mathrm{ml}$ of extraction buffer I (50 mM Tris HCl (pH 7,3), $100 \mathrm{mM} \mathrm{NaCl} 5 \mathrm{mM}$ EDTA, 1 mM EGTA, 3 mM NaN3, 1 $\mathrm{mM}$ PMSF, $1 \mathrm{mg} / \mathrm{ml}$ pepstatin, $2.5 \mathrm{mg} / \mathrm{ml}$ leupeptin, $10 \mathrm{mg} / \mathrm{ml}$ aprotinin and $0.2 \%$ CHAPS). After incubation for 15 minutes at room temperature, $100 \mathrm{ml}$ of the extraction buffer II was added (extraction buffer I without protease inhibitors and CHAPS but including $4 \mathrm{mM}$ DTT and $50 \mathrm{mM}$ peptide substrate Ac-DEVD-AMC; Biomol, Germany). Cleavage of the Ac-DEVD-AMC was measured at $37^{\circ} \mathrm{C}$ using a Spectramax Gemini microplate fluorometer (Molecular Devices, USA) using an excitation wavelength of $380 \mathrm{~nm}$ and an emission wavelength of $460 \mathrm{~nm}$. Cleavage was followed starting 15 minutes after adding extraction buffer II at 2-min intervals for 3 hours. Fluorometric measures were expressed as nnol AMC produced per milligram wet weight of brain tissue per minute. To check the specificity of the assay, an additional $5 \mathrm{ml}$ of $5 \mathrm{mg} / \mathrm{ml}$ DEVD-CHO (Biomol, Germany), a selective caspase-3 inhibitor, was added to one sample of each region at each time point.

\section{Blood sampling and corticosterone radioimmunoassay}

Blood samples taken from the neck stump into heparinised blood collection tubes (Microvette" CB300, Sarstedt, Germany) were kept on ice and subsequently centrifuged at $3000 \mathrm{~g}$ for $5 \mathrm{~min}$ utes at $4^{\circ} \mathrm{C}$ after which the plasma was frozen down to $-75^{\circ} \mathrm{C}$ for subsequent determination. For the determination of the plasma corticosterone concentrations, $50 \mathrm{ml}$ of plasma was extracted with $3 \mathrm{ml}$ dichloromethane and vortexed for one minute. The corticosterone was subsequently measured directly on $1 \mathrm{ml}$ dried dichloromethane and extracted for radioimmunoassay using corticosterone- ${ }^{125}$ I. The radioimmunological reaction was performed overnight at $4^{\circ} \mathrm{C}$, after which a second antibody system was used to separate bound and unbound steroid as previously described in detail. In the original experiment, trunk blood samples were taken from the pups 1 hour after separating them from their mother, which is a known stressor. Therefore, these data do not represent basal corticosterone levels ( 


\section{BDNF content}

Brain derived neurotrophic factor content was measured in the brain homogenates using the BDNF Emax ImmunoAssay system from Promega (Madison, MI, USA). Corning high affinity ELA/RIA 96-well plates (Corning, NY, USA) were used and the resultant absorbency was read using a microplate reader at $450 \mathrm{~nm}$ (Biorad, CA, USA). We used the acid treatment as described previously (Scheepens et al., 2003b). Tissue samples were diluted within range of the standard curve, either 5 times (P1 and P2 animals) or 20 times (P5, P8, and P15 animals). Further, the manufacturer's recommendations were followed. All samples were measured in duplicate. Only tissues from male pups could be used.

\section{Statistics}

Differences in dam weights, litter sizes and male BDNF protein contents were tested using Student t-tests. Pre-weaning mortality was tested using the Fisher exact test. In the control experiment corticosterone data were evaluated using a three-way ANOVA (experimental group $\times$ gender $\times$ basal/maternal deprivation). In all other cases, the data were evaluated with a two-way analysis of variance (ANOVA; experimental group 'gender). Effects were analyzed in more detail with least significant difference (LSD) post hoc tests ( $\mathrm{P}<0.05$ ). Correlation analysis was performed using Pearson's correlation coefficient $\left(r_{p}\right)$. Note that both the degree of cell proliferation, caspase-3-like activity and BDNF protein content were determined using the same homogenate. All statistics were carried out using SPSS software version 11.5 (SPSS Inc, USA).

\section{Results}

\section{Dam weights}

Whereas starting dam weights were the same in both groups, PS dam weights were $\Perp 0.8 \%$ lower at E21 compared to controls ( $\mathbb{P}<0.001$; see Fig. 1), corresponding to $28 \%$ less weight gain over gestation. At the time of weaning (postpartum day 21), the stressed dams still had lower body weights relative to control dams $(-7.8 \% ; \mathrm{P}<0.01)$.

\section{Gestational length, litter size, birth weight and pre-weaning mortality}

PS had no effect on gestational length (all dams delivered at E22; data not shown). There was no difference in litter size between the groups $(10.0 \pm 0.6$ and $9.9 \pm 0.6$ pups/litter for controls and PS, respectively). We found a slight overall reduction in birth weight of PS pups (PS effect: $-3.0 \%$; $P<0.001$; see Fig. 2). Post hoc analysis showed that both male and female PS birth weights were lower than their corresponding controls (see Fig. 2). In addition, male 
pups were heavier than female pups (gender effect: $7.2 \%, \mathrm{P}<0.001$ ). There were no significant differences in pre-weaming mortality $(0.38 \pm 0.15$ and $0.73 \pm 0.23$ dead pups/litter for controls and $P S$, respectively).

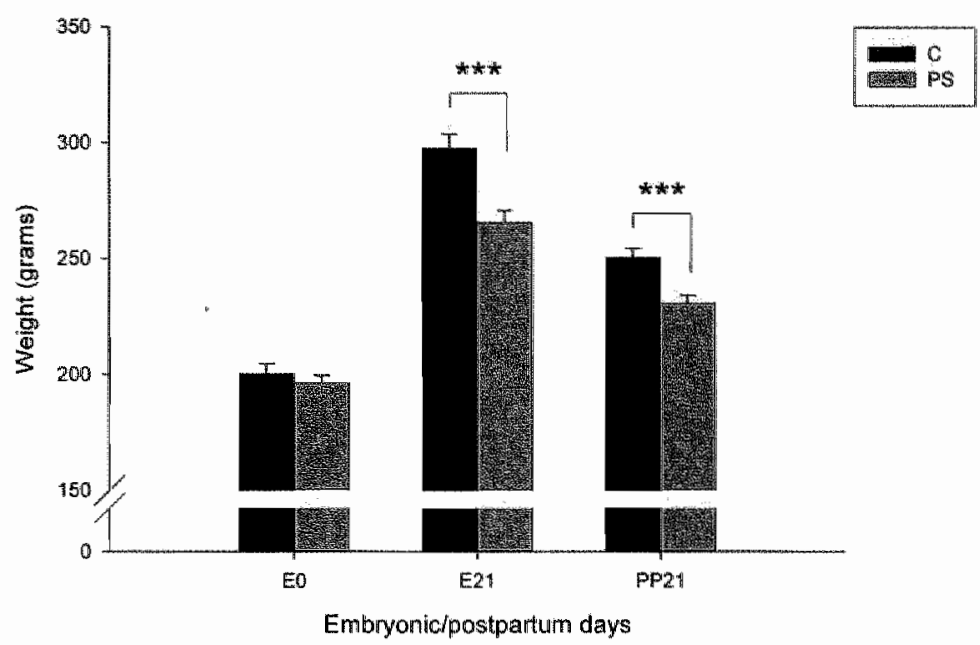

Figure 1. Dam weights over gestation, ie. embryonic day 0 and 21 (E0 and E21), and at postpartum day 21 (PP21), in both stressed (PS; $n=15$ ) and control $(C ; n=16)$ dams. Bars represent means $\pm S E M$. Whereas initial dam weights (ED) were the same, restraint stress resulted in a reduction in body weight at E21 (PS effect; **+P<0,001; t-lest). At PP21, PS dam weights were still llower compared to the controls. (PS effect; *** P<0.001; t-kest).

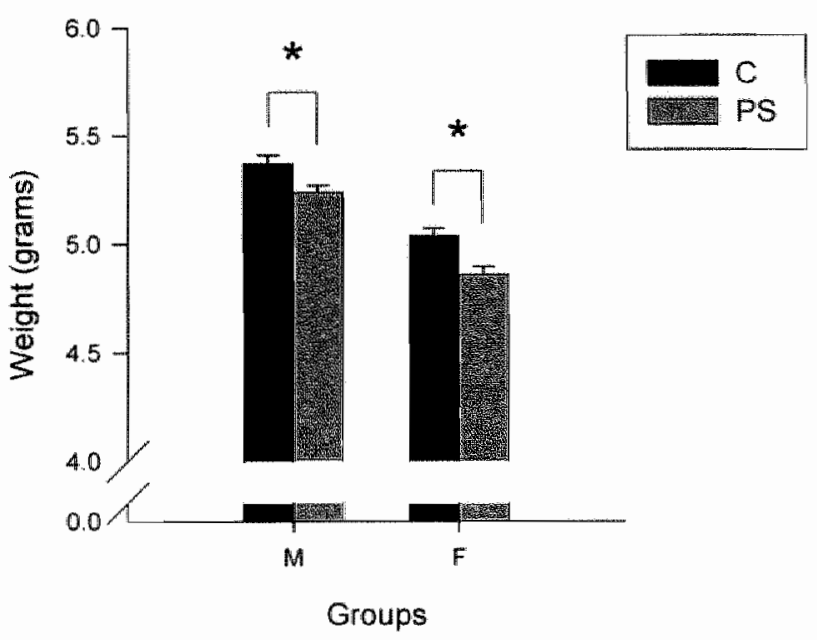

Figure 2. Birth weights of both male (M) and female (F) prenatally stressed (PS) and control (C) pups; ma 70 per group Bars represent means $\pm S . E$.M. Both male and female PS birth weights were lower than the corresponding controls (* $\mathrm{P}<0.05 ; 1.5 \mathrm{D})$ tests). Overall, males were heavier than females (gender effect; $\mathrm{P}<0.001$ ). 


\section{Stress-induced corticosterone secretion}

The corticosterone response in the normal developing rat is shown in Fig. 3. In general corticosterone levels changed with age, with low and consistently decreasing levels up to an age of 8 days. At P15, corticosterone levels were much higher again.

With respect to the effects of PS, corticosterone levels at $\mathrm{P} 1$ were increased in PS pups (PS effect: $33.8 \% ; \mathrm{P}<0.05)$. Over time this pattern reversed, with lower corticosterone levels in the PS group at P8 (PS effect: $-46.5 \% ; \mathrm{P}<0.001$ ). By P15, there were no differences between PS and control pups.
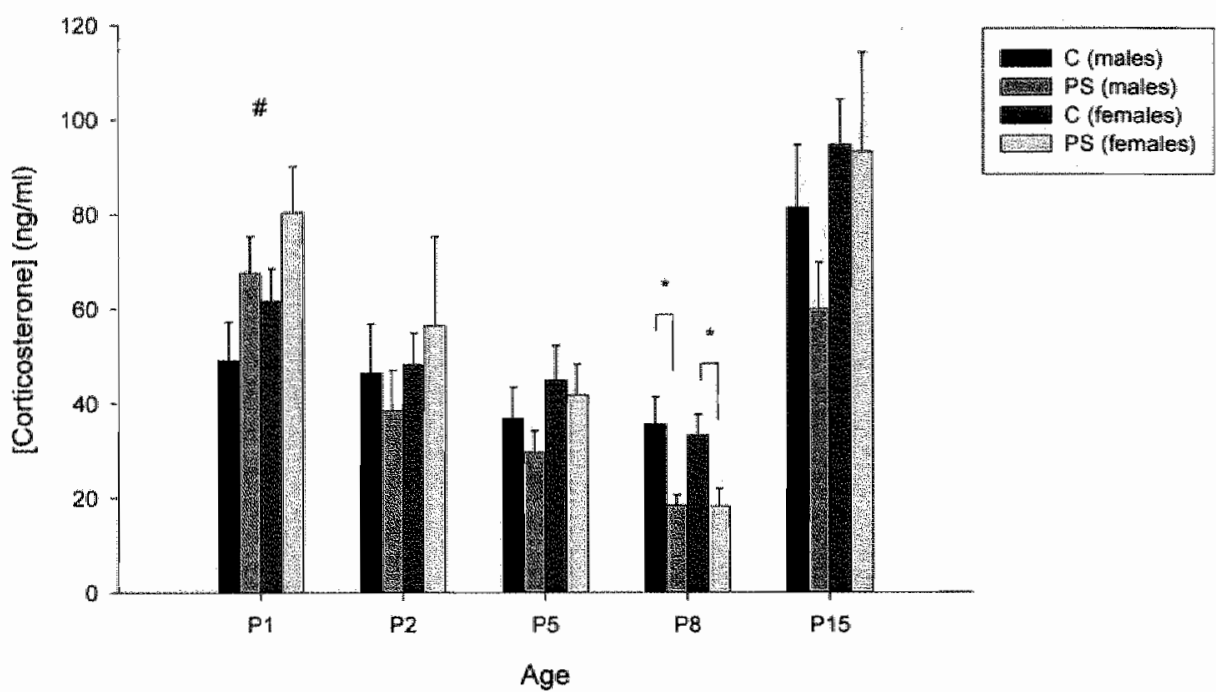

Figure 3. The effect of prenatal stress on matermal depriwation-induced plasma corticosterone secretion during neonatal de-

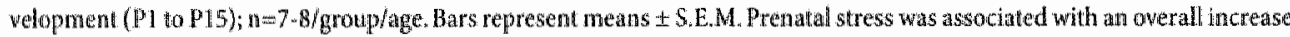
iz conticosterone levets at PI (PS effect (males + females]; \# $\mathrm{P}<0.05$ ). At P8, both male and fenale PS rats had decreased corticosterota levels companed to control pups ( $\mathrm{P}<0.05$, LSD tests).

\section{Control experiment: basal HPA axis activity}

To investigate the nature of the changed corticosterone levels after 1 hour of maternal deprivation seen with PS, a control experiment was performed in which the original experiment, in terms of maternal deprivation, was repeated. In addition, an equal number of pups were decapitated immediately after taking them away from the mother. These experiments were performed at both $\mathrm{P} 1$ and P8.

Results are shown in Table 1. At P1 basal corticosterone levels tended to be higher in PS pups as compared to controls (PS effect: $31.6 \% ; \mathrm{P}=0.065$ ). This difference was more profound within the maternal deprivation group (PS effect: $46.3 \% ; \mathrm{P}<0.01$ ). In addition, overall, basal corticosterone levels were higher as compared to levels after maternal depri- 
vation (34.9\%; $\mathrm{P}<0.01$ ). Post-hoc analysis showed that these effects were more profound in female offspring (Table 1.).

At P8, a significant effect of gender was observed, with female offspring showing higher levels of plasma corticosterone as compared to males (gender effect: $22.6 \% ; \mathrm{P}<0.001$ ). In addition, overall, levels after maternal deprivation were much higher as compared to basal levels (159.4\%; $\mathrm{P}<0.001)$.

Table 1. Control experiment. The effects of PS on basal (B) and maternal depriwation induced (MD) pllasma corticosterione

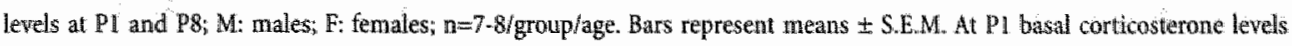
tended to be higher in PS pups as compared to controls (PS effect [males + females]; $P=0.065$ ). This difference was more profound within the maternal deprivation group (PS effect [males + females] ; 40.01 ). In addition overall, basal corticosterone levels were higher as compared to levels after maternal deprivation $(\mathrm{P}<0,01)$ at $\mathrm{Pl}$. At P8, in contrast, levels after maternal deprivation were higher as compared to basal levels $(\mathrm{P}<0.001)$. LSD tests: $* 00.05$ prenatal stress compared with control: WP $<0.05$ maternal deprivation compared with basal; $\$ \mathrm{P}<0.05$ females compared with nales. For more information, see text.

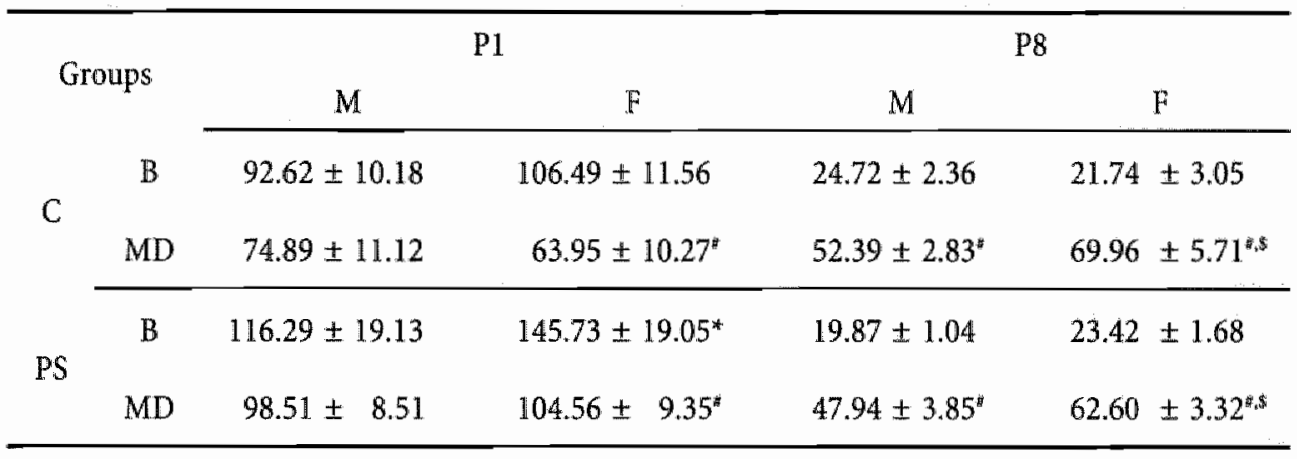

\section{Cell proliferation rate}

The pattern of cell proliferation within the neonatal brain is shown in Fig. 4. Cell proliferation levels at $\mathrm{P} 1$ were lower in all brain regions compared to those at P2. From P2 onwards, all structures showed a decrease in the degree of cell proliferation over time.

$P S$ induced a strong decrease in cell proliferation at $P 1$ in all regions (all PS effects; $O B$ : $-55.8 \% ; \mathrm{P}<0.001$; cerebellum: $-40.2 \% ; \mathrm{P}<0.001$; hippocampus $-56.5 \% ; \mathrm{P}<0.001 ; \mathrm{SVZ}:-53.0 \%$; $\mathrm{P}<0.001$; Fig 4). At P8, PS pups showed a slight increase in cell proliferation within the cerebellum (PS effect: $4.1 \% ; \mathrm{P}<0.01$ ). Importantly, the total amount of ${ }^{3} \mathrm{H}-$ Thy taken up by the tissue, i.e. tracer availability, did not differ between PS and control offspring in any of these cases, except for the SVZ at P1, where tracer availability was actually higher in PS pups as compared to controls (PS effect: 33.5\%; $\mathrm{P}<0.01$; data not shown). No significant differences were found in any of the other cases. In addition, no gender differences were found. Of note, no differences in brain region weights or total brain weights were observed between PS and control offspring (data not shown). 
Olfactory bulb

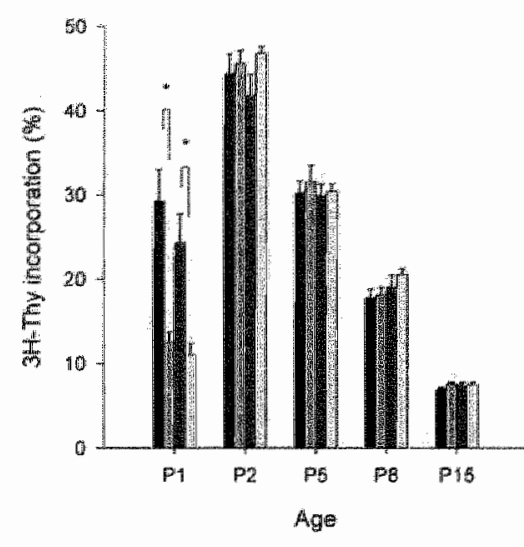

Hippocampus

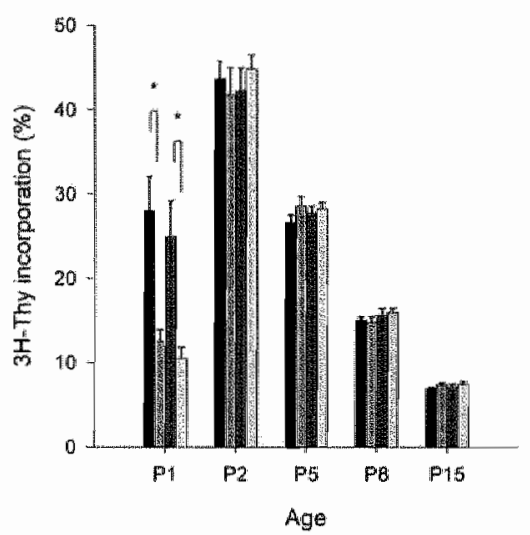

Cerebellum

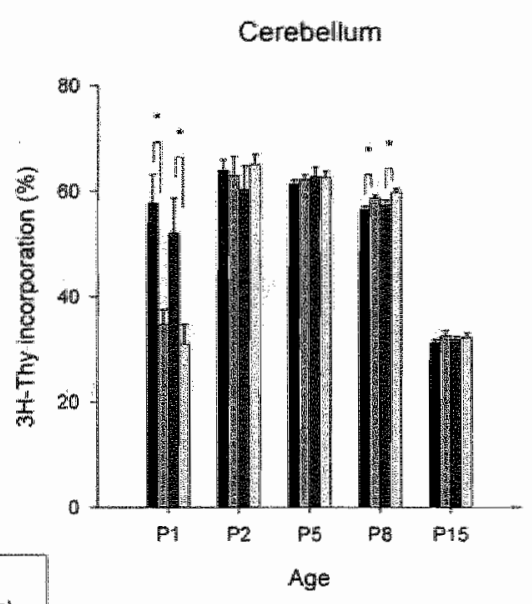

Subventricular zone

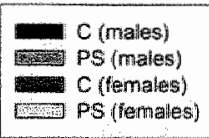

Figure 4. The effect of prenatal stress on developmental cell proliferation rate within the olfactory bull, cerebellum, hippocampus, and subventricular zone, from P1 to P15; n=7-8igroup/age. Bars represent means it S.E.M. Prenatal stress induced a strong decrease in cell proliferation at PI in all regions studied of both male as well as female pups ( $\mathrm{P}$ P $<0.05$; LSD tests). In corttrast, there was a small increase in cerebolllat cell proliferation at P8 in both male and female PS pups ( ${ }^{*} \mathrm{P}<0.05$; LSD tests).

\section{Caspase-3-like activity}

Overall, caspase-3-like activity was relatively low in the $O B$ and hippocampus compared to the SVZ and cerebellum (Fig. 5). In the $\mathrm{OB}$ and hippocampus caspase-3-like activity declined after $\mathrm{P} 1$, whereas it increased in the cerebellum and SVZ after $\mathrm{P} 1$, peaking at $\mathrm{P} 8$ and P5, respectively.

Regarding the effects of PS, we found an increase in caspase-3-like activity within the hippocampus at P1 (PS effect: 36.1\%; P<0.05) and at P5. The PS effect at P5 was however confirmed with post-hoc analysis only for the females (20.1\%; P<0.05; LSD test). No significant differences were found in any of the other cases. 
Olfacony bulb

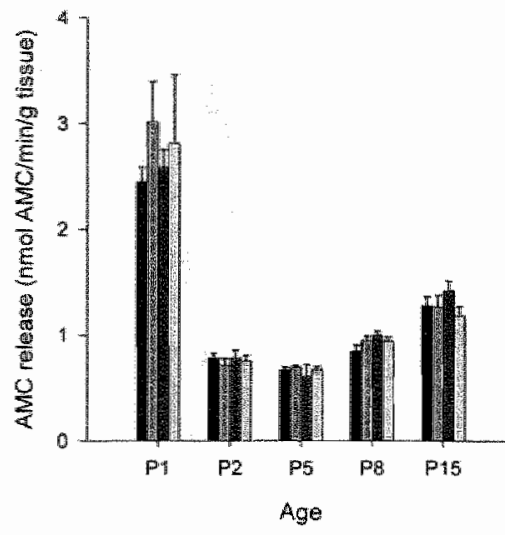

Hippocampus

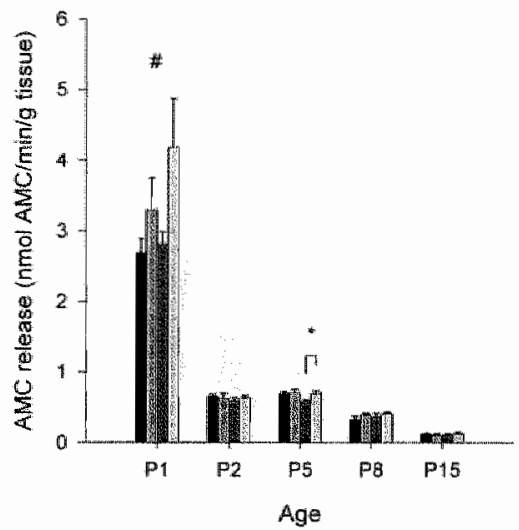

Cerebellum

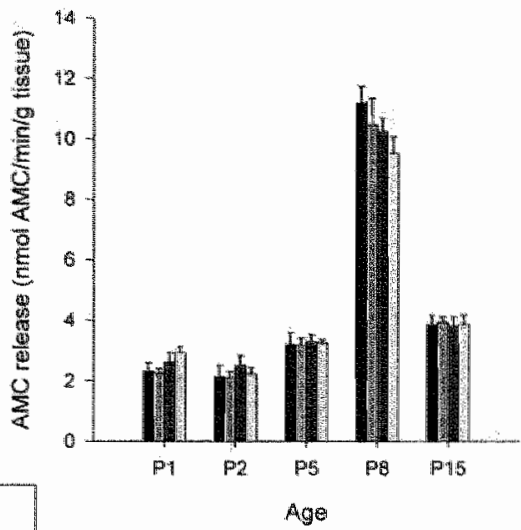

Subventricular zone

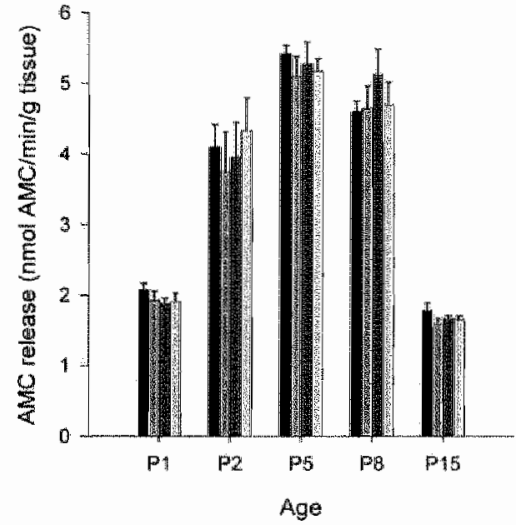

Figure 5. Developmental caspase-3-like actwity within the olfactory bulb, cerebellum, hippocampus, and subwentriculat zone,

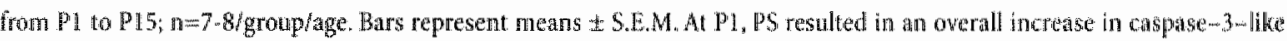

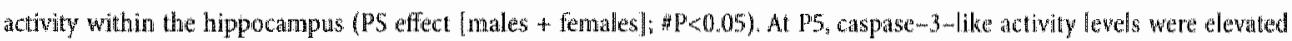
within the hippocampus of PS females only $(* \mathbb{P}<0.05 ; 1 . S D$ test).

\section{BDNF content}

The pattern of BDNF content within the normal and PS male brain is illustrated in Fig. 6 . All structures had relatively low levels at P2 compared to the other time points. In contrast to the other regions, cerebellar BDNF levels decreased again after P8, as has been described previously (Das et al., 2001).

Male PS BDNF levels all tended to be lower at PI compared to controls. However, this difference was only significant in the $\mathrm{OB}(-24.6 \% ; \mathrm{P}<0.05$; of note, cerebellum: $-50.1 \%$; $\mathrm{P}=0.062$ ). Hippocampal BDNF content at $\mathrm{P} 5$ was $28 \%$ lower in PS rats compared to controls $(\mathrm{P}<0.05)$. No significant differences were found in any of the other cases. 


\section{Correlations}

Only when an effect of PS was observed, correlation analysis was performed (see Table 1). At $P^{\prime} 1$, there was a negative correlation between cell proluferation values and plasma corticosterone levels ( $r_{p} \approx-0.6$ in each region; $P<0.001$ in all cases).

In addition, male $\mathrm{P} 1 \mathrm{OB}$ cell proliferation values were positively correlated to BDNF levels in this region $\left(r_{p}=0.63, P<0.01\right)$. Furthermore, hippocampal caspase-3-like activity levels were negatively correlated to cell proliferation walues within this region at $\mathrm{P} 1\left(\mathrm{r}_{\mathrm{p}}=-0.44\right.$; $\mathrm{P}<0.05$ ). Further, $\mathrm{Pl}$ plasma corticosterone levels were negatively correlated to caspase $-3-$ like activity within the $S V Z\left(r_{p}=-0.49 ; P<0.01\right)$. Finally, there was a trend towards a negative correlation between BDNF protein content and the levels of caspase-3-like activity within the hippocampus at $\mathrm{P} 5\left(\mathrm{r}_{\mathrm{p}}=-0.53 ; \mathrm{P}=0.052\right)$.

Olfactory bulb

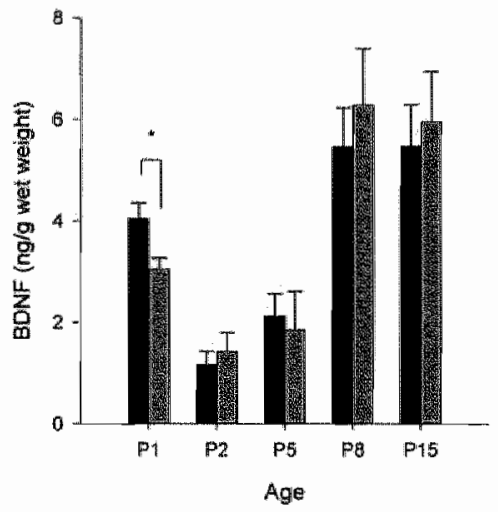

Hippocampus

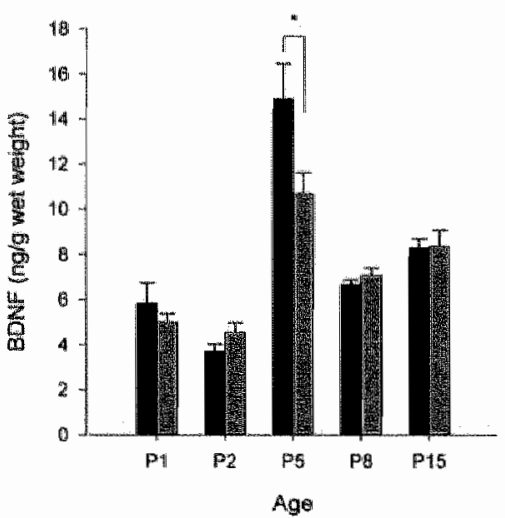

Cerebellum

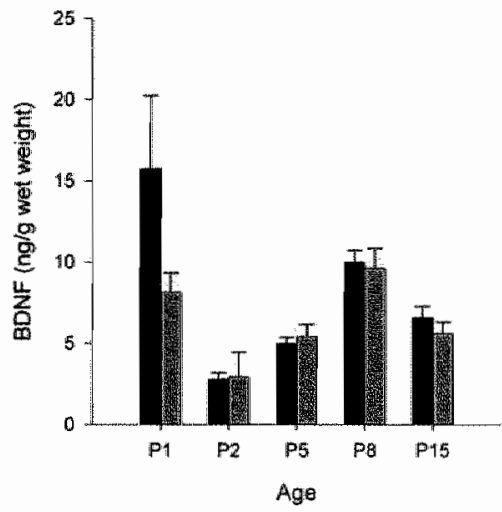

Subventricular zone

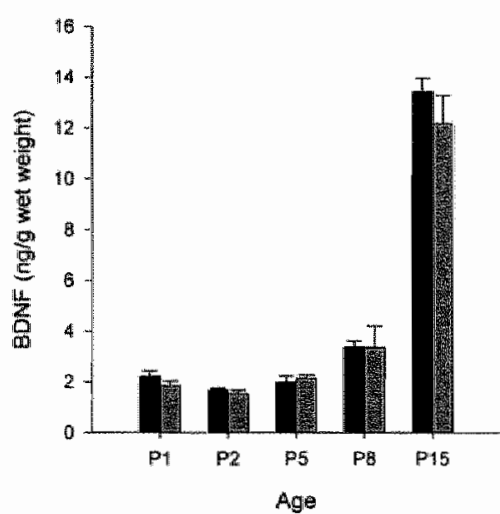

Figure 6. The effect of prenatal stress on brain derived neurotrophic factor (BDNF) protein content within the olfactory bulb, cerebellum, hippocampus, and subventricular zone of the neonatal male rat brain, from P1 to P1 5 ; $n=7-8 /$ group/age. Bars rep-

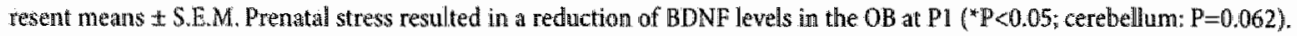
Further, PS resulted in a reduction of BDNFl level within the hippocampus of 5 -day-ald male pups (*P<0.05). 
Table 2. The effect of PS on corticosterome, cell proliferation, caspas-3-3ike activity and BDNh content and the BS induced changes and corfelations between the different variables. Depicted are Pearsons correlation coeftichts $\left(\mathrm{r}_{\mathrm{f}}\right)$ representing the associations between the PS-induced changes and the other wariables measured in the same plasma andior tissue samples. Note that BDNF was measured in males only, Ja addition, caspase-3-like activity in the hippoctampus at 95 was only affected

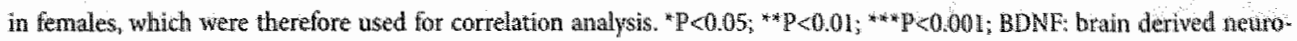
trophic factor; OB: olfactory bulb; CRB: cerebellum: HIP. hippocanpus; SVZ: subwentricular zone n a: not applicable.

\begin{tabular}{|c|c|c|c|c|c|c|c|}
\hline Affected variable & Age & Reg. & $\begin{array}{c}\text { Eiffect } \\
\text { PS }\end{array}$ & $\begin{array}{l}\text { Cortico- } \\
\text { sterone }\end{array}$ & $\begin{array}{c}\text { Cell } \\
\text { proliferation }\end{array}$ & Caspase--3 & BDNF \\
\hline \multirow{2}{*}{ Cortico-sterone } & P1 & n.a. & $\uparrow$ & & see below & $949(s) 2)$ & n.a. \\
\hline & P8 & n.a. & $\downarrow$ & & see below & nia. & na. \\
\hline \multirow{5}{*}{ Cell proliferation } & P1 & $\mathrm{OB}$ & $\downarrow$ & 0.64 & & -0.33 & $0.63^{*}$ \\
\hline & P1 & $\mathrm{CRB}$ & $\downarrow$ & $0,57+x$ & & -0.16 & 0.17 \\
\hline & P1 & HIP & $\downarrow$ & $0.60^{7}$ & & r. 044 & 0.15 \\
\hline & $\mathrm{Pl}$ & SVZ & $\downarrow$ & $0.57 x+$ & & 0.12 & -0.11 \\
\hline & P8 & CRB & $\uparrow$ & -0.19 & & -0.11 & -0.05 \\
\hline \multirow{2}{*}{$\begin{array}{c}\text { Caspase-3-like } \\
\text { activity }\end{array}$} & P1 & HIP & $\uparrow$ & 0.17 & see above & & -0.06 \\
\hline & P5 & HIP & $\uparrow$ & -0.26 & 0.05 & & \\
\hline \multirow{2}{*}{$\mathrm{BDNF}$} & P1 & $\mathrm{OB}$ & $\Downarrow$ & -0.10 & 0.07 & -0.13 & \\
\hline & P5 & HIP & $\downarrow$ & 0.46 & -0.09 & $-0.53^{\mathrm{r}-0,053}$ & \\
\hline
\end{tabular}

\section{Discussion}

Besides impaired fetal growth, PS was associated with an aberrant HPA axis (re-) activity, a strong decrease in brain cell proliferation, increased caspase-3-like activity, and reduced brain BDNF content just after birth. These developmental abnormalities are likely to have sïgnificant long-term detrimental consequences on brain functioning.

\section{Somatic growth}

Pups of dams exposed to stress during pregnancy weighed less at birth as compared to control offspring. Reduced birth weight has been related to various diseases in adulthood including coronary heart disease, hypercholesterolemia, hypertension, stroke and non-insulin-dependent diabetes mellitus, referred to as the "Barker Hypothesis" or the "fetal origins of adult disease hypothesis" (Barker, 1995). In addition, low birth weight has more recently been as- 
sociated with an increased susceptibility to stress (Nilsson et al., 2001) and depression in later life (Thompson et al., 2001, Gale and Martyn, 2004).

The observed reduction in birth weight in PS pups may be explained by the reduced weight gain over gestation $(-28 \%)$ of the stressed dams. Unfortunately; we were not able to check whether this was due to a reduction in food and water intake and/or an impaired conversion of dietary calories into maternal weight gain as seen in reaction to stress (Ward and Wainwright, 1988, Hobel and Culhane, 2003). Both phenomena might indirectly impair fetal growth, eventually resulting in a lower birth weight. It has been suggested that a reduced food and water intake by the mother may largely explain the effects of pregnancy stress on offspring development (Ward and Wainwright, 1988). In addition, the transplacental transfer of maternal stress hormones and a reduction in uteroplacental blood flow, both of which are commonly observed in pregnancy stress, may affect fetal growth (Hobel and Cullhane, 2003, Huizink et al., 2004).

\section{Stress-induced corticosterone secretion}

The first two weeks of postnatal life in rats are characterized by a hyporesponsiveness to stress (stress-hyporesponsive period) (Henning, 1978, De Kloet et al., 1988). In line with this, we found low and consistently decreasing corticosterone levels up to an age of 8 days in both groups, increasing dramatically by $\mathrm{P} 15$. Interestingly, at P1 we observed higher corticosterone levels after a 1 hour maternal deprivation in both male and female PS pups as compared to controls. In contrast, at P8, corticosterone levels were lower in the PS group as compared to the control group.

\section{Control experiment: basal HPA axis activity}

From the original experiment it was unclear whether the higher corticosterone levels after a I hour maternal deprivation in PS pups at PI were the result of a higher basal HPA axis activity or an affected negative feedback function of the HPA axis. The control experiment performed suggests that basal HPA axis activity is affected by PS immediately after birth.

At P8 plasma corticosterone levels were much higher in both PS and control pups after maternal deprivation, a known stressor, as compared to basal levels. Surprisingly, at P1 maternal deprivation resulted in decreased corticosterone levels. The implications of this new and rather unexpected finding are not clear at the moment. One could speculate that since this decrease was observed in both PS and control offspring, a common physiological mechanism is involved, related to parturition, which may reflect the start of the stress-hyporesponsive period. This awaits further research though.

The higher corticosterone levels in the PS group as compared to controls after maternal deprivation at $\mathrm{P} 8$ as seen in the original investigation were not found in the control experiment. This might be explained by the fact that for the control experiment, rats were delivered pregnant to our apartment at $\mathrm{E} 4$ for practical reasons, which may have had a stressful effect 
on both groups of dams and their oflspring, possible causing a slight shiftchange in the pattern observed.

Taken together, these data support the idea that PS perturbs the development and function of the HPA-axis; a disruption that may have important consequences for adult stress-related behavior.

\section{Cell proliferation and caspase-3-like activity within the neonatal brain}

As discussed in the introduction, several studies have shown that PS results in an inhibition of proliferation of future neurons in the adult hippocampus. We now show that already during early neonatal development, at $\mathrm{PI}$, hippocampal cell proliferation is drastically (-58\%) inhibited by PS. Interestingly, this effect was not restricted to the hippocampus, since cell proliferation was affected to the same extent in all brain regions investigated. Future experiments using ${ }^{3} \mathrm{H}$-Thymidine with subsequent autoradiography or 5-bromo-2-deoxyuridine (BrdU) labeling and stereology should be performed to investigate whether the effects of PS are primarily on neuronal or glial cells, i.e. does PS have consequences for the different types of differentiation of progenitor cells ultimately?

Interestingly, cell proliferation values in all brain regions at $\mathrm{P} 1$ were negatively correlated to plasma corticosterone levels. It is not clear though, whether both features are indeed linked in terms of cause and effect. In a recent investigation by Yu and colleagues (2004) it was shown that both corticosterone and dexamethasone, a glucocorticoid receptor agonist, were able to suppress the proliferation of cells derived from the hippocampus of 16.5-day-old rat embryos (Yu et al., 2004). This might suggest that elevated levels of corticosterone resulting from HPA-axis (hyper-) activity may play an important role in controlling (hippocampal) cell proliferation. Kippin and colleagues (2004) recently showed that PS in hamsters is associated with a reduction in the number of neural stem cells derived from the subependyma of the lateral ventricle (Kippin et al., 2004). In support of our findings, they showed that this reduction was already present at birth, endured into late adulthood and was accompanied by a reduced cell proliferation in the adult subependyma of the lateral ventricle. Interestingly, they also showed that postnatal handling was able to increase neural stem cell number, thus reversing the effects of PS.

At postnatal day 8 , we observed a slight increase in the degree of cell proliferation in the cerebellum of PS pups. We think this may represent a compensatory or catch-up effect to the decrease in cell proliferation seen at $\mathrm{P}_{1}$; a detrimental effect that may also be present even earlier, i.e., prenatally. Another explanation for the higher levels of cell proliferation in the PS group could be the higher corticosterone levels in the control group at this time point. As discussed before, corticosterone may exert a negative influence on brain cell proliferation.

In our investigation, the activity of caspase-3 - a pivotal mediator of apoptosis - was significantly increased after PS within the hippocampus, both at P1 (males + females) and at P5 (females only). In agreement with our results, Ladefoged and colleagues, using a combination of various prenatal stressors, found a similar increase in caspase-3 activity in the hip- 
pocampus of male (females were not included) Wistar pups at 6 days of age (Ladefoged et al, 2004). In addition, they also found an increase in cerebellar caspase-3 activity at this age. These data show that both hippocampal cell proliferation and apoptosis are affected by PS during early postnatal development, which is likely to have long-term consequences for adult hippocampal functioning.

\section{BDNF content in the neonatal brain}

We show that PS resulted in a reduction in BDNF levels at $P 1$ in the $O B$ of male rats. Further, there was a positive correlation between the levels of BDNF and cell proliferation within this region at this time point. In addition, PS resulted in a reduction in BDNF level within the hippocampus of 5 -day-old pups. In this particular case, BDNF levels showed a trend towards a negative correlation with caspase-3-like activity. BDNF, as a member of the neurotrophin family of regulatory factors, is necessary for the survival and function of neurons, and plays an important role in the modulation of synaptic transmission and synaptic plasticity. In this respect, reduced $B D N F$ function is thought to play an important role in the pathophysiology of mood disorders (see review by Manji et al., 2003).

Interestingly, our findings differ from those of Koo and colleagues (Koo et al., 2003), who found a reduction in cortical, but not in hippocampal BDNF level, after PS. Koo and coworkers did, however, not investigate the neonatal, but the young adult rat brain instead. In addition, as shown by others, fetal hypothalamic BDNF protein content was not altered by maternal restraint stress (Fujioka et al., 2003).

Altogether, the observed changes in BDNF content may have important consequences for cellular and synaptic plasticity, both during development and in adulthood.

In conclusion, in this study we show that prenatal stress has several important consequences for early postnatal development. In addition to a reduction in birth weight, PS caused a disturbed H.PA axis (re-) activity, a strong decrease in brain cell proliferation, increased caspase-3-like activity, and reduced brain BDNF levels just after birth. The observed developmental abnomalities may have significant long-term detrimental consequences for brain functioning and may explain the increased susceptibility to psychopathology (e.g. depression) observed in PS subjects.

\section{Acknowledgements}

The authors would like to thank Mrs. Marjanne Markerink for her assistance and expert advice with the ELISAs. 


\section{References}

ars

Alonso, S. J., Castellano, M. A., Quintero, M. and Navarro, E., 1999. Action of antidepressant drugs on maternal stressinduced hypoactivity in female rats. Methods Find Exp Clin Pharmacol. 21, 291-295.

Archer, J. E. and Blackman, D. E., 1971. Prenatal psychological stress and offspring behavior in rats and mice. Dev Psychobiol. 4, 193-248.

Barker, D. J., 1995. The fetal origins of adult disease. Proc R Soc Lond B Biol Sci. 262, 37-43.

Cabrera, R. J., Rodriguez-Echandia, E. L., Jatuff, A.S. and Foscolo, M., 1999. Effects of prenatal exposure to a mild chronic variable stress on body weight, preweaning mortality and rat behavior. Braz I Med Biol Res. 32, 1.229-1237.

Chapman, R. H. and Stern, J. M., 1978. Maternal stress and pituitary-adrenal manipulations during pregnancy in rats: effects on morphology and sexual behavior of male offspring. I Comp Physiol Psychol. 92, 1074-1083.

Coe, C. L., Kramer, M., Czeh, B., Gould, E., Reeves, A. J., Kirschbaum, C. and Fuchs, E, 2003. Prenatal stress diminishes neurogenesis in the dentate gyrus of juvenile rhesus monkeys. Biol Psychiatry. 54, 1025-1034.

Das, K. P, Chao, S. L., White, L. D., Haines, W. T., Harry, G. I., Tilson, H. A. and Barone, I. S., 2001. Differential patterns of nerve growth factor, brain-derived neurotrophic factor and neurotrophin-3 mRNA and protein levels in developing regions of rat brain. Neuroscience. $103,739-761$.

De Kloet, E. R., Rosenfeld, P., Wan Eekelen, J. A., Sutanto, W. and Levine, S., 1988. Stress, glucocorticoids and development. Prog Brain Res. 73, 101-120.

Dugovic, C. Maccari, S. Weibel, L., Turek, F. W. and Van Reeth, O., 1999. High corticasterone levels in prenatally stressed rats predict persistent paradoxical sleep alterations. I Neurosci. 19, 8656-8664.

Fujioka, T., Fujioka, A., Endoh, $\mathbb{H}_{n,}$ Sakata, Y. Furukawa, S. and Nakamura, S. 2003. Materno-fetal coordination of stress-induced fos expression in the hypothalamic paraventricular nucleus during pregmancy. Neuroscience. 118 , 409-415.

Gale, C.R. and Martyn, C. N., 2004. Birth weight and later risk of depression in a national birth cohort. Br J Psychiatry. $184,28-33$.

Gue, M., Bravard, A., Meunier, I., Veyrier, R., Gaillet, S., Recasens, M. and Maurice, T., 2004, Sex differences in learning deficits induced by prenatal stress in juvenile rats. Behav Brain Res. 150, 149-157.

Hayashi, A., Nagaoka, M., Yamada, K., Ichitani, Y., Miake, Y. and Okado, N., 1998. Maternal stress induces synaptic loss and developnental disabilities of offspring. Int I Dev Neurosci. 16, 209-216.

Henning, S. J., 1978. Plasma concentrations of total and free corticosterone during development in the rat. Am I Physiol. 235, E451-456.

Hobel, $\mathrm{C}$ and Culhane, J., 2003. Role of psychosocial and nutritional stress on poor pregnancy outcome. J Nutr. 133, $17095-17175$.

Huizink, A. C., Mulder, E. J. and Buitelaar, J. K., 2004. Prenatal stress and risk for psychopathology: specific effects or induction of general susceptibility? Psychol Bull. 130, 115-142.

Huttunen, M. O. and Niskanen, P. 1978. Prenatal loss of father and psychiatric disorders. Arch Gein Psychiatry. 35, $429-431$.

Imumi, J., Washizuka, M., Hayashi-Kuwabara, Y., Yoshinaga, K., Tanaka, Y.s lkeda, Y., Kinthi, Y. and Oguchi, K., 1997. Evidence for a depressive-like state induced by repeated saline injections in Fischer 344 rats. Pharmacol Biochem. Behav $57,883-888$.

Kippin, T. E., Cain, S. W., Masum, Z, and Ralpls, M. R., 2004, Neural stem cells show bidirectional experience-dependent plasticity in the perinatal mammalian brain. I Neurosci. 24, 2832-2836.

Koehl, M., Darnaudery, M., Dulluc, I., Van Reeth, O, Le Moal, M. and Maccari, S., 1999. Prenatal stress alters circadian activity of hypothalamo-pituitary-adrenal axis and hippocampal corticosteroid receptors in adult rats of both: gender. J Neurobiol. 40, 302-315.

Koo, J. W., Park, C. H., Choi, S. H., Kim, N. J., Kim, H. S., Choe, J. C. and Suh, Y. H., 2003. The post natal enwironment can counteract prenatal effects on cognitive ability, cell proliferation, and synaptic protein expression. Faseb J. 17. $1556-1558$.

Ladefoged, O., Hougaard, K. S., Hass, U., Sorensen, L. K., Lund, S. P., Svendsen, G. W. and Lam, H. R., 2004. Effects of combined prenatal stress and toluene exposure on apoptotic neurodegeneration in cerebellum and hippocampus of rats. Basic Clin Pharmacol Toxicol. 94, 169-176. 
Lemaire, $\mathrm{V}$, KoeH, M., Le Mod, M. and Abrous, D. W., 2000. Prenatal stress produces learning deficits afsaciated with an intibition of neurogenesis in the hippocampus. Proc Nat Acad Sci U S $4,97,11032-11037$.

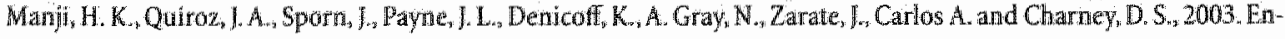
bancing newromal plasticity and cellular resilience to derelop novel, improwed therapeutics for Difficalto-to-Treat depression. Biological Psychiatry. $53,707-742$

Meijer, A., 1985. Child psychiatric sequelae of matemal war stress. Acta Psychiatr Scand 72, 505-511.

Morley-Fletcher, S., Darraudery, M. Koeh, M, Casolini, D, Van Reeth, O and Maccar, S. 2003. Prenatal stress in rats predicts immobility behavior in the forced swim test. Effects of a chrowic treatment with tianeptine. Brain Res. $989,246-251$

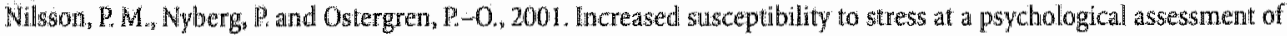
stress folerance is associated with impaired fetal growth. Int J Epideniol. 30, 75 iw 80 .

Puka-Sundwall, M., Hallin, U, Zhu, C, Wang, X., Karlssom, I, O., Blomgren, K, and Hagberg, H., 2000. NMDA blockade attenuates caspase-3 activation and DNA fragmentation after neonatal hypoxia-ischemia. Neuroreport. 11 . $2833-2836$

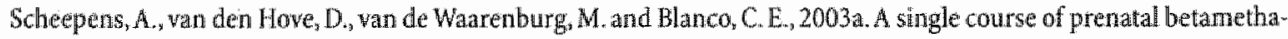
sone in the rat alters postmatal brain cell proliferation but not apoptosis. I Physiol $552,163-175$.

Scheepens, A., Wassink, G. Piersma, M. J., Van de Berg, W. D. and Blanco, C. E, 2003b. A delayed increase in hippocampal prolifienation following global asphyxia in the meonatlal rat. Brain Res Dev Brain Res. 142, 67-76.

Schmitz, C, Rhodes, M. E., Bludat, M., Kaplan, S, Ong, P., Ueffung, I, Vehof, J, Kort, H. and Frye, C. A., 2002. Depression: reduced number of granule cells in the hippocampus of female, but not male, rats due to prenatal restraint stress Mol Psychiatry. 7,810-813.

Secoli, S. R. and Teixeira, N. A., 1998. Chronic prenatal stress affects development and behavioral depression in rats. Striess. 2, 273-280.

Stott, D. H, 1973, Follow-up study from birth of the effects of prenatal stresses. Dev Med Child Neurol. 15,770-787.

Szuran, T. F, Pliska, V, Pokorny, I, and Weld, H., 2000. Prenatal stress in rats: effects on plasma corticosterone, hippocampal glucocorticoid receptors, and maze performance. Physicl Behav. 7l, 353-362.

Tao, Y, Black, 1 . B. and DiCicco Bloom, E., 1997 . In wivo newrogenesis is inhibited by neutralizing antibodies to basic fibroblast growth factor. I Neurobiol. 33, 289-296.

Thompson, C., Syddall, H., Rodin, I, Osmond, C. and Barker, D. I., 2001. Birth weight and the risk of depressive disorder in late life. Br J Psychiatry. 179, 450-455.

Vallee, M., MacCari, S, Dellu, F. Simon, H., Le Moal, M. and Mayo, W, 1999. Long-term effects of prenatal stress and postmatal handling on age-rehated glucocorticoid secretion and cognitive performance: a longitudinal study in the rat. Fur I Neurosci. 11,2906-2916.

Vallee, M. Mayo, W. Dellu, F., Le Moal, M., Simon, H. and Maccari, S., 1997 . Prenatal stress induces high anxiety and postinatal handling induces low anxiety in adult offspring: correlation with stress-induced corticosterone secrelion. I Netrosei. 17, 2626-2636.

Wagner, I, P., Black, I, B. and DiCicco-Bloom, E, 1999. Stimulation of neonatal and adult brain neurogenesis by subcutaneous injection of basic fibroblast growth bactor. "N Newrosci. 19,6006-6016.

Ward, A. J., 19g1. Prenatal stress and childhood psychopathology. Child Psychiatry Hum Dev. 22, 97-110.

Ward, G. R. and Wanwright, P. F, 1988. Reductions in naternal food and water intake arcount for prenatal stress effects on neurobehwioral development in B6D2F2 mice. Physiology \& Behavior. $44,781-786$.

Ward, H. L... and Weisz, J., 1984. Differental effects of maternal stress on circulating levels of corticosterone, progesterone. and testogterone in male and female rat fetuses and the mothers. Endocrinology. 114, 1635-1644.

Watson, J. B. Mednick, S.A. Huttunen, M. and Wang, X., 1999. Prenatal teratogens and the development of adull mental Illiness. Dew Psychopathol, 11,457-466.

Weinstock, M., 2001. Alterations induced by gestational stress in brain morphology and behaviour of the offspring Prog Neurobiol. 65,427-451.

Welberg. L. A. and Seckl, J. R. 2001 . Prenatal stress, glucocorticoids and the programming of the brain. II Neuroendocrind. $13,113-128$.

$\mathrm{Yu}_{\mathrm{w}}$ I. T., Lee, S,-H, Lee, Y.-S. and Son, H, 2004. Differential effects of corticosterone and dexamethasone on hippocampal neurogenesis in vitro. Biochemical and Biophysical Research Communications. 317,484-490. 


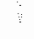

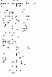




\title{
Chapter 3
}

\section{Prenatal stress reduces $S 100 \mathrm{~B}$ in the neonatal rat hippocampus in a sexually divergent manner}

\author{
Van den Hove DLA ${ }^{1 / 2}$, Steinbusch HWM ${ }^{2}$, Bruschettini $\mathrm{M}^{2}$, \\ Gazzolo $\mathrm{D}^{3 / 4}$, Frulio $\mathrm{R}^{4}$, Scheepens $\mathrm{A}^{1 / 5}$, Prickaerts J ${ }^{2}$, Blanco $\mathrm{CE}^{1}$
}

'Department of Pediatrics, Maastricht University, Maastricht, The Netherlands.

${ }^{2}$ Department of Psychiatry and Neuropsychology, Mastricht University, Maastricht, "The Netherlands.

${ }^{5}$ Department of Maternal Fetal and Neonatal Health, Garibaldi Hospital, Catania "Italy.

${ }^{4} \mathrm{G}$. Gaslini Children's Hospital, University of Genoa, Genoa, Italy. ${ }^{5}$ Liggins Institute, University of Auckland, Auckland, New Zealand.

NeuroReport, Submitted 


\section{Abstract}

In a prewious study we showed that prenatal stress in the rat disturbed neonatal brain development. The astroglial-specific neurotrophic factor $S 100 B$ is known to play an important role in normal brain development. In the present study; we investigated the effects of prenatal stress on $5100 \mathrm{~B}$ concentrations in the hippocampus of 1 -day-old Fischer 344 rats.

Overall, prenatal stress resulted in a $25 \%$ reduction in hippocampal levels of $\$ 100 \mathrm{~B}$. Further, male hippocampal $\$ 100 \mathrm{~B}$ content was negatively correlated with plasma corticosterone at that time. Positive correlations were found between female $S 100 \mathrm{~B}$ levels and fetal growth, and brain-derived neurotrophic factor content of the hippocampus.

In conclusion, the observed reduction in neonatal hippocampal $S 100 \mathrm{~B}$ levels, as a consequence of prenatal stress may be involved in affecting postnatal brain development in a gender-specific manner.

\section{Introduction}

There is growing evidence that prenatal stress (PS) leads to an increased risk for psychopathology in later life (for review see Huizink et al., 2004). In a previous study we investigated the effects of PS on early postmatal brain development, a disturbance of which may contribute to this increased vulnerability to psychopathology seen in PS offspring (Van den Hove et al., 2006). We found that PS decreased hippocampal cell proliferation at postnatal day (P) 1 in both genders with a concomitant increase in hippocampal caspase-3-like activity, a measure of apoptotic activity. In addition, brain derived neurotrophic factor (BDNF) protein content was reduced in the hippocampus of PS male offspring at this age (Van den Hove et al., 2006).

PS has also been shown to affect the serotonergic (5-hydroxytryptamine; 5-HT') system in the hippocampus of rat offspring (Huizink et al., 2004). Serotonin is known to play a prominent role during brain development (Whitaker-Azmitia, 2001). Through $5-H T_{1 A}$ receptor activation, 5-HT controls the growth and maturation of its own serotonergic neurons, a process referred to as autoregulation of development (Whitaker-Azmitia, 1998, Whitaker-Azmitia, 2001). Secondly, 5-HT regulates the development of several target tissues including the hippocampus and primary somatosensory cortex. In both these processes, the astrogliall specific $\mathrm{Ca}^{2+}$ binding protein $\mathrm{S100B}$, plays an important role and is released in response to astroglial 5-HT, receptor activation (Whitaker-Azmitia and Azmitia, 1989, Whitaker-Azmitia et al., 1990, Whitaker-Azmitia, 2001, Ramos et al., 2004). In vitro, nanomolar concentrations of S100B have been shown to stimullate glial cell proliferation (Selinfreund et al, 1991), neuronal survival (Winningham-Major et al., 1989, Brewton et al, 2001), and to induce neurite outgrowth (Kligman and Marshak, 1985, Winningham-Major et al., 1989, Azmitia et al., 1990, Nishi et al., 1997). Conversely, micromolar concentrations of $\mathrm{S100B}$ are considered to be cytotoxic (Fano et al., 1993). 
In this study, we investigated the effects of PS on the concentration of SIOOB in the neonatal hippocampus using hippocampal homogenates. In a previous study we measured cell proliferation, caspase- 3 , and BDNF in these same homogenates (Van den Hove et al, 2006). A correlation analysis was performed to determine the relationship between $\$ 100 \mathrm{~B}$ and these other parameters in each gender. By doing so, we aim to determine if S100B contributes to the reported PS-induced disturbance of neonatal brain development and its sequela.

\section{Experimental procedures}

\section{Animals and procedures}

These animal studies were all approved by the Animal Ethics Board of the University of Maastricht, The Netherlands. For this study, acclimatized time-pregnant normal Fischer 344 rats (Charles River, The Netherlands) were used. The animals were housed individually within a temperature-controlled environment $\left(21 \pm 1^{\circ} \mathrm{C}\right)$ with $12 \mathrm{hr}$ light/12hr dark cycle (lights on from 7.00-19.00 h) and standard rat chow and water ad libitum. Pregnancy was determined by observation of vaginal plugs (embryonic day 0 - EO). PS was performed daily during the last week of pregnancy (E14-E21). Pregnant female rats $(n=15)$ were individually restrained three times a day (at approximately $9.00,13.00$, and $17.00 \mathrm{~h}$ ) for 45 minutes in transparent plastic cylinders and simultaneously exposed to bright light (Ward and Weisz, 1984). Control pregnant females $(n=16)$ were left undisturbed in their home cages. Day of birth was defined as P0. As soon as the last pup of a litter had been born, litter size was defined and pup gender and individual body weights were determined. Only litters of 8 or more pups were included in this study. No more than 2 male and/or 2 female randomly chosen pups per litter were examined to prewent litter effects (Chapman and Stern, 1978). For each group 7-8 pups were investigated.

\section{Tissue preparation}

In order to determine the degree of cell proliferation, as described previously in detail (Van den Hove et al., 2006), pups received a single dose of ${ }^{3} \mathrm{H}$-thymidine (Amersham; $5 \mathrm{mCi} / \mathrm{g}$ body weight) at $P 1$. This was administered by subcutaneous injection into the nape of the neck with an ultrafine ( 30 gauge, fine-tipped, Teflon coated) needle. Following ${ }^{3} \mathrm{H}$-thymidine infusion the pups were placed in a pediatric incubator set at $34^{\circ} \mathrm{C}$ and $75 \%$ humidity to prevent heat loss. Exactly 1 hour later the pups were decapitated and a blood sample was taken from the neck stump for corticosterone determination. The brains were then carefully removed and microdissected using the method of Wagner and colleagues (1999). "The hippocampus was isolated, weighed and quickly snap frozen in liquid nitrogen after which it was stored at $-75^{\circ} \mathrm{C}$ until further analysis. The dissected hippocampi were homogenized using a Bead Beater (Biospec products, OK, USA) for $3 \times 30$ seconds in $350 \mathrm{ml}$ ice-cold lysis buffer 
(137 $\mathrm{mM} \mathrm{NaCl}, 20 \mathrm{mM}$ Tris-HCl $(\mathrm{pH} 80), 1 \% \mathrm{NP}-40,10 \%$ glycerol and a complete protease mibitor tablet; Roche, The Netherlands).

\section{Hippocampal BDNF content}

Brain derived neurotrophic factor content was measured in female hippocampal homogenates using the BDNF Emax ImmunoAssay system from Promega (Madison, MI, USA). Corning high affinity EIA/RIA 96-well plates (Corning, NY, USA) were used for the study and the resultant absorbency was read using a microplate reader at $450 \mathrm{~nm}$ (Biorad, $C A$, USA). We used the acid treatment as described previously (Van den Hove et al, 2006). Tissue samples were diluted 5 times within a range of the standard curve. Further, the manufacturer's recommendations were followed. All samples were measured in duplicate. Of note, only female hippocampal BDNF was determined in this study, since male homogenates were examined previously (Van den Hove et al, 2006).

\section{Hippocampal S100B assay}

$5100 B$ protein content was measured in the hippocampal homogenates by use of a commercially available S100B immunoluminometric assay (Liaison, Byk-Sangtec Diagnostica, Germany). This is a two-step sandwich assay based on paramagnetic particles as solid phase and a tracer antibody labelled with an isoluminol derivative. Data reduction is done with a master curve after recalibration with two calibrators. Data were corrected for hippocampal weight and expressed as $\mu g \mathrm{~S} 100 \mathrm{~B} / \mathrm{g}$ wet weight tissue.

\section{Correlations}

A correlation analysis was performed to investigate the relationship between hippocampal S100B content and cell proliferation, caspase-3-like activity, and BDNF content in the same hippocampal homogenates as well as plasma corticosterone levels; parameters that had been examined previouslly (Van den Hove et al., 2006).

\section{Statistics}

Effects of PS on S100B content were examined using a 2-way analysis of variance (ANOVA; experimental group $\times$ gender). Effects were analyzed in more detail using Bonferroni post hoc. Correlation analysis was performed using Pearson's correlation coefficient $\left(r_{p}\right)$. Statisticall significance was assumed to exist at $\mathrm{P}<0.05$. All statistics were carried out using SPSS software version 11.5 (SPSS Inc, USA). 


\section{Results}

\section{Hippocampal BDNF content}

Female hippocampal BDNF levels were not affected by PS $(4.37 \pm 0.95$ and $4.75 \pm 0.48 \mathrm{ng}$ $B D N F / g$ wet weight for control and PS pups, respectively; $\mathrm{P}=0.70$; data not shown).

\section{Hippocampal S100B content}

The effect of PS on hippocampal S100B levels are depicted in the graph below. Overall, PS resulted in a $25.3 \%$ reduction in hippocampal $S 100 \mathrm{~B}$ level ( $\mathrm{PS}$ effect; $\mathrm{P}=0.024$ ). No gender difference was observed. Post hoc analysis showed no differences between the various groups:

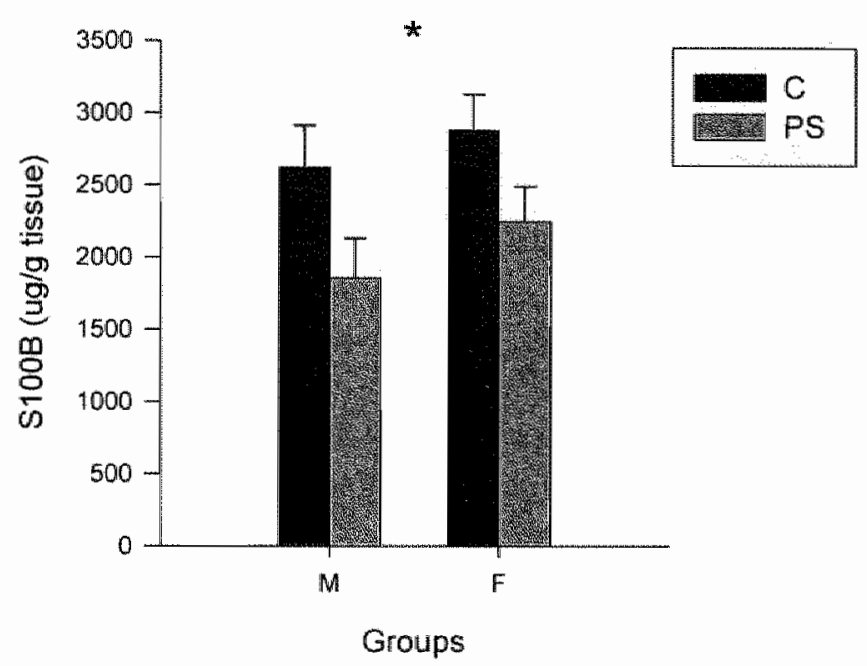

Figure. The effect of PS on hippocampal $5100 \mathrm{~B}$ conten of one-day-ald pups. Overall, PS resulted in a $25.3 \%$ reduction in

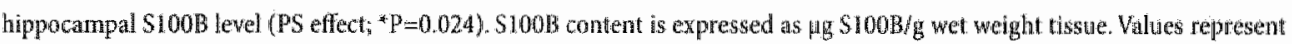
means + S.E.M.; now-8 animals per group.

\section{Correlations}

In our previous investigation (Van den Hove et al, 2006) we showed that PS resulted in a reduction of birth weight (PS effect: $-3.0 \% ; \mathrm{P}<0.001$ ). Further, PS resulted in a $33.8 \%$ increase in stress-induced corticosterone levels at P1 (PS effect; males and females; P<0.05). In addition, PS induced a decrease in hippocampal cell proliferation rate (PS effect; males and females: $-56.5 \% ; \mathrm{P}<0.001$ ) and an increase in hippocampal caspase-3-like activity (PS effect; males and females: $36.1 \% ; \mathrm{P}<0.05$ ) at Pl. 
Pearson's correlations between the different variables are depicted in the table below. Hippocampal $5100 \mathrm{~B}$ concentration showed a strong negative correlation with plasma corticosterone levels in males $\left(r_{p}=-0.73 ; \mathrm{P}=0.025\right)$. Female hippocampal $5100 \mathrm{~B}$ content was positively correlated with body weight $\left(r_{p}=0.64 ; P=0.020\right)$ and hippocampal BDNF content $\left(r_{p}=0.70\right.$; $\mathrm{P}=0.011$ ). In addition, there was a tendency towards a significant correlation between female $\mathrm{S} 100 \mathrm{~B}$ and the rate of cell proliferation within the hippocampus $\left(\mathrm{r}_{\mathrm{p}}=0.53 ; \mathrm{P}=0.061\right)$. No correlation was found between $\$ 100 \mathrm{~B}$ and caspase-3-like activity in any gender.

Besides its relation to $\$ 100 \mathrm{~B}$, body weight at one day of age was negatively correlated to hippocampal caspase-3-like activity in males $\left(r_{p}=-0.58 ; P=0.024\right)$ and positively to hippocampal cell proliferation rate $\left(r_{p}=0.51 ; P=0.035\right)$ and BDNF content $\left(r_{p}=0.58 ; P=0.018\right)$ in female offspring. Body weight of female pups tended to correlate negatively to plasma corticosterone levels $\left(r_{p}=-0.46 ; P=0.074\right)$.

Table. Pearson's correlation coefficients $\left(r_{\mathrm{g}}\right)$ representing the associations between the various measures in male (A) and female $(B)$ one-day-old pups. Note that $\$ 100 B_{3}$ cell proliferation, caspase-3 and BDNF are measured in the same hippocampal homogenates." $: 0.05<\mathrm{P}<0.1 ;{ }^{*} \mathbb{P}<0.05 ; * \mathrm{P}<0.01$; ns; not significant: BDNF: brain-derived neurotrophic factor.

\begin{tabular}{|c|c|c|c|c|c|c|}
\hline \multicolumn{7}{|c|}{ A. Males } \\
\hline Variable & Body weight & Corticosterone & S100B & $\begin{array}{c}\text { Cell } \\
\text { proliferation }\end{array}$ & Caspase 3 & BDNF \\
\hline Body weight & & $\mathrm{ns}$ & $\mathrm{n} s$ & ns & -.58 & ns \\
\hline Corticosterone & ns & & $-.73^{*}$ & ns & ms & ns \\
\hline$\$ 100 \mathrm{~B}$ & ns & $-.73^{*}$ & & ns & ns & das \\
\hline $\begin{array}{c}\text { Cell } \\
\text { proliferation }\end{array}$ & ns & ns & ns & & $-.52^{*}$ & ns \\
\hline Caspase- 3 & $-.58^{*}$ & $\mathrm{~ns}$ & ns & $-.52^{*}$ & & ns \\
\hline BDNF & ns & ns & ns & ns & $\mathrm{ns}$ & \\
\hline \multicolumn{7}{|c|}{ B. Females } \\
\hline Variable & Body weight & Corticosterone & $\$ 100 \mathrm{~B}$ & $\begin{array}{c}\text { Cell } \\
\text { proliferation }\end{array}$ & Caspase-3 & BDNF \\
\hline Body weight & & .46 & $.64^{*}$ & $.51^{*}$ & ns & $.58^{*}$ \\
\hline Corticosterone & $-.46^{\prime \prime}$ & & ns & -.69 & ns & ns \\
\hline \$100B & $.64 *$ & ns & & $.53^{i}$ & ns & $.70^{*}$ \\
\hline $\begin{array}{c}\text { Cell } \\
\text { proliferation }\end{array}$ & $.51^{*}$ & $-.69 * *$ & $.53 \#$ & & $\mathrm{~ns}$ & $.43^{\circ}$ \\
\hline Caspase -3 & $\mathrm{~ns}$ & ns & ns & ns & & ns \\
\hline BDNF & $.58^{*}$ & ns & $.70^{*}$ & $.43^{a}$ & nis & \\
\hline
\end{tabular}




\section{Discussion}

We show for the first time that $P S$ is able to reduce $S 100 \mathrm{~B}$ content in the neonatal rat hippocampus. Interestingly, hippocampal $S 100 \mathrm{~B}$ concentration was negatively correlated with plasma corticosterone levels in malles, whereas it was positively correlated with body weight, reflecting fetal growth, and BDNF levels in the hippocampus of female offspring. Further, S1OOB levels tended to correlate with the rate of cell proliferation within the female hippocampus.

The observed reduction in $\$ 100 B$ levels just after birth seen with PS may have significant implications for brain development in PS subjects, considering the important role of $S 100 \mathrm{~B}$ in the development of the 5-HT system. The 5-HT system is known to play an important role in the pathophysiology of anxiety and depressive disorders, and has been shown to be affected by $P$ S (see review by Huizink et al., 2004). Several studies have shown a close inter-relationship between the regulation of the hypothalamo-pituitary-adrenal (HPA) axis, the 5-HT system and mood disorders including depression (see review by Porter et al, 2004). Whether $\$ 100 \mathrm{~B}$ plays a role in establishing this rela tionship in mood disorders that have a developmental origin remains to be elucidated.

Scaccianoce and colleagues (2004) suggested a glucocorticoid-independent relationship between stress and serum S100B. In the present study, hippocampal S100B concentration was negatively correlated to plasma corticosterone levels in malles thus suggesting a gender-dependent link. In line with our findings, a single course of antenatal betamethasone, a synthetic corticosteroid, resulted in a decrease in hippocampal S100B concentration also at P1 (Bruschettini et al., 2005). Further, S100B concentrations were significantly lower in the urine of human newborns whose mothers were treated antenatally with glucocorticoids (Gazzolo et al...2003).

A mechanism that may have contributed to the stress-induced decrease in hippocampal $S 100 B$ levels reported here is a redistribution of $S 100 B$ protein from the brain to the periphery as the result of an increased blood-brain barrier (BBB) permeability associated with stress (Scaccianoce et $\mathrm{al}_{\mathrm{s}, \mathrm{2}} 2004$ ). However, an investigation by Tramontina and colleagues (2002) suggests that extracellular $\$ 100 \mathrm{~B}$ represents less than $1 \%$ of the intracellular S100B content, which would imply that the effect of a change in BBB permeability on total hippocampal $\$ 100 \mathrm{~B}$ content as measured in the present study should be negligible.

Female hippocampal $\mathrm{S} 100 \mathrm{~B}$ levels were strongly correlated to BDNF levels, a relationship that has been described previously (Nishi et al, 2000, Djalali et al., 2005). The observed correlation between $S 100 B$ and cell proliferation in females is in line with a previous study by Selinfreund and colleagues (1991), in which $\mathrm{S100B}$ was shown to stimulate the proliferation of glial cells.

Interestingly, hippocampal $5100 \mathrm{~B}$ seems to be related to these various parameters in a gender-specific way. In males it correlates only negatively with plasma corticosterone levels. In females $\mathrm{S} 100 \mathrm{~B}$ seems to be closely related to BDNF, paralleling BDNF in its positive 
correlations with fetal growth and hippocampal cell proliferation. Whether this observed gender-specificity is related to adult gender-specific behavioral consequences of PS awaits further research.

Another interesting point these data reveal is the importance of fetal growth. The fetal origins of health and disease' concept states that the risk of disease in adulthood partly depends upon variations in the prenatal enwironment (Barker, 1995). Fetal undernutrition, for example, resulting in impaired fetal growth and reduced birth weight, predisposes individuals to the development of e.g. cardiovascular disease and non-insulin-dependent (type 2) diabetes mellitus in adulthood (Curhan et al., 1996, Barker et al, 2002). Reduced birth weight is also associated with an increased risk for depression in later life (Thompson et al., 2001, Gale and Martyn, 2004). We have already shown that PS resulted in impaired fetal growth in the offspring examined for $5100 \mathrm{~B}$ in this study (Van den Hove et al., 2006). In the present study, body weight at one day of age, which reflects fetal growth, was negatively correlated to cell death in malles and positively to hippocampal growth factor levels including $\$ 100 \mathrm{~B}$ and BDNF and to cell proliferation in females. Further, there was a tendency towards a negative correlation with stress hormone lewels in females. How and to what extent changes in these parameters contribute to an increased disease risk in adulthood awaits further research. Of note is that impaired fetal growth seems to be related to both these measures in a gender-specific manner, as do depressive disorders in later life.

In conclusion, $\mathrm{S} 100 \mathrm{~B}$ is a developmental factor linked to growth and differentiation and is reduced by PS. It is associated with negative factors including low birth weight and cell death in a gender-specific manner. Given its strong link with the 5-HT system, the measured decrease in S100B levels may have significant implications for adult 5-HT-related functioning.

\section{References}

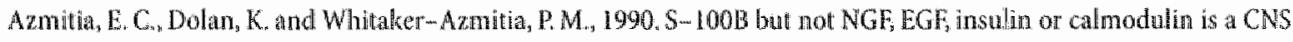
serotonergic growth factor. Bran Res. $516,354-356$.

Batker, D. 1., 1995. The fotal origins of adult disease. Proc R Soc Lond B Biol Sci. 262, 37-43.

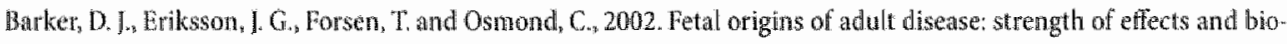
logical basis. Int J Lepidemtol. $31,1235-1239$.

Brewton, L., S, Haddad, L. and Azmitia, E, C., 2001. Colchicine-induced cytoskeletal collapse and apoptosis in N-18 neuroblastoma cultures is rapidly reversed by applied $S-100$ beta. Brain Res. 912, 9-16.

Brusehettini, M., van den Hove, D. L., Gazzolo, D, Bruschettini, P., Blanco, C. E. and Steinbusch, H. W, 2005. A sungle course of antenatal betamethasone reduces neurotrophic factor $\$ 100 B$ concentration in the hippocampus and Sertum in the theonatal at. Brain Res Dev Brain Res.

Chapman, R. H. and Stern, I. M. 1978. Maternal stress and pituitary-adrenal manipulations during pregnancy in rats: effects on morphology and sexual behavior of male of spring / Comp Physiol Psychol 92, 1074-1083.

Curhan, G. C., Willett, W. C., Rimm, E. B., Sptegelnan, D. Ascherio, A. L. and Stampfer, M. 1., 1996. Birth weight and adult hypertension, diabetes mellitus, and obesity in US men. Circallation. 94, 3246-3250. 
Djalali, S, Hoilfe, M., Grosse, G., Rothe, T., Stroh, T., Grosse, J., Deng, D. R., Hellweg, R., Grantyn, R., Hortnagl, H. and Ahnert-Hilger, G., 2005. Effects of brain-derived neurotrophic factor (BDNF) on glial cells and serotonergic neurones during development. J Neurochem. 92, 616-627.

Fano, G., Mariggio, M. A., Angelella, P, Nicoletti, I., Antonica, A., Fulle, S. and Calissano, P., 1993. The S-100 protein causes an increase of intracellular calcium and death of PC12 cells. Neuroscience. 53, 919-925.

Gale, C. R. and Martyn, C. N. 2004. Birth weight and later risk of depression in a national birth cohort. Br 》 Psychiatry. $184,28-33$.

Gazzolo, D., Kornacka, M, Bruschettini, M., Lituani, M., Giovannini, L, Serra, G., Majewski, U. and Michetti, F., 2003. Maternal glucocorticoid supplementation and $\$ 100 B$ protein concentrations in cord blood and urime of preterm infants. Clin Chem. 49, 1215-1218.

Huizink, A. C., Mulder, E. J. and Buitelaar, J. K., 2004. Prematal stress and risk for psychopathology: specific effects or induction of general susceptibility? Psychol Bull. 130, 115-142.

Kligman, D. and Marshak, D. R., 1985. Purification and characterization of a neurite extension factor from bowine brain. Proc Natl Acad Sci U SA. 82, 7136-7139.

Nishi, M., Kawata, M. and Azmitia, E. C., 1997. S100beta promotes the extension of microtubule associated protein2 (MAP2)-immunoreactive neurites retracted after colchicine treatment in rat spinal cord culture. Neurosci lett. $229,212-214$.

Nishi, M., Kawata, M. and Azmitia, E. C., 2000. Trophic interactions between brain-derived neurotrophic factor and sloobeta on cultured serotonergic neurons. Brain Res. 868, 113-118.

Porter, R. J., Gallagher, P., Watson, S. and Young, A. H., 2004. Corticosteroid-serotonin interactions in depression: at review of the human evidence. Psychopharmacology (Berl). 173, $1-17$.

Ramos, A. J., Rubio, M. D., Defagot, C., Hischberg, L., Villar, M. J. and Brusco, A. 2004. The 5HT' receptor agonist, 8-OH-DPAT; protects neurons and reduces astrogial reaction after ischemic damage caused by cortical devascularization. Brain Res. 1030, 201-220.

Scaccianoce, S., Del Bianco, P., Pannitteri, G. and Passarelli, F. 2004. Relationship between stress and circulating levels of $\$ 100 B$ protein. Brain Res. 1004, 208-21 J.

Selinfreund, R. H., Barger, S. W., Pledger, W. J. and Van Eldik, L. J., 199 I. Neurotrophic protein 5100 beta stimulates glial cell proliferation. Proc Nat Acad Sci U S A. 88, 3554-3558.

Thompson, C., Syddall, H., Rodin, I., Osmond, C. and Barker, D. I., 2001. Birth weight and the risk of depressive disorder in late life. Br J Psychiatry. 179, 450-455.

Tramontina, F, Conte, S., Goncalves, D., Gottfried, C., Portela, L. V., Vinade, L., Salbego, C. and Goncalves, C. A., 2002. Developmental changes in $\$ 100 \mathrm{~B}$ content in brain tissue, cerebrospinal fluid, and astrocyte cultures of rats. Cell Mol Neurobiol. 22, 373-378.

Van den Hove, D. L., Steinbusch, H. W., Scheepens, A., Van de Berg, W. D., Kooiman, L. A., Boostell, B. J., Prickaerts, I. and Blanco, C. E, 2006. Prenatal stress and neonatal rat brain development. Neuroscience, 137, 145-155,

Wagner, J. P., Black, I. B. and DiCicco-Bloam, E., 1959. Stimulation of neonatal and adult brain neurogenesis by subcutaneous injection of basic fibroblast growth factor, I Neurosci. 19,6006-6016.

Ward, I. L. and Weisw, I., 1984. Differential effects of maternal stress on circulating levels of corticosterone, progesterone, and testosterone in male and female rat fetuses and their mothers. Endocrinology. 114, 1635-164.4.

Whitaker-Azmitia, P. M., 1998. Role of the neurotrophic properties of serotonin in the delay of brain naturation induced by cocaine. Ann N Y Acad Sci. 846, 158-164.

Whitaker-Azmitia, P. M., 2001. Serotonin and brain development: role in human developmental diseases. Brain Res Bull. 56, 479-485.

Whitaker-Azmitia, P. M. and Azmitia, E. C. 1989 . Stimulation of astroglial serotonin receptors produces cuiture media which regulates growth of serotonergic neurons. Brain Res. 497, 80-85.

Whitaker-Azmitia, P. M., Murphy, R. and Azmitia, E. C., 1990. Stimulation of astroglial 5-HT 1 receptors releases the serotonergic growth factor, protein S-100, and alters astroglial morphology. Brain Res. 528, 155-158.

Winningham-Major, F., Staecker, J. L., Barger, S. W., Coats, S. and Van Eldik, L. J., 1989. Neurite extension and neuronal survival activities of recombinant $\$ 100$ beta proteins that differ in the content and position of cysteine residues. ICell Biol. 109, 3063-3071. 


\title{
Chapter 4
}

\section{Prenatal stress in the rat alters $5 \mathrm{HT}_{1 \mathrm{~A}}$ receptor binding in the ventral hippocampus}

\author{
Van den Hove DLA ${ }^{1,2}$, Lauder $\mathrm{JM}^{3}$, Scheepens $\mathrm{A}^{1 / 4}$, \\ Prickaerts $\mathrm{J}^{2}$, Blanco $\mathrm{CE}^{1}$, Steinbusch $\mathrm{HWM}^{2}$
}

"Department of Pediatrics, Maastricht University, Maastricht, The Netherlands.

2Department of Psychiatry and Neuropsychology, Maastricht University, Maastricht, The Netherlands.

${ }^{3}$ Department of Cell and Developmental Biology,

University of North Carolina, Chapel Hill, NC, USA.

${ }^{2}$ Liggins Institute, University of Auckland, Auckland, New Zealand.

Brain Research, In Press 


\section{Abstract}

Physical and/or psychological stress during pregnancy may affect the offspring by promoting the development of various learning, behavioral and/or mood disorders in later life. The $5-\mathrm{HT}_{1 \mathrm{M}}$ and $5-\mathrm{HT}_{2 \mathrm{~A}}$ receptors are prominently implicated in the modulation of anxiety and mood-related behaviors. Using a semi-quantitatiwe radiolabel immunocytochemical analysis (immunobinding), we studied the effect of prenatall stress on binding of these two receptor subtypes in the hippocampus of 4-week-old male and female Fischer 344 rats. Levels of $5-\mathrm{HT}_{1 \mathrm{~A}}$ immunobinding in the ventral hippocampus, which is primarily implicated in emotional processing, were significantly decreased in male offspring following prenatal stress. A trend towards a decrease was observed in the ventral hippocampus of females. In contrast, $5-\mathrm{HT}_{1 / 2}$ immunobinding within the dorsal hippocampus, related mainly to learning and memory, was not affected by prenatal stress in offspring of either gender. Likewise, no significant differences between control and prenatally stressed rats were observed for levels of $5-\mathrm{HT}_{2 \mathrm{~A}}$ immunobinding in either part of the hippocampus.

The obserwed reduction in hippocampal 5-HT , receptor binding in male offspring after prenatal stress may have important consequences for adult anxiety-and depression-related behavior.

\section{Introduction}

Chronic or repeated stress during human prenatal brain development has been associated with various learning, behavioral and/or mental disorders in later life (see reviews by Weinstock, 2001, Huizink et al., 2004). In studies using rodents, prenatal stress (PS) has been associated with disturbances in the hypothalamo-pituitary-adrenal (HPA) axis and is associated with conditions including schizophrenia, anxiety, and depressive-like behavior (Weinstock, 2005). PS has also been shown to affect the serotonergic (5-HT) system in the hippocampus of rat offspring (Peters, 1986, Peters, 1988, Peters, 1990, Hayashi et al., 1998). Disturbances of the 5-HT system are known to play an important role in the pathophysiology of anxiety and depressive disorders in adulthood (Ressler and Nemeroff; 2000).

Before 5-HT functions as a neurotransmitter in the mature brain, it has a prominent role in normal brain development (Whitaker-Azmitia, 2001). The last part of rat gestation is characterized by rapid differentiation and axonal growth of 5-HT neurons (Lidov and Molliver, 1982, Wallace and Lauder, 1983, Aitken and Tork, 1988). Serotonin is involved in the maturation of the central nervous system as a differentiation signal for progenitor cells developing along serotonergic pathways (Lauder and Krebs, 1978, Lauder et al., 1982, Lauder, 1990). Through the activation of $5-\mathrm{HT}_{1 \mathrm{~A}}$ receptors (Whitaker-Azmitia, 1998), 5-HT appears to regulate the growth and maturation of its own 5-HT neurons, referred to as autoregulation of development (Whitaker-Azmitia, 2001),

'The 5-HT $\mathrm{T}_{\mathrm{A}}$ receptor is prominently implicated in the modulation of anxiety and moodrelated behaviors (Sargent et al., 2000, Gross et al., 2002). In addition, the $5-\mathrm{HT}_{1 \mathrm{~A}}$ receptor is 
ajor target in the development of effective climical anxiolytics and antidepressants (Blier and Ward, 2003).

Hippocampal 5-HT, receptor densities as well as hippocampal 5-HT levels parallel the activity and responsiveness of the HPA axis in the rat (Bumet et al: 1992). Furthermore, 5 $\mathrm{HT}_{1 \mathrm{~A}}$ receptor gene expression is under tonic inhibition by corticosterone (Burnet et $\mathrm{al}_{2,} 1992$, Chalmers et al., 1994), and through its effect on HPA axis functioning, PS may indirectly affect the $5-\mathrm{HT}_{1 \mathrm{~A}}$ receptor, the 5-HT system, and related functions.

Although the precise role of the $5-\mathrm{HT}_{2 \mathrm{~A}}$ receptor subtype in the pathophysiology of depression is still unclear, this 5 -HT receptor subtype also has significant therapeutic potential for the treatment of depression (Celada et al., 2004).

The aim of the present study was to investigate the effects of PS on hippocampal $5-\mathrm{HT}_{\text {IA }}$ and $5-\mathrm{HT}_{2 \mathrm{~s}}$ receptor levels. For this purpose, the brains of 4 -week-old Fischer 344 rat offspring derived from dams subjected to restraint stress on embryonic days $14-21$ or dams left undisturbed throughout pregnancy were analyzed by semi-quantitative radiolabel immuno* cytochemistry (immunobinding).

\section{Experimental procedures}

\section{Animals}

The animal studies were all approved by the Animal Ethics Board of the Uniwersity of Maastricht, The Netherlands. Pain and discomfort were minimized as much as possible. Acclimatized pregnant Fischer 344 rats (Charles River, The Netherlands) were housed individually within a temperature-controlled environment $\left(21 \pm 1^{\circ} \mathrm{C}\right)$ with $12 \mathrm{hr}$ light/12hr dark and standard rat chow and water ad libitum. Pregnancy was determined by observation of vaginal plugs (embryonic day 0 - E0). Restraint stress was performed daily during the last week of pregnancy (E14-E21). Pregnant female rats $(n=8)$ were individually restrained three times a day (at approximately 9:00 AM, 1:00 PM, and 5:00 PM) for 45 minutes in transparent plastic cylinders (IDEE, Maastricht, The Netherlands) whilst being exposed to bright light (Ward and Weisz, 1984). Control (C) pregnant females $(n=6)$ were left undisturbed in their home cages. Only pups from litters of 8 or more pups were included in this study. Animals were left undisturbed up to postnatal day 28 (P28) at which time they were anesthetized and perfused intracardially ( $n=6 /$ group; see below). Only $1-2$ male and/or female pups per litter were ex. amined in a single experiment to avoid litter effects (Chapman and Stern, 1978).

\section{Semi-quantitative immunocytochemical analysis of 5-HT $\mathrm{HA}_{1 \mathrm{~A}}$ and $5-\mathrm{HT}_{2 \mathrm{~A}}$ receptors}

Effects of $\mathrm{PS}$ on $5-\mathrm{HT}_{\mathrm{IA}}$ and 5 - $\mathrm{HT}_{2 \mathrm{~A}}$ receptor immunobinding in 4-week-old offspring were analyzed using radiolabel ([25I]protein) immunocytochemistry performed on cryostat sec- 
tions [adapted from (Hunt and Mantyh, 1984)], as described previously (Johns et al., 2002) Radiolabels were quantified using a Molecular Dymamics Storm phosphorimager (Amersham Biosciences, USA).

Animals (postnatal day 28 male and female of spring; $n=6 /$ group) were anesthetized with pentobarbital (Nembutal, $60 \mathrm{mg} / \mathrm{kg}$, i.p.; CEVA, Maassluis, The Netherlands) and perfused with cold $4 \%$ paraformaldehyde and $0.1 \%$ glutaraldehyde in $0.07 \mathrm{M}$ phosphate buffer (pH 6.8 ), preceded by phosphate-buffered saline (PBS). Brains were removed and post-fixed with the same fixative overnight at $4^{\circ} \mathrm{C}$, then washed in 3 changes of PBS and immersed in $30 \%$ sucrose in PBS until they sank. Brains were serially sectioned on a cryostat at $20 \mu \mathrm{m}$. Matched anatomical sections from both the dorsal (approximately -3.0 relative to Bregma) and ventral (approximately -6.0 relative to Bregma) hippocampus were chosen for immunobinding from a Toluidine Blue-stained cryostat section series (see insets Figure 1). Sections were permeabilized with Triton-X in PBS, rinsed in PBS followed by normal sheep serum (NSS) and incubated overnight at $4^{\circ} \mathrm{C}$ with primary antibody, either $5-\mathrm{HT}_{\mathbb{I A}}$ [rabbit polyclonal (Raymond et al., 1993), gift of John Raymond], or 5- $\mathrm{HT}_{2 \mathrm{~A}}$ (mouse monoclonal, BD Biosciences, USA) at: a dilution of $1.5000\left(5-\mathrm{HT}_{1 A}\right)$ or $1: 500\left(5-\mathrm{HT}_{2 A}\right)$, respectively, or with diluent (bovine serum albumin/PBS/sodium azide). Sections were rinsed in PBS followed by NSS, then incubated for 2 hours at room temperature in PBS containing [ $\left.{ }^{125} \mathrm{I}\right]$ protein $A(400,000 \mathrm{cpm} / \mathrm{ml})$, which binds to the primary antibody. Following this, sections were rinsed thoroughly in several changes of PBS, followed by deionized water, and air dried. Dried slides were placed in a phosphorimaging cassette at room temperature for two days. Phosphorimaging of sections was done directly from exposed phosphorimaging screens using a Molecular Dynamics Storm phosphorimager (Amersham Biosciences, USA) utilizing the same-size (dorsal or ventral) hippocampal sampling area for both treatment groups. Background label (sections exposed to diluent instead of primary antibody) was adjusted using the object-averaging mode of the Imagequant software. Specificity of the 5-HT $\mathrm{HA}_{\mathrm{A}}$ antibody was determined previously by blocking antibody with the peptide antigen (Moiseiwitsch and Lauder, 1995). Specificity of the $5-\mathrm{HT}_{2 \mathrm{~A}}$ antibody was determined by blocking antibody with the peptide antigen in preliminary experiments. The validity of this immunobinding method has been established in a study where immunobinding results were confirmed by Western blotting (Grobin et al., 2000).

\section{Statistics}

Each animal had two coronal sections containing the ventral hippocampus or dorsal hippocampus scanned (bilaterally) for each immunobinding experiment. Three immunobinding replicates were performed on adjacent sections ( $n=36$ sections in total/experimental group). For each replicate, raw phosphorimaging values, i.e., phosphor units, for the sampling area of each section (see insets in Fig. 1) were taken as a percentage of the mean raw value for control sections in that experimental group. Percent control values from the three replicates were averaged, and means and standard error of the mean calculated (see Figs 1 and 2). For each sex, differences in $5-\mathrm{HT}_{1 \mathrm{~A}}$ and $5-\mathrm{HT}_{2 \mathrm{~A}}$ receptor immunobinding levels after PS was 
analyzed using a one-tailed t-test. Possible gender effects were not analyzed statistically, since phosphorimaging of male and female sections was not done simultaneously (only a limited number of sections could be analyzed together). All statistics were carried out using SPSS software version 11.5 (SPSS Inc, USA).

\section{Results}

\section{5-HT ${ }_{1 \mathrm{~A}}$ receptor}

PS resulted in a reduction in $5-\mathrm{HT}_{1 \mathrm{~A}}$ receptor presence within the ventral hippocampus of male offspring (-24.7\%; $\mathrm{P}=0.019$; Fig. $1 \mathrm{~b})$. In addition, there was a tendency towards a decrease in $5-\mathrm{HT}_{1 \mathrm{~A}}$ receptor level in the ventral hippocampus of female PS offspring $(-10.2 \%$; $\mathrm{P}=0.068$; Fig. 1b). No difference was observed in levels of $5-\mathrm{HT}_{1 \mathrm{~A}}$ receptor immunobinding in the dorsal hippocampus (Fig. la).

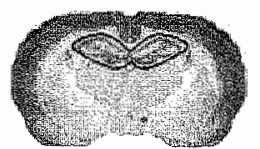

Dorsall

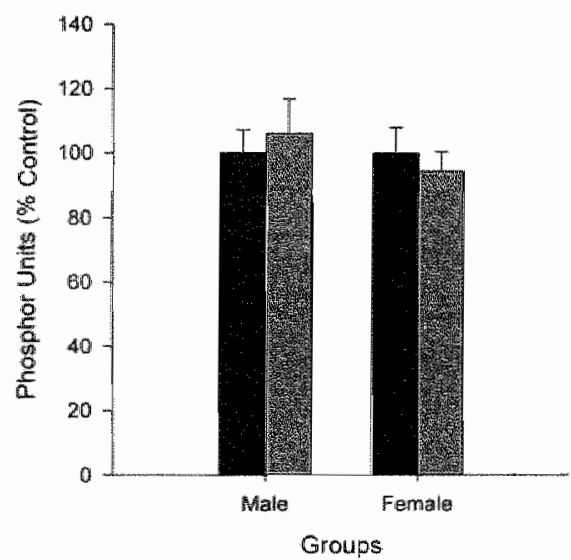

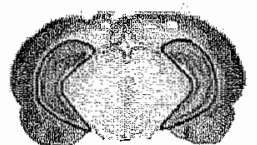

Ventral

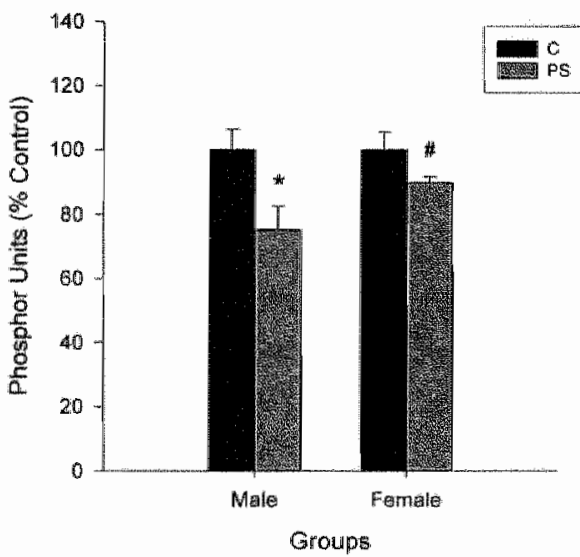

Figare 1. The effect of prenatal stress (PS) on 5-HT immunobinding levels in the dorsal (a) and ventral (bi) hippocampus. Insets: region of dorsal and ventral hippocampus sampled by phosphorimaging (Toluidine Blue staning). Datta are expressed as w control. Bars represent means $+5 . \mathrm{E} . M, n=6$ animals/group (total of 36 sections sampled/group). No differemce betwe gra groups was observed in $5-\mathrm{HT}_{1 \mathrm{~A}}$ receptor inmunobinding in the dorsal hippocampus. Prenatal stress was associated with an overall decrease in $5-\mathrm{HT}$, receptor inmunobinding levels within the ventral hippocampal of males ( $\mathrm{P}=0.019$ ). A trend towards a decrease in $5-\mathrm{HT}_{1}$ receptor immunolinding within the ventral hippocampus was observed in female of 


\section{5- $\mathrm{HT}_{2 \mathrm{~A}}$ receptor}

The effects of PS on 5-HT $\mathrm{H}_{2.8}$ receptor immumobinding are shown in Fig. 2. No differences were observed in either hippocampal region.

Dorsal

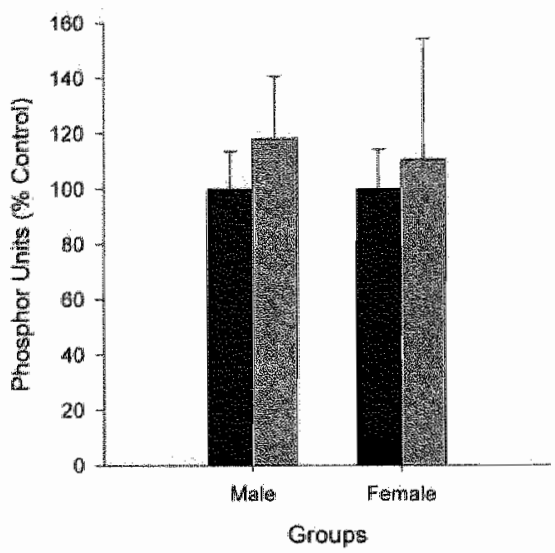

Ventral

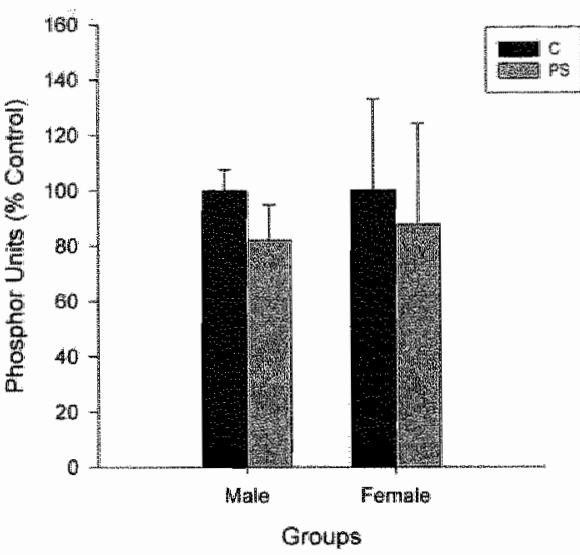

Figure 2. The effect of prenatal stress (PS) on 5-HT ${ }_{2 \mathrm{~A}}$ receptor immunobinding lewels in the dorsal (a) and ventral (b) hippocampus. Inset: region of dorsal and ventral happocampus samplled by phosphorimaging. Data are expressed ats \%ontrol. Bars represent means * S.E.M.; $n=6$ animals/group (total of 36 sections sampled/group). No significant differences were observed in any of the cases.

\section{Discussion}

The present study reveals that exposure of pregnant female Fischer 344 rats to restraint stress during the last week of gestation results in a reduction in $5-\mathrm{HT}_{1 \mathrm{~A}}$ immunobinding levels in the ventral hippocampus of 4 -week-old male offspring. There was a trend towards a reduction in $5-\mathrm{HT}_{14}$ receptor immunobinding levels, in the ventral hippocampus of female offspring although this did not reach statistical significance. No significant effect of PS on levels of 5-HT $T_{2 A}$ immunobinding was found for either gender.

The hippocampus can be divided into two functionally different regions, the dorsal and ventral hippocampus. Whereas the ventral part of the hippocampus is primarily implicated in emotional processing, the dorsal part is mainly linked to learning and memory (Bannerman et al., 2004). Since 5-HT $1 \mathrm{H}$ receptor immunobinding was only significantly decreased in the ventral hippocampus after PS, it is likely that only the emotional aspect of hippocampal 5- $\mathrm{HT}_{1 \mathrm{~A}}$ receptor-mediated functions is affected.

The 5-HT , receptor is very sensitive to the perinatal environment, as is evident from several studies. Prenatal exposure to drugs targeting 5-HT synthesis or acting as ligands 
for 5-HT receptors can alter postnatal levels of 5- $\mathrm{HT}_{1 \mathrm{H}}$ receptors in a wide variety of brain regions, including the hippocampus (Whitaker Azmitia et al, 1987, Lauder et al 2000 , Johns et al., 2002). Corticosterone administration to lactating rats has been shown to be associated with decreased $5-\mathrm{HT}_{\text {in }}$ receptor binding in the hippocampal CAI region of their adult offspring (Meerlo et al., 2001).

In another investigation, Gross and colleagues (2002) used a 5-HT, receptor knockout mouse with a "rescue" copy of the $5-\mathrm{HT}_{1 \mathrm{~A}}$ receptor gene. When the $5-\mathrm{HT}^{\mathrm{n}}$ receptor gene was activated only during the perinatal period and subsequently inactivated in adulthood, the mice showed no differences in anxiety-related behavior in adulthood as compared to wild-type mice. However, when the gene was inactivated during the perinatal period and subsequently activated in adulthood, these mice showed increased levels of anxicty-related behavior as compared to wild-type mice, comparable to mice in which the $5-\mathrm{HT}_{1 \mathrm{~A}}$ receptor gene had remained inactivated throughout their lives. Whereas these findings stress the pivotal role of the $5-\mathrm{HT}_{1 \mathrm{~A}}$ receptor during early development, they suggest a more limited role for this receptor in regulating adult anxiety-related behavior.

Conversely, Lopez-Figueroa and colleagues (1998) reported that rats subjected to chronic unpredictable stress in adulthood showed a decrease in hippocampal $5-\mathrm{HT}_{1 \mathrm{~A}}$ mRNA levels and receptor binding. Along similar lines, several other studies have shown that patients suffering from major depression show reduced hippocampal 5-HT receptor mRNA levels and receptor binding (Cheetham et al., 1990, Lowther et al., 1997, LopezFigueroa et al., 2004).

Taken together, these studies suggest that the role of the hippocampal $5-\mathrm{HT}_{1 \mathrm{~A}}$ receptor during early development is different from its function in adult affective behavior. The relative importance of the perinatal versus the adult environment and the precise role of altered $5-\mathrm{HT}_{\mathbb{A}}$ receptor functioning in the pathophysiology of anxiety and mood disorders including depression remain to be elucidated.

The decreased hippocampal 5-HT $\mathrm{HA}_{1 \mathrm{~A}}$ immunobinding levels observed in the present study might be explained by an overactive and dysregulated HPA axis seen after PS (Weinstock, 2005), a phenomenon that has also been linked to the pathophysiology of depression (Barden, 2004). There is a close link between the activity and responsiveness of the HPA axis and the hippocampal 5-HT, receptor, which is under tonic inbibition by corticosterone (Burnet et al., 1992, Chalmers et al., 1994). Consequently, an overactive/dysregulated HPA axis associated with PS, leading to increased levels of circulating stress hormones, may result in impaired hippocampal $5-\mathrm{HT}_{\text {IA }}$ receptor signaling.

We observed no significant effect of $\mathrm{PS}$ on $5-\mathrm{HT}_{2 \mathrm{~A}}$ immunobinding levels in either the ventral or dorsal hippocampus. Hippocampal 5-HT, receptor binding sites have been shown to be reduced in depressed suicide victims (Cheetham et al., 1988, Rosel et al., 1998, Rosel et al., 2000, Rosel et al., 2004) and in depressed subjects in vivo (Mintun et al., 2004). However, in a recent investigation by Lopez-Figueroa and colleagues (2004), no differences in hippocampal 5- $\mathrm{HT}_{2 \AA}$ mRNA expression were observed between subjects with a history of major depressive disorder and controls. 


\section{Conclusion}

There is growing evidence that stress during prenatal life is associated with an increased risk for psychopathology in later life. Considering the role of the ventral hippocampus in emotional processing, the observed reduction in $5-\mathrm{HT}_{1 \mathrm{~A}}$ immunobinding levels in this brain region of male PS offspring may have important implications for anxiety-and depressive-like behavior in adult PS males.

\section{Acknowledgements:}

This work was supported by a grant from the Netherlands Organization for Scientific Research (NWO).

\section{References}

Aitken, A, R and Tork, $I_{18}$ 1988. Early development of serotonin-containing neurons and pathways as seen in wholemount preparations of the fetal rat brain. J Comp Neurol. 274, 32-47.

Bannerman, D. M., Rawlins, I. N., McHugh, S. B., Deacon, R. M., Yee, B. K., Bast, T., Zhang, W. N., Pothuizen, H. H. and Feldon, J., 2004. Regional dissociations within the hippocampus--memory and anxiety. Neurosci Biobehav Rev, $28,273-283$

Barden, N., 2004. Implication of the hypothalamic-pituitary-adrenal axis in the physiopathology of depression. I Psychiatry Neurosci. 29, 185-193.

Blier, P. and Ward, N. M., 2003. Is there a role for 5-HT a agonists in the treatment of depression? Biol Psychiatry. 53, 193-203.

Burnet, P. W., Mefford, I. N., Smith, C. C., Gold, P. W. and Sternberg, E. M., 1992. Hippocampal 8-[3H]hydroxy-2-(di-npropylamino) tetralin binding site densities, serotonin receptor (5-HT $\left.\mathrm{BA}_{\mathrm{A}}\right)$ messenger ribonucleic acid abundance, and serotonin levels parallel the activity of the hypothalanopituitary-adrenal axis in rat. I Neurochem. 59, 10621070 .

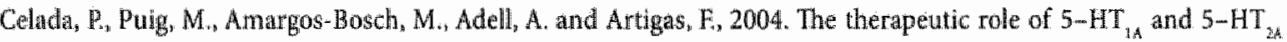
receptors in depression. I Psychiatry Neurosci, 29, 252-265.

Chalmers, D. T, Lopez, J. F., Vazquez, D. M., Akil, H. and Watson, S. J.s 1994. Regulation of hippocampal 5-HT, receptor gene expression by dexamethasone. Neuropsychopharmacology 10, 215-222.

Chapman, R. H. and Stern, I. M., 1978. Maternal stress and pituitary-adrenal manipulations during pregnancy in rats: effects on morphology and sexual behavior of male offspring. ) Comp Physiol Psychol. 92,1074-1083.

Cheetham, S. C., Crompton, M. R., Katona, C. L. and Horton, R. W., 1988. Brain 5-HT2 receptor binding sites in depressed suicide victims. Brain Res. 443, 272-280.

Cheetham, S. C., Crompton, M. R. Katona, C. L.. and Horton, R. W., 1990. Brain 5-HTl binding sites in depressed suicides. Psychopharmacology (Berl), 102, 544-548.

Grobin, A. C.. Fritschy, I. M. and Morrow, A. In, 2000. Chronic ethanol administration alters immunoreactivity for GABA(A) receptor subunits in rat cortex in a region-specific manner. Alcohol Clin Exp Res. 24, 1137-1144.

Gross, C., Zhuango X., Stark, K., Ramboz, S., Oosting, R., Kirby, L., Santarelli, L., Beck, S. and Hen, R., 2002. Serotonin ${ }^{\text {th }}$ receptor acts during development to establish normal anxiety-like behaviour in the adult. Nature. 416,396-400.

Hayashi, A., Nagaoka, M., Yamada, K., Ichitani, Y., Miake, Y. and OKado, N., 1998. Maternal stress induces synaptic loss and developmental disabilities of offspring. Int I Dev Neurosci. 16, 209-216.

Huizink, A. C., Mulder, E. J. and Buitelaar, J. K., 2004. Prenatal stress and risk for psychopathology: specific effects or induction of general susceptibility? Psychol Bull. 130, 115-1.42.

Hunt, $S_{u}$ P. and Mantyh, P. W. 1984. Radioimmunocytochemistry with [3H] biotin. Brain Res. 291, 203-217. 
Johns, I. M, Lubin, D. A. Lieberman, I. A and Lander, J. M., 2002 . Developmental effects of prenatal cocane exposure an 5-HT, receptors in male and fernale rat oflspring. Dev Neurosci. $24,522,530$.

Lauder, I. M., 1990. Ontogeny of the serotonergic system in the rat serotomin as a developmental signal Ann N Y Acad Sci. 600, 297-313; discussion 314 .

Lauder, I. M. and Krebs, H., 1978. Serotonin as a differentiation signal in early neurogenesis. Dev Neurosci. $1,15.30$

Lauder, T. M. Liu, J. and Grayson, D. R., 2000. In utero exposure to serotonergic drugs alters ineonatal expression of 5-HT(1A) receptor transcripts: a quantitative RT-PCR study. Int I Dev Neurosci. 18, 171-176.

Lajuder, J.M., Wrallace, J.A., Krebs, H., Petrusz, P. and McCartho, K., 1982. In wivo and in vitro development of serotonergic neurons. Brain Res Bull, 9,605-625.

Lidow, H. G. and Molliver, M. E., 1982. Immunohistochemical study of the development of serotonergic neurons in the rat CNS. Brain Res Bull. 9, 559-604.

Lopex-Figueroa, A. L., Norton, C. S., Lopez-Figueroa, M. O., Armellini-Dodel, D., Burke, S., Akil, H. Lopez, I. F, and Watson, S. J., 2004. Serotonin 5- $\mathrm{HT}_{1 \mathrm{~A}^{\prime}}$ 5- $\mathrm{HT}_{\text {ia }}$ and $5-\mathrm{HT}_{2 \mathrm{~A}}$ receptor mRNA expression in subjects with major depression, bipolar disorder, and schizophrenia. Biol Psychiatry. 55, 225-233.

Lopez, J. F., Chaimers, D. T., Little, K. Y. and Watson, S. J., 1998. A. E. Benneti Research Award. Regulation of serotonin IA, glucocorticoid, and mineralocorticoid receptor in rat and human hippocampus: implications for the neurobiology of depression. Biol Psychiatry. 43,547-573.

Lowther, S., De Paermentier, F, Cheetham, S.C., Crompton, M. R., Katona, C. L. and Horton, R. W., 1997. 5-HT, receptor binding sites in post-mortem brain samples from depressed suicides and controls.) Affect Disord. 42, 199-207.

Meerlo, P., Horvath, K. M., Luiten, P. G., Angelucci, L., Catalani, A. and Koolhas, I. M., 2001. Increased maternal corticosterone levels in rats: effects on brain $5-\mathrm{HT}_{\text {iA }}$ receptors and behavioral coping with stress in aduit offspring. Behav Neurosci. 115,1111-1117.

Mintun, M. A., Sheline, Y. I., Moerlein, S. M., Vassenko, A. G., Huang, Y. and Snyder, A. Z., 2004. Decreased hippocampal $5-\mathrm{HT}_{2 \mathrm{~A}}$ receptor binding in major depressive disorder: in vivo measurement with [18F]altanserin positron emission tomography. Biol Psychiatry, 55, 217-224.

Moiseiwitsch, J. R. and Lauder, J. M., 1995. Serotonin regulates mouse cranial neural crest migration. Proc Natl Acad SciU SA. 92, 7182-7186.

Peters, D. A, 1986. Prenatal stress: effect on development of rat brain serotonergic neurons Pharmacol Biochem Behaw. 24, 1377-1382.

Peters, D. A. 1988. Effects of maternal stress during different gestational periods on the serotonergic system in adult rat offspring. Pharmacol Biochem Behav. 31,839-843.

Peters, D. A., 1990. Maternal stress increases fetal brain and neonatal cerebral cortex 5-Hydroxytryptamine synthesis in rats: a possible mechanism by which stress inffuences brain development. Pharmacol Biochem Behav, 35, 943 . 947.

Raymond, J. R., Kim, I., Beach, R. E. and Tisher, C. C., 1993. Immunohistochentical mapping of cellular and subcellular distribution of $5-\mathrm{HT}_{1 \mathrm{~A}}$ receptors in rat and human kidneys. American Journal of Physiology. $264, \mathrm{~F} 9-19$.

Ressler, K. J. and Nemeroff, C. B., 2000. Role of serotonergic and noradrenergic systems in the pathoplyysiology of depression and anxiety disorders. Depress Anxiety. 12 Suppl 1, 2-19.

Rosel, P., Arranz, B., San, L., Vallejo, J., Crespo, J. M., Urretavizcaya, M. and Navarro, M. A., 2000. Altered 5-HT(2A) binding sites and second messenger inositol trisphosphate (IP(3)) levels in hippocampus but not in frontal cortex from depressed suicide victims. Psychiatry Res. 99, 173-181.

Rosel, ,., Arranz, B., Urretavizcaya, M., Oros, M, San, L. and Navarro, M. A., 2004. Altered 5-HT 2 and 5-HT4 postsynaptic receptors and their intracellular signalling systems IP3 and CAMP in brains from depressed violent suicide victims. Neuropsychobiology. 49, 189-195.

Rosell, P., Arranz, B., Vallejo, J., Oros, M., Crespo, J. M., Menchon, J. M. and Navarro, M. A., 1998. Variations in $[3 \mathrm{H}]$ imipramine and $5-\mathrm{HT}_{2 \mathrm{~A}}$ but not $[3 \mathrm{H}]$ paroxetine binding sites in suicide brains. Psychiatry Res. $82,161-170$.

Sargent, R.A., Kjaer, K. H., Rench, C. I., Rabiner, E. A., Messa, C., Meyer, J, Gunn, R. N., Grasby, P. M. and Cowen, P. J., 2000. Brain serotonin'" receptor binding measured by positron emission tomography with [11C] WAY-100635: effects of depression and antidepressant treatment. Arch Gen Psychiatry. 57, 174-180.

Wallace, J.A. and Lauder, J. M., 1983. Development of the serotonergic system in the rat embryo: an immunocytochemical study. Brain Res Bull. 10, 459-479.

Ward, I. L. and Weisz, I., 1984. Differential effects of maternal stress on circulating levels of corticosterone, progesterone, and testosterone in male and female rat fetuses and their mothers. Endocrinology. 114, 1635-1644. 
Winstock M, 2001 Alterations induced by gestalional stress in brain morphology and behaviour of the offspringt Prog Neurobiol. $65,427-451$.

Weinstock, M. 2005: The potential influence of maternal stress hormones on development and mental health of the offspring Brain Bethaw Immun. 19,2960308.

Whitaker-Azmitia, P. M, 1998 . Role of the neurotrophic properties of serotonin in the delay of brain maturation induced by cocaine Ann X Y Acad Sci. 846, 158-164:

Whitaker-Azmitia, P. M, 2001. Serotonin and brain development: rolle in human developmental diseases. Brain Res Bull. $56,479-485$.

Whitaker-Azmita, P. M, Lauder, J. M., Shemmer, A and Azmitia, E. C., 1987. Postnatal changes in serotonin receptors following prenatal alterations in serotonin lewels: further evidence for functional fetal serotonin receptors. Brain ines. $40,285-289$ : 
ald

d

\section{$\because$}

3

(a) 


\section{Chapter 5}

\section{Prenatal restraint stress and long-term affective consequences}

Van den Hove $\mathrm{DLA}^{1 / 2}$, Blanco $\mathrm{CE}^{1}$, Aendekerk $\mathrm{B}^{2}$, Desbonnet $\mathrm{L}^{2 / 3}$, Bruschettini $M^{2}$, Steinbusch $\mathrm{HP}^{1 / 2}$, Prickaerts J ${ }^{2}$, Steinbusch HWM ${ }^{2}$

'Department of Pediatrics, Maastricht Uniwersity, Maastricht, The Netherlands.

2Department of Psychiatry and Neuropsychology, Maastricht University,

Maastricht, The Netherlands.

${ }^{3}$ Department of Psychiatry, University College Cork, Cork, Ireland

Developmentall Neuroscience $27: 313-20$ 


\section{Abstract}

Chronic or repeated stress during critical periods of human fetal brain development has been associated with various learning, behavioral, and/or mood disorders in later life. In this investigation, pregnant Fischer 344 rats were individually restrained three times a day for 45 minutes during the last week of gestation in transparent plastic cylinders with concurrent exposure to bright light. Control pregnant females were left undisturbed in their home cages. Anxiety and depression-related behavior was measured in the offspring at an age of 6 months using the open field test, the home cage emergence test, and the forced swim test. Prenatally stressed rats spent more time in the corners and less time along the walls of an open field, while no difference in total distance moved was observed. In addition, prenatally stressed rats took more time to leave their home cage in the home cage emergence test. On the other hand, no differences in immobility were observed in the forced swim test. Moreover, prenatally stressed rats showed lower stressed-induced plasma corticosterone levels as compared to control rats. Prenatal stress had no effect on the number of 5-bromo-2-deoxyuridine positive cells - used as a measure for cell proliferation - in the hippocampal dentate gyrus of these rats.

These data further support the idea that PS may perturb normal anxiety-related development. However, the present data also suggest that an adaptive or protective efiect of prenatal stress should not be ignored. Genetic factors are likely to play an important role in this respect.

\section{Introduction}

In recent years, there has been increasing awareness that chronic exposure to stress during prenatal development can predispose progeny to various psychological disorders in adulthood. In humans, prenatal stress (PS) has been associated with various learning, behavioral and mood disorders in later life (Stott, 1973, Huttunen and Niskanen, 1978, Meijer, 1985, Ward, 1991, van Os and Selten, 1998, Watson et al., 1999). In studies using rodents, PS has been associated with high anxiety (Thompson, 1957, Archer and Blackman, 1971, Grimm and Frieder, 1987, Wakshlak and Weinstock, 1990, Weinstock et all., 1992, Poltyrev et al., 1996, Vallee et al., 1997), persistent paradoxical sleep alterations (Dugovic et al., 1999), learning and memory deficits (Archer and Blackman, 1971, Grimm and Frieder, 1987, Hayashi et al., 1998, Vallee et al., 1999, Szuran et al., 2000, Gue et al., 2004), and depressive-like behavior (Secoli and Teixeira, 1998, Alonso et al., 1999, Morley-Fletcher et al., 2003).

Investigations on the possible underlying mechanisms have focused primarily on the hypothalamic-pituitary-adrenal (HPA) axis, the regulation of which is thought to be impaired in PS subjects (Koehl et al, 1999. Szuran et al., 2000, Welberg and Seckl, 2001). This is likely the result of an increased production of both maternal and placental stress hormones, i.e., 
corticotropin-releasing factor (CRF) and cortisol/corticosterone, which subsequently enter the fetal circulation and influence fetal (HPA axis) development (see reviews by Weinstock, 2001, Huizink et al,, 2004).

Recently, PS has also been shown to be able to reduce the formation of new neurons within the hippocampal dentate gyrus (DG) of adult rats (Lemaire et al, 2000, Koo el al., 2003) and juvenile nonhuman primates (Coe et al., 2003). In the latter study (Coe et al., 2003), PS rhesus monkeys also showed a reduced hippocampal wolume. Schmitz and colleagues (2002) found a reduced number of granule cells in the hippocampus of adult female, but not male, rats due to prenatal restraint stress. Importantly, reduced neurogenesis within the adult DG has been linked to the pathogenesis of depression (Duman et al, 2000, Jacobs et al., 2000). Further, there are indications that the behavioral effects of chronic antidepressants are linked to the formation of new neurons in the adult hippocampus (Duman et al., 2001, Santarelli et al., 2003).

In the present study, we (1) investigated the effects of PS on adult anxiety- and depression-related behavior using the open field test, the home cage emergence test, and the forced swim test; (2) examined the stress-responsiveness of these Fischer 344 rats by looking at restraint stress-induced plasma corticosterone secretion; (3) determined the degree of cell proliferation within the DG of these rats by determining the number of 5-bromo-2. deoxyuridine (BrdU) positive cells.

\section{Experimental procedures}

\section{Animals}

The animal studies were all approved by the Animal Ethics Board of the University of Maastricht, The Netherlands. Acclimatized time-pregnant normal Fischer 344 rats (Charles River, The Netherlands) were used. Fischer 344 rats were chosen, since these rats are relatively susceptible to a depressive-like state (Sternberg et al., 1992, Izumi et al., 1997). "The animals were housed individually within a temperature-controlled environment $\left(21 \pm 1^{\circ} \mathrm{C}\right)$ with $12 \mathrm{hr}$ light/12hr dark and standard rat chow and water ad libitum. Pregnancy was determined by abservation of vaginal plugs (embryonic day $0-$ E0). Restraint stress was performed daily during the last week of pregnancy (E14-E21). Pregnant female tats $(n=8)$ were individually restrained three times a day (at approximately 9:00 AM, 1:00 PM, and 5:00 PM) for 45 minutes in transparent plastic cylinders (Instrument Development Engineering \& Evaluation, Maastricht, "The Netherlands) while at the same time being exposed to bright light (Ward and Weisz, 1984). Control pregnant females ( $n=6$ ) were left undisturbed in their home cages. Body weight of the dams was measured at E0 and E21. Only litters of 8 or more pups were included in this study. As soon as the last pup of a litter had been born, litter size was defined and pup gender and individual body weights were determined. At postnatal day 21 (P21), 
male pups were taken away from their mother (weaning), housed together (2-3 rats/cage) and left undisturbed up to an age of 6 months (P180), at which time they were subjected to the behavioral analysis as described below. Body weights of the offspring were measured at P0, P21, P60, P90, P120, P150, and P180. No more than 2 males per litter were used to control for litter effects (Chapman and Stern, 1978).

\section{Open field test}

This test was conducted in a square Plexiglas base $(100 \times 100 \mathrm{~cm})$ with a black floor and 40 $\mathrm{cm}$ high transparent Plexiglas walls. The arena was subdivided into a $60 \times 60 \mathrm{~cm}$ central zone, $20 \times 20 \mathrm{~cm}$ corners and $60 \times 20 \mathrm{~cm}$ walls. A camera was placed $250 \mathrm{~cm}$ above the centre of the open field. Immediately after the rat had been placed in the centre of the open field, the movements of the rat were scored automatically with a computerized system (Ethovision Color Pro, Noldus, The Netherlands). The floor of the open field was cleaned with ethanol after each session to prevent transmission of olfactory cues. Both the time spent in the different zones and total distance moved were scored. Testing was carried out for four days, consisting of a single $5 \mathrm{~min}$ session per day. Data were aggregated over four days to enhance reliability (Ossenkopp and Mazmanian, 1985, Lieben et al., 2004).

\section{Home cage emergence test}

In the home cage emergence test, the home cage with the rat inside was placed in the middle of the open field (Prickaerts et al., 1996). The home cage was left open and the rats were offered the possibility of emerging from the home cage via a grid. The latency to emerge from the home cage, l.e., the time until a rat had placed all four paws on the grid outside its home cage was scored. If the rat did not emerge from its home cage within 180 seconds, the session was ended, the rat was given a score of 180 . This test was carried out daily for three consecutive days.

\section{Forced swim test}

The Porsolt or forced swim task is the most commonly used behavioral task to investigate depressive-related behavior in rodents (Porsolt et al., 1978). Central in this test is the aspect of behavioral despair. On the pre-test day animals were individually placed for 5 min into a perspex cylinder ( $40 \mathrm{~cm}$ tall; $17 \mathrm{~cm}$ in diameter) filled to a height of $29 \mathrm{~cm}$ of water and maintained at $23^{\circ} \mathrm{C}$. They were then removed from the water and dried before returning to their home cages. 24 h later (test day) rats were put back into the cylinder for 5 min. The sessions were video taped for later analysis. Immobility was scored, which was defined as making no movements or making minimal movements only in order to keep their nose above the water. Trying to escape from the cylinder and/or active climbing and swimming along the wall were not scored as immobility. 


\section{Blood sampling and corticosterone radioimmunoassay}

Within 90 seconds of taking the rat from its home cage a first blood sample was collected to determine basal corticosterone level. For this purpose, rats were taken to an isolated room at approximately $11 \mathrm{AM}$ and briefly sedated using carbon dioxide after which a small volume of blood was taken via orbital puncture. Immediately after taking the first blood sample the animals were individually placed in restrainer tubes (as described above) for 20 minutes after which a second blood sample was taken. After this, the rats were returned to their home cage and normal housing room and left undisturbed for 40 minutes after which a third blood sample was taken. Blood samples were kept on ice and subsequently centrifuged at $3000 \mathrm{~g}$ for 10 minutes at $4^{\circ} \mathrm{C}$ after which the plasma was frozen down to $-75^{\circ} \mathrm{C}$ for subsequent determination (in duplicate). For the determination of the plasma corticosterone concentrations, $50 \mathrm{ml}$ of plasma was extracted with $3 \mathrm{ml}$ dichloromethane and vortexed for one minute. The corticosterone was subsequently measured directly on $1 \mathrm{ml}$ dried dichloromethane and extracted for radioimmunoassay using corticosterone- ${ }^{-25}$. The radioimmunological reaction was performed overnight at $4^{\circ} \mathrm{C}$, after which a second antibody system was used to separate bound and unbound steroid as previously described in detail (Sulon et al., 1978).

\section{BrdU immunohistochemistry}

At P180, rats were injected with $50 \mathrm{mg} / \mathrm{kg}$ body weight of the Thymidine analogue 5-Bromo-2'-deoxyuridine ( $\mathrm{BrdU}^{\prime}, 10 \mathrm{mg} / \mathrm{ml}$; in $0.9 \% \mathrm{NaCl}$; i.p.). 2 hours later, the animals were anesthetized with pentobarbital (Nembutal ${ }^{\star} ; 60 \mathrm{mg} / \mathrm{kg} ; \mathrm{i} . \mathrm{p}$.) and perfused intracardially with $4 \%$ paraformaldehyde in $0.1 \mathrm{M}$ phosphate buffer ( $\mathrm{pH} 7.4$ ), preceded by tyrode solution. The 2 hour time point was chosen, because it is sufficient for uptake of BrdU but not for mitosis, migration or differentiation (Cameron and McKay, 2001). The brains were removed and post-fixed with the same fixative overnight, after which they were immersed in $15 \%$ sucrose in $0.1 \mathrm{M}$ phosphate buffer for one day. Afterwards, the brains were frozen and stored at $-75^{\circ}$ $C$ until further examination.

Brains were cut on a cryostat into $30 \mu \mathrm{m}$ sections throughout the whole hippocampus. Sections were collected as free-floating material. After being washed in $0.1 \mathrm{M}$ Tris-buftered saline (TBS), the free-floating sections were incubated for $30 \mathrm{~min}$ in $0.6 \% \mathrm{H}_{2} \mathrm{O}_{2}$ at room temperature (RT). After this, the sections were incubated for 2 hours in $50 \%$ formamide at $65^{\circ} \mathrm{C}$. They were then rinsed in sodium citrate solution $(0.3 \mathrm{M} \mathrm{NaCl}, 0.03 \mathrm{M}$ sodium citrate; $\mathrm{Ph} 7.0$; RT) for $15 \mathrm{~min}$, in $2 \mathrm{M} \mathrm{HCl}$ for $30 \mathrm{~min}$ at $37^{\circ} \mathrm{C}$, in $0.1 \mathrm{M}$ borate buffer for $10 \mathrm{~min}$ (RT, $\mathrm{pH} 8.5$ ) and washed in TBS. Before incubating overnight with rat BrdU antibody (Accurate Chemical \& Scientific Corporation, USA; $1: 1000 ; 4^{\circ} \mathrm{C}$ ), sections were blocked with TBS + + (3\% donkey serum in TBS supplemented with $0.25 \%$ Triton-X100) for 60 min at RT. The next day, the sections were washed in TBS, incubated with the secondary antibody donkey anti-rat biotin-sp (Jackson Immunoresearch Laboratories, USA; 1:400) in TBS++ for 2 hours, washed in TBS, incubated with biotin streptavidin (ABC-kit, Vector Laboratories, USA), washed in TBS and 
reacted with a solution of diaminobenzidine, $0.09 \% \mathrm{H}_{2} \mathrm{O}_{2}$ and $0.02 \%$ nickel chloride. After mounting the sections, the slides were counterstained with hematoxylin (Merck, Germany, 1 hour incubation), dehydrated, cleared and covered with a coverslip with Permount (Fisher scientific, USA). BrdU -positive cells on every twentieth section through the whole DG were counted at a $40 \times$ magnification. Only every twentieth section was analyzed to ensure that the same cell would not be counted in two sections. At each level, cell counts were aweraged for both groups and expressed as percentage of control. Finally, data from the different levels were averaged.

\section{Statistics}

Birth weight data were evaluated with a two-way analysis of variance (ANOVA; experimental group $x$ gender). Pre-weaning mortality was tested using the Fisher exact test. For the home cage emergence test, the data were not normally distributed since some rats remained in the home cage for the entire observation period. Therefore, these data were transformed to rank scores, after which they were analyzed using a repeated measurements analysis (experimental group $x$ time). In all other cases, the data were evaluated using one-way ANOVA (experimental group). Only when an effect of PS was observed, correlation analysis was performed using Pearson's correlation coefficient $\left(r_{p}\right)$. Statistical significance was assumed to exist at $\mathrm{P}<0.05$. All statistics were carried out using SPSS software version 11.5 (SPSS Inc, USA).

\section{Results}

\section{Dam weights}

No difference in dam weight over gestation between the different groups was observed. (data not shown).

\section{Litter size, birth weight and pre-weaning mortality}

There was no difference in litter size between the groups (9.2 and 8.9 pups/litter for controls. and $\mathrm{PS}$, respectively). We found a slight overall reduction in birth weight of PS pups (PS effect: $-2.9 \%$; $P<0.05$; see Fig. 1). In addition, male pups were heavier than female pups (gender effect: $6.3 \% ; \mathrm{P}<0.001$ ). There were no significant differences in pre-weaning mortality $(7$ pups died; 3 control and 4 PS pups).

\section{Somatic growth}

From P21 onwards, no significant differences in body weights were observed (data not shown). 


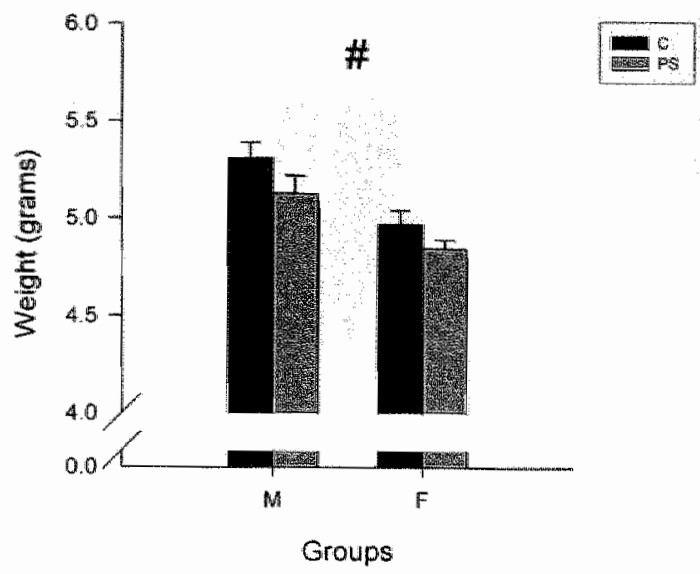

Figure 1, Wipth weights of both mals (W) and female (W) prenataly stressed $(P S)$ and control (C) pups n 30 per group Briss represent means + SE M. Overall PS nas we ghed less at buth than the corresponding controls (ps effect A P 005$)$ Overall, males were hearier than te. males (gender eftect $p<0,001)$.

\section{Open field test}

The effects of PS on performance in the open field test are depicted in Fig. 2. PS rats spent more time spent in the corners $(15.5 \% ; \mathrm{P}<0.05)$, but less time along the walls $(-27.8 \% ; \mathrm{P}<0.05)$ of the open field (Fig. 2a). Both time spent in the center (Fig. 2a) and total distance moved (Fig. 2b) were not different between the two groups. Whereas time spent in the center was negatively correlated with time spent in the corners $\left(r_{p}=-0.58 ; P<0.01\right)$, it was positively correlated with the total distance moved $\left(r_{p}=0.67 ; P<<0.01\right)$. In addition, there was a strong negative correlation between time spent in the corners and time spent along the walls $\left(\mathrm{r}_{\mathrm{p}}=\right.$ $-0.98 ; \mathrm{P}<0.001)$. Finally, there was a tendency for a negative correlation between time spent in the corners and total distance moved $\left(r_{\mathrm{p}}=-0.44 ; \mathrm{P}=0.058\right)$.

\section{Home cage emergence test}

The escape latencies in the home cage emergence test are shown in Fig. 3. Over the three trials, PS rats took more time to leave the home cage $\left(42.1 \%\right.$; $\left.{ }^{*} \mathrm{P}<0.05\right)$. In addition, there was a clear decrease in escape latency over the three trials $(P<0.001)$. Escape latency in the home cage emergence test was negatively correlated with time spent along the walls in the open field test $\left(r_{\mathrm{p}}=-0.62 ; \mathrm{P}<0.01\right)$, whereas it was positively correlated with time spent in the corners $(r p=0.62 ; \mathrm{P}<0.01)$. In addition, there was a tendency towards a significant negative correlation between escape latency in the home cage emergence test and total distance moved in the open field test $\left(R_{\mathrm{p}}=-0.39 ; \mathrm{P}=0.096\right)$.

\section{Forced swim test}

The results of the forced swim test are depicted in Fig. 4. No significant differences were observed in immobility score. 

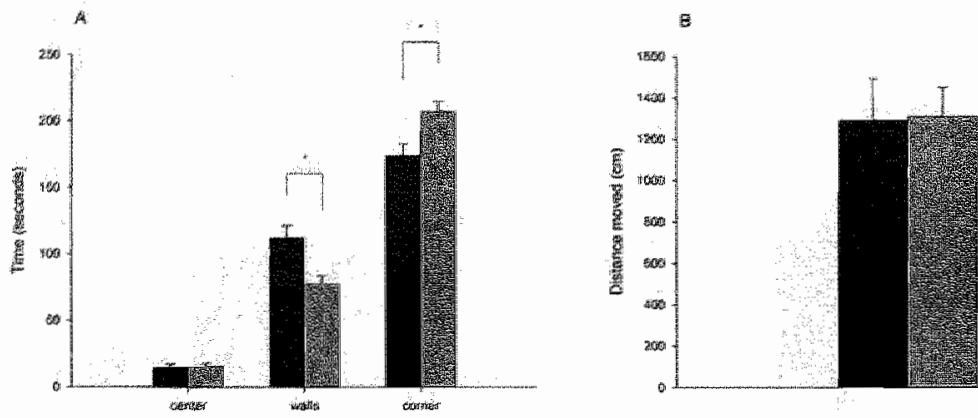

Figure 2. Affects of PS on open field behavior: (A) time spent in the different zones of the open field; (B) total distance moved in the arena. Dat represent aggregated data of four 5 min sessions. Data represent means + S.E.M. (PS. n=11, C: n=8). PS rats spent more time spent in the corners (PS effect; $P<0.05$ ), but less time along the walls (PS effect; * $\mathrm{P}<0.05$ ).

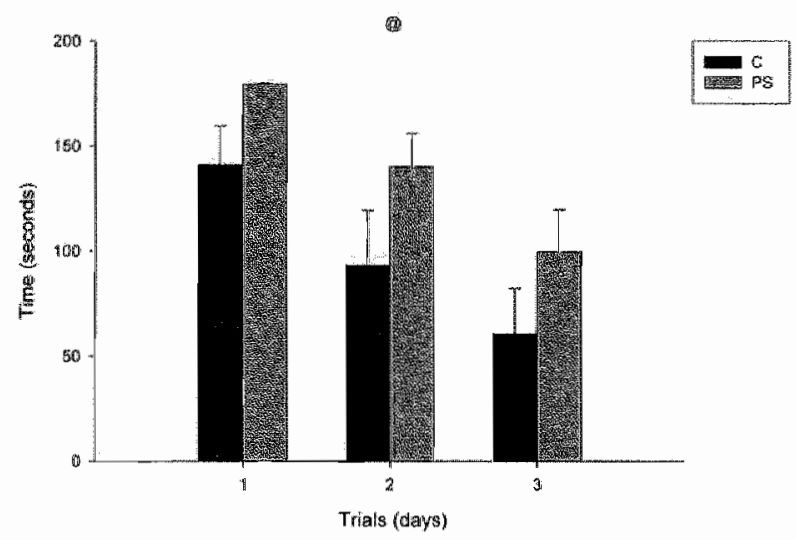

Figure 3. The effect of PS on escape behavior in the home cage emergence test. Bars represent means d S.E.M. (PS: $n=11 ; C: n=8$ ). There was a clear decrease in escape latency over the three trials ( $\mathrm{P}<0,001)$. Ower the three trials, PS rats took more time to leave the home cage (PS effect; $@ P<0.05$ ).

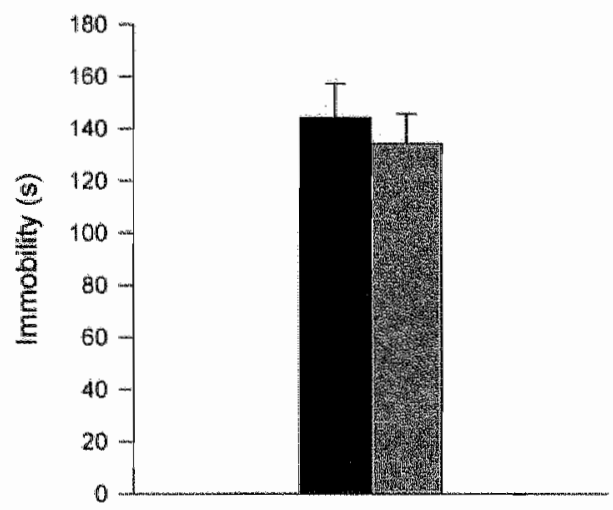

Figure 4. Effects of PS on the immobility score in the forced swiruming test. Wal. ues represent means + S.E.M. (PS; $n=41$; C: $n=8$ ). No significant difference was found between $\mathbb{P} S$ and $C$ rats. 


\section{Stress-induced corticosterone secretion}

Whereas basal corticosterone levels were the same in both groups, control rats showed high er plasma corticosterone levels compared to PS rats immediately following a $20 \mathrm{~min}$. period of restraint stress $(23.4 \%, \mathrm{P}<0.05$, Fig. 5$)$. Plasma corticosterone levels did not decline 40 minutes after putting the rat back into its home cage. At this time, there was still a tendency towards elevated corticosterone levels in control animals $(16.3 \% ; \mathrm{P}=0.055)$.

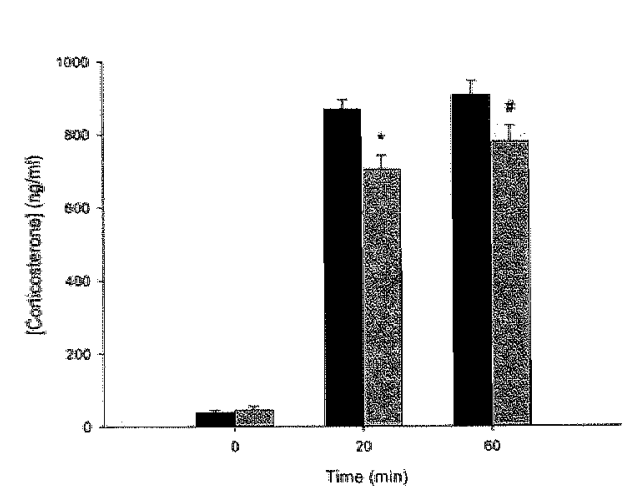

Figure 5. The effect of PS on stress indiced corticosterone secretion. Depicted are plasima corticosterone levels either just before "Time $=0$ min; representing basall corticosterone level), immediately after a 20 min period of restraint stress (Time $=20$ min), or 40 min after taking the rat out of the restrainer. Bars represent means + S.E.M. (PS: $1=11$; C: $n=7$ ). Just after the restraint stress, $C$ rats had significantly elewated conticosterone levels conpared to PS rats $\left(23.4 \% ; * p_{<}<0.05\right)$. At 60 min, there was still a tendency towards elevated corticosterone levels in control animals $(16.39 ; 4 P=0.055)$.

\section{BrdU immunohistochemistry}

The effect of PS on the number of BrdU-positive cells is shown in Fig. 6. Numbers of BrdU-positive cells are expressed as percentage of control. No significant differences were observed.

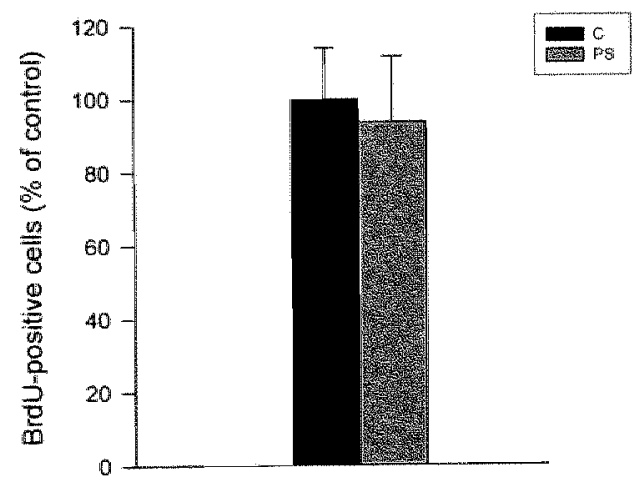

Pigure 6. The effect of PS on cell proliferation within the adult DG. Shown are the number of Brdu-positive cells (expressed as of ontrol).

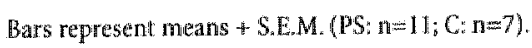
No significant difference was observed between PS and control offspring. 


\section{Discussion}

Besides impaired fetal growth, PS was associated with higher levels of anxiety in the open field and home cage emergence test. Stress-induced corticosterone secretion was actually lower in PS rats compared to controls, whereas no differences were observed in depressiverelated behavior and cell proliferation within the hippocampal DG.

We did not observe any significant differences in maternal weight gain over gestation between the different groups in this investigation (data not shown). Nevertheless, pups of dams exposed to stress during pregnancy weighed less at birth compared to control offspring. Of note, reduced birth weight has been related to various diseases in adulthood, e.g. coronary heart disease, hypercholesterolemia, hypertension, stroke and non-insulin-dependent diabetes mellitus, which is referred to as the "fetal origins of adult disease" hypothesis (Barker, 1995). More recently, low birth weight has also been associated with an increased susceptibility to stress (Nilsson et al., 2001) and depression (Thompson et al., 2001, Gale and Martyn, 2004) in adulthood. The observed fetal growth impairment in PS pups may be caused by the transplacental transfer of maternal stress hormones and/or a reduced uteroplacental blood flow seen in reaction to stress (see reviews by Hobel and Culhane, 2003, Huizink et al., 2004).

In the present study, PS rats spent more time spent in the corners and less time along the walls of the open field. In addition, PS rats were less willing to leave their cage in the home cage emergence test. Data from both anxiety-related tests used support the general idea that PS may lead to more anxious offspring (Thompson, 1957, Archer and Blackman, 1971, Grimm and Frieder, 1987, Wakshlak and Weinstock, 1990, Weinstock et al., 1992, Poltyrev et al., 1996, Vallee et al., 1997).

Surprisingly, no differences were observed in the forced swim test, which differs from most other studies on PS which reported more immobility in the forced swim after PS (Alonso et al., 1999, Morley-Fletcher et al., 2003). However, in line with our findings, in another study by Stöhr and colleagues (1998), immobility was increased in Lewis rats, but not in Fischer 344 rats after PS. Moreover, Fischer 344 rats showed much more immobility in the forced swim test compared to Lewis rats in this particular investigation, even under control conditions, suggesting that Fischer 344 rats are relatively susceptible to a depressive-like state (see also lzumi et al, 1997). Of note, Fischer 344 rats are known for their in. creased CRF, adrenocorticotropic hormone (ACTH), and corticosterone release in response to a variety of stressful stimuli, e.g. open field and forced swim test exposure (Glowa et al 1992, Sternberg et al., 1992). Maybe the intensive behavioral analysis in the present study - where both anxiety-related tests were performed prior to the forced swim test - exerted a significant, long-lasting, stressful effect on both groups of rats by which, as a result, effects of PS may have been masked.

Moreover, control rats showed higher stress-induced corticosterone levels than PS rats, an unexpected finding. Again, the explanation may be found in the intensive behavioral testing together with the use of a strain that is hyperresponsive to stress compared to e.g. Lewis 
rats. We argue that PS Fischer 344 rats, when challenged, i.e, under stressful conditions, show less reactivity than control rats, as they have already been exposed to stress, 1, , prenatally. An adaptive or protective effect of $P S_{x}$ dependent on e.g. genetic badkground, should therefore not be excluded.

As with the forced swim test, cell proliferation within the hippocanpal DG was not changed after PS in this investigation, which is in contrast to several other studies (Lemaire et al., 2000, Coe et al., 2003, Koo et al., 2003). As mentioned above, this might also be explained by the intensive behavioral testing acting upon a stress-sensitive genetic background. However, in line with our findings, Schmitz and colleagues (2002) did not find a reduced number of granule cells in the hippocampus of adult male Long-Evans rats after prenatal restraint stress, whereas female rats were affected in their study. Gender-effects may therefore play an important role in this respect too.

In conclusion, the present study supports the idea that PS may lead to impaired fetal growth and more anxious offspring. Conversely, an adaptive or protective effect of PS towards stress (coping), dependent on the genetic background should not be excluded. Further, the present study stresses the impact of strain and gender in stress-related investigations.

\section{References}

Alonso, S. J., Castellano, M. A., Quintero, M. and Navarro, E., 1999. Action of antidepressant drugs on maternal stressinduced hypoactivity in female rats. Methods Find Exp Clin Pharmacol. 21, 29:-295.

Archer, J. E. and Blackman, D. E., 1971 . Prenatal psychological stress and offspring behavior in rats and mice. Dew Psychobiol. 4, 193-248.

Barker, D. J, 1995. The fetal origins of adult disease. Proc R Soc Lond B Biol Sci. 262, 37-43.

Cameron, H. A. and McKay, R. D., 2001. Adult neurogenesis produces a large pool of new granule cells in the dentate gyrus. J Comp Neuroll. 435, 406-417.

Chapman, R. H. and Stern, J. M. 1978. Maternal stress and pituitary-adrenal manipulations during pregnancy in rats: effects on morphology and sexual behavior of male offspring. I Comp Physiol Psychol. 92, $1074-1083$.

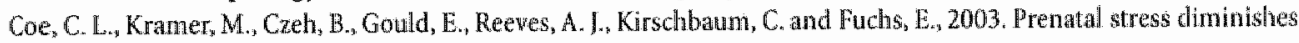
neurogenesis in the dentate gyrus of juvenile rhesus monkeys. Biol Psychiatry. 54, 1025-1034.

Dugawic, C., Maccari, S., Weibe]. L., Turek, F. W. and Van Reeth, O., 1999. High corticosterone lewels in prenatally stressed rats predict persistent paradoxical sleep alterations. I Neurosci. 19,8656-8664.

Duman, R. S., Malberg, I., Nakagawa, S. and D'Sa, C., 2000. Neuronal plasticity and survival in mood disorders. Biol Psychiatry. 48,732-739.

Duman, R. S. Nakagawa, S. and Malberg, J., 2001. Regulation of adult neurogenesis by antidepressant treatiment. Neuropsychopharmacology: $25,836-844$.

Galle, C. R. and Martyn, C. N., 2004. Birth weight and later risk of depression in a national birth cohort. Br I Psychiatry. $184,28-33$.

Glowa, J. R.s Sternberg, E. M. and Gold, P. W.1992. Differential behawioral response in LEW/N and F344/N rats: effects of corticotropin releasing hormone. Prog Neuropsychopharmacol Biol Psychiatry. 16, 5.49-560.

Grimm, V. E. and Frieder, B., 1987. The effects of mild maternal stress during pregnancy on the behavior of rat pups. Int INeurosci. 35, 65-72

Gue, M., Braward, A., Meunier, J., Veyrier, R., Gaillet, S., Recasens, M. and Maurice, T., 2004. Sex differences in learning deficits induced by prenatal stress, in juwenile rats. Behav Brain Res. 150, 149-157.

Hayashi, A., Nagaoka, M., Yamada, K., Ichitani, X., Miake, Y. and Okado, N., 1998. Maternal stress induces synaptic loss and developmental disabilities of offspring. Int I Dev Neurosci. 16, 209-216. 
Hobel, $\mathrm{C}$ and Culthane, . 2003. hole of psychosecial and nutritional stress on poor pregnancy outcome. I Wutr. 133, $17095-17175$

Hitink, A. C. Mulder, E. J. and Buitelaar, I. K. 2004. Prenatal stress and rist for psychopathology: specific effects or induction of general susceptibility? Psychol Bull $130,115-142$.

Hutturen, M. O. and Wiskanen, P, 1978. Prenata loss of Gather and psychiatric disorders. Arch Gen Psychiary. 35, $429-431$.

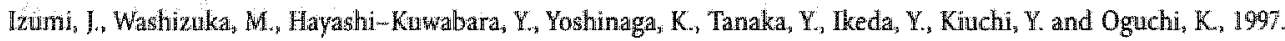
Evidence for a depressive-wike state induced by repeated saline injections in Fischer 344 rats. Pharmacol Bochem Behaw, $57,883-888$.

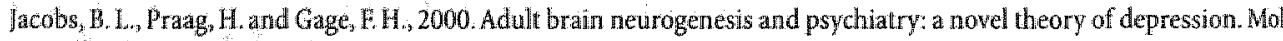
Psychiatry. $5,262-269$.

Koehl, M., Darnaudery, M., Dullic, J., Wan Reeth, 0. Le Mod, M. and Maccari, \$., 1999. Prenatal stress alters circadian activity of hypothalamo-pituitary-adrenal axis and hippocampal corticosteroid receptors in adult rats of both gender. I Neurobiol. $40,302-315$

Koo, I. W, Park, C. H. Choi, S. H. Kim, N. J., Kim, H. S, Choe, I. C. and Suh, Y. H., 2003. The postnatal environment can counteract prenatal effects on cognitive ability, cell proliferation, and synaptic protein expression. Faseb I. 17, $1556-1558$.

Lemaire, V., Koehl, M., Le Moal, M. and Abrous, D. N., 2000. Prenatal stress produces learring deficits associated with an inhibition of neurogenesis in the hippocampus. Proc Natl Acad Sci U S A. 97, 11032-11037.

Lieben, $C$. K., van Oorsouw, $K_{n,}$ Deutz, N. E. and Blokland, A., 2004. Acute tryptophan depletion induced by a gelatin-based mixture impairs object memory but not affectwe behavior and spatial learning in the rat. Behav Brain Res. 151,53-64:

Mejer. $A_{\text {, }}$ 1985. Child psychiatric sequelae of maternal war stress. Acta Psychiatr Scand, 72, 505-511.

Morley.-. Fletcher, S., Darnaudery, M. Koehl, M., Casolini, F, Wan Reeth, O. and Maccari, S., 2003. Prenatal stress in rats predicts immobillity behavior in the forced swim test. Effects of a chronic treatnent with tianeptine. Brain Res. $989,246-251$.

Nilsson, P. M., Nyberg, P. and Ostergren, P-O., 2001. Increased susceptibility to stress at a psychological assessment of stress tolerance is assoctated with impaired fetal growth. Int J Epidemiol. 30,75-80.

Ossenkopp, K. P. and Maxmanian, D. S, 1985. The measurement and integration of behavioral variables: aggregation and complexity as important issues, Neurobehav Toxicol Teratol. 7,95-100.

Poltyrev, "T. Keshet, G. I., Kay, G. and Weinstock, M., 1996. Role of experimental conditions in determining differences in exploratory betawior of prenatally stressed rats. Dev Psychobiol. 29, 453-462.

Porsolt, R. D. Anton, G., Blavet, N. and Jalfre, M., 1978. Behawioural despair in rats: a new model sensitive to antidepres. sant treatments. Eur. J Pharmacol. 47, 379-391.

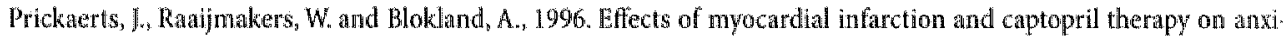
ety-related behaviors ith the rat. Physiol Behaw 60, 43-50.

Santatell, L., Saxe, M., Gross, C., Surget, A., Battaglia, F, Dulaw, S., Weisstatub, N., Lee, I., Duman, R., Arancio, O., Belzang, $C$ and Hen, $R$. 2003. Requirenent of hippocampal neurogenesis for the behavioral effects of antidepres. sants. Science. 301, 805-809:

Schmitz, C. Rhodes, M. E, Bludau, M., Kaplan, S., Ong, P, Jeffing, L., Wehoff, J, Korr H. and Frye, C. A., 2002. Depression: reduced number of granule cells in the hippocampus of female, bul not male, rats due to prenatal restraint stress. Mol Psychiatry. $7,810-813$.

Secoli, S. R. and Teixeira. N. A., 1998. Chronic prenatal stress affects development and behavioral depression in rats. Stress. $2,273-280$.

Sternberg, E. M., Glowa, J. R., Snith, M. A., Calogero, A. E., Listwak, S. I., Aksentijevich, S., Chrousos, G. P., Wilder, R. L. and Gold, P. W. 1992. Corticotropin releasing hormone related behaviorat and neuroendocrine responses to stress in lewis and Fischer tats. Brain Res, 570, 54-60.

Stohr, T., Schulte Wermeling, D., Sturan, T., Pliska, V, Domeney, A. Welzl, H., Weiner, I. and Feldon, J, 1998. Differential effects of prenatal stress in two inbred strains of rats. Pharmacol Biochem Behav 59, 799-805.

Stott, D. H., 1973. Follow-up study from birth of the effects of prenatal stresses. Dev Med Child Neurol. 15,770-787.

Sulon, J., Demey-Ponsart, L., Beauduin, P. and Sodoyez, J. C., 1978. Radioimnumoassay of corticosterone, cortisol and cortisone: their application to human cord and maternal plasma. J Steroid Biochem. 9,671-676. 


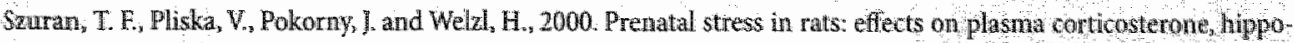
campal gucocorticoid receptors, and maze performance. Physiol Behaw 7, $353-362$.

Thompson, C, Syddall, H, Rodin, I, Osmond, C. and Barker, D. J., 200 . Birth werght and the rak of depressivedusorder in late life. Br J Psychiatry. 179, 450 455 .

Thompson, W. R, 1957. Influence of prenatal maternal awxiety on enotionality in yotng rats $801 e n c e, 125,698-699$.

Wailee, M., MacCari, S., Dellu, E., Simon, H., Le Moal, M. and Mayo, W., 1999. Long-term effects of prental stress and postnatal handling on age-related glucocorticoid secretion and cognitive performance a longitudinal study in the rat. Eur I Neurosci. 11, 2906-2916.

Vallee, M., Mayo, W., Dellu, F., Le Moal, M., Simon, H. and Maccari, S., 1997. Prenatal stress induces high anxiety and postmatal handling induces lon anxiety in adult offspring correlation with stress-induced corticosterone secretion. II Neurosici. 17, 2626-2636.

wan Os, J. and Selten, J. P., 1998. Prenatal exposure to maternal stress and subsequent schizophrenia. The May 1940 imasion of The Netherlands. Br I Psychiatry 172, 324-326.

Wakshlak, A and Weinstock, M, 1990. Neonatal handling reverses behavioral abnormalities induced in rats by prenatal stress. Physiol Behar. 48, 289-292.

Ward, A. J., 1991. Prenatal stress and childhood psychopathology. Child Psychiatry Hum Dew. 22, 97-110.

Ward, $1 . \mathrm{L}_{\text {. and Weis }}$, I., 1984. Differential effects of maternal stress on circulating levels of corticosterone, progesterone, and testosterone in male and female rat fetuses and their mothers. Endocrinology. 114, 1635-1644.

Watson, I. B., Mednick, S.A., Huttunen, M. and Wang, X., 1999. Prenatal teratogens and the development of adult mental jilness. Dev Psychopathol. 11,457-466.

Weinstock, M., 2001. Alterations induced by gestational stress in brain morphology and behaviour of the offspring. Prog Neurobiol. 65, 427-451.

Weinstock, M., Matlina, E. Maor, G. I, Rosen, H. and McEwen, B. S, 1992, Prenatal stress selectively alters the reactivity of the hypothalamic-pituitary adrenal system in the female rat. Brain Res. 595, 195-200.

Welberg, L.A. and Seckl, J.R., 2001. Prenatal stress, glucocorticoids and the programruing of the brain. J Neuroendom crinol. $13,113-128$. 
8

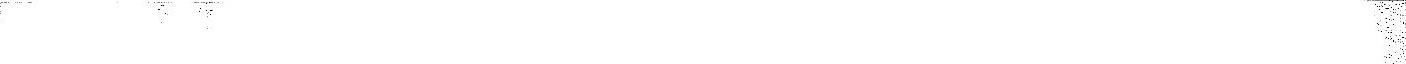

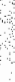




\title{
Chapter 6
}

\section{Prenatal stress and behavior in the rat; the implications of a subsequent exposure to stress}

\author{
Van den Hove DLA ${ }^{1 / 2}$, Steinbusch $\mathrm{HWM}^{2}$, Desbonnet $\mathrm{L}^{2 / 3}$, \\ Bruschettini $\mathrm{M}^{2}$, Steinbusch $\mathrm{HP}^{1 / 2}$, Scheepens $\mathrm{A}^{1 / 4}$, Prickaerts $\mathrm{J}^{2}$, Blanco $\mathrm{CE}^{1}$
}

'Department of Pediatrics, Maastricht University,

Maastricht, The Netherlands.

${ }^{2}$ Department of Psychiatry and Neuropsychology, Maastricht University,

Maastricht, The Netherlands.

${ }^{3}$ Department of Psychiatry, University College Cork, Cork, Ireland

${ }^{4}$ Liggins Institute, University of Auckland, Auckland New Zealand.

American Journal of Obstetrics \& Gynecology, Submitted 


\section{Abstract}

Chronic stress during human fetal brain development has been associated with an increased risk for adult (psycho-) pathology. Recently, howewer, it was suggested that prenatal stress may also have adaptive effects towards stress coping ability in adulthood. In the present study the effect of a subsequent exposure to stress on adult anxiety-and depression-related behavior was studied in both prenatally stressed and control male Fischer 344 rats. Whereas prenatally stressed rats were more anxious before the subsequent exposure to stress, as measured in the open field and home cage emergence tasks, afterwards, they were less anxious than controls. In addition, prenatally stressed animals initially exhibited more depression-related behavior, as measured in the forced swim test, which normalized after the subsequent exposure to stress. At the same time, no differences were observed in stress-induced corticosterone secretion or in the degree of cell proliferation within the dentate gyrus of these rats. Our data are in favor of the "predictive adaptive response' (PAR) hypothesis, which suggests that prenatal stress allows offspring to better cope with stress in later life as compared to offspring that developed under "normal" prenatal conditions.

In conclusion, prenatally-stressed Fischer 344 rats seem to perform relatively better under stressful conditions as compared to control rats. The present data provide further evidence for the idea that prenatal stress may also have, dependent upon the genetic background and history, positive adaptiwe properties. Finally, this study once more underlines the importance of the choice of strain in stress-related investigations.

\section{Introduction}

Increasing evidence suggests that the risk of disease in adulthood partly depends upon variations in the prenatal environment, a phenomenon which is also referred to as the "fetal origims of adult disease' concept (Barker, 1995). Accordingly, the emotional state of a pregnant woman has been shown to be able to affect the unborn child, with offspring exposed to prenatal maternal distress showing an increased risk for adult (psycho--) pathology (Weinstock, 2001, Huizink et al., 2004),

However, in a previous study by our group, adult prenatally stressed male Fischer 344 rats that underwent an intensive behavioral test regime were stress-hyporesponsive as compared to control oftspring as indicated by lower corticosterone levels after 20 minutes of restraint stress (Van den Hove et al., 2005). Thus, it was suggested that prenatal stress (PS) may also have a relatively adaptive effect in relation to stress coping, probably dependent on the genetic background.

The aim of the present study was to further investigate the stress response of this rat strain in our PS model by exposing both PS and control offspring to a subsequent exposure to stress at an age of 3 months. Anxiety-and depression-related behavior was examined both before and after this short period of stress. Further, stress-induced corticosterone secretion 
and the degree of cell proliferation within the dentate gyrus (DG) of these rats - a reduction of which has been linked to the pathogenesis of depression (Duman et al; 2000, Jacobs et al., 2000) - were examined.

\section{Experimental procedures}

\section{Animals}

These animal studies were all approved by the Animal Ethics Board of the University of Maastricht, The Netherlands. Acclimatized time-pregnant normal Fischer 344 rats (Charles River, The Netherlands) were used. The animals were housed individually within a temperature-controlled environment $\left(21 \pm 1^{\circ} \mathrm{C}\right.$ ) with a $12 \mathrm{hr}$ light/12hr dark cycle (lights on from 7.00-19.00 h) and had access to standard rat chow and water ad libitum. Pregnancy was determined by observation of vaginal plugs (embryonic day 0 - E0). Restraint stress was performed daily during the last week of pregnancy (E14-E21). Pregnant female rats $(n=8)$ were individually restrained 3 times a day (at approximately 9.00,13.00, and 17.00 h) for 45 minutes in transparent plastic cylinders (IDEE, The Netherlands) while at the same time being exposed to bright light (Ward and Weisz, 1984). Control (C) pregnant females ( $n=6$ ) were left undisturbed in their home cages. Only litters of 8 or more pups were included in this study. As soon as the last pup of a litter had been born, litter size and pup gender was defined (based on anogenital distance) and individual body weights were determined. At postnatal day 21 (P21), male pups were weaned and housed together (2 rats/cage) for further examination. "To examine the effect of a subsequent exposure to stress control and PS rats were exposed to a 3-day period of stress at an age of 3 months (P90) during which they were housed in small cages, placed in plastic cylinders (as described above; for a single 45 minute period) and exposed to wet bedding. Rats were housed individually from this point onwards. The behavior of the rats was tested both before and after the pertod of stress, i.e., at an age of 2 (P60) and 6 months (P180). Body weights of all offspring were measured every month. Only $1-2$ males per litter were examined to prevent litter effects (Chapman and Stern, 1978).

\section{Open field test}

This test was performed in a square Plexiglas base $(100 \times 100 \mathrm{~cm})$ with a black floor and $40 \mathrm{~cm}$ high transparent Plexiglas walls. The arena was subdivided into a $60 \times 60 \mathrm{~cm}$ central zone, $20 \times 20 \mathrm{~cm}$ corners and $60 \times 20 \mathrm{~cm}$ walls. A camera was placed $250 \mathrm{~cm}$ above the centre of the open field. Immediately after the rat had been placed in the centre of the open field, its movements were scored automatically with a computerized system (Ethovision Pro, Noldus, The Netherlands). After each session, the floor of the open field was cleaned with ethanol to prevent transmission of olfactory cues. Both the time spent in 
the different zones and the total distance moved were scored. Testing was carried out for 4 consecutive days, consisting of a single 5 minute session per day. Data were aggregated over 4 days to enhance reliability (Ossenkopp and Mazmanian, 1985).

\section{Home cage emergence test}

The rats home cage was left open in the middle of an open field, as described above, and the rats were offered the possibility of emerging from the home cage via a grid (Prickaerts et al: 1996). The latency to emerge from the home cage, i.e., the time until a rat was on the grid outside its home cage with all 4 paws, was scored. If the rat did not emerge from its home cage within 180 seconds, the session was ended, the home cage was closed again and the rat was given a score of 180 . This test was carried out on 3 consecutive days.

\section{Forced swim test}

The Porsolt or forced swim task (Porsolt et al., 1978) was conducted over 2 days. On the pretest day animals were individually placed into a glass cylinder $(40 \mathrm{~cm}$ tall; $17 \mathrm{~cm}$ in diameter) filled up to a height of $29 \mathrm{~cm}$ with water maintained at $23^{\circ} \mathrm{C}$. After 5 minutes they were re. moved from the water and dried and returned to their home cages. 24 hours later (test day) rats were put back into the cylinder for 5 minutes. The sessions were video taped for later analysis. Immobility was scored, which was defined as making no or minimal movements only in order to keep the nose above the water. Trying to escape from the cylinder and/or active climbing and swimming along the wall or diving was not seen as immobility.

\section{Blood sampling and corticosterone radioimmunoassay}

"Co test the responsiveness of the hypothalamo-pituitary-adrenal (HPA) axis the rats were individually placed in restrainer tubes (as clescribed above). For this purpose, rats were taken to an isolated room at approximately $11: 00$ and briefly sedated using carbon dioxide. Within 90 seconds of taking the rat from its home cage a first blood sample was collected via orbital puncture representing the basal corticosterone level. Immediately after this the animals were put in the restrainer tube for 20 minutes after which a second blood sample was taken. Afterwards, rats were returned to their home cage and left undisturbed for 40 minutes after which a third and final blood sample was taken. Blood samples were kept on ice and subsequently centrifuged at $3000 \mathrm{~g}$ for 10 minutes at $4^{\circ} \mathrm{C}$ after which the plasma was frozen down to $-75^{\circ} \mathrm{C}$ for subsequent determination (in duplicate). For this purpose, $50 \mathrm{ml}$ of plasma was extracted with $3 \mathrm{ml}$ dichloromethane and vortexed for 1 minute. Corticosterone was subsequently measured directly on $1 \mathrm{ml}$ dried dichloromethane and extracted for radioimmunoassay using corticosterone- ${ }^{125}$ I. The radioimmunological reaction was performed overnight at $4^{\circ} \mathrm{C}$, after which a second antibody system was used to separate bound and unbound steroid as previously described in detail (Sullon et al., 1978). 


\section{BrdU immunohistochemistry}

A week after the last behavioral test, rats were injected with $50 \mathrm{mg} / \mathrm{kg}$ body weight of the tliymidine analogue 5-Bromo-2'-deoxyuridine ( $\mathrm{BrdU}, 10 \mathrm{mg} / \mathrm{ml}$; in $0.9 \% \mathrm{NaCl}$ i.p.). 2 hours fate, the animals were anesthetized with pentobarbital (Nembutal; $60 \mathrm{mg} / \mathrm{kg} ; \mathrm{i} . \mathrm{p}$ ) and perfused intracardially with $4 \%$ paraformaldehyde in $0.1 \mathrm{M}$ phosphate buffer $(\mathrm{pH} 7.4)$, preceded by tyrode solution. The 2 hour time point was chosen, because it is sufficient for uptake of BrdU but not for mitosis, migration or differentiation (Cameron and Mckay, 2001. Prickaerts et al, 2004). The brains were removed and post-fixed with the same fxative overnight, after which they were immersed in $15 \%$ sucrose in $0.1 \mathrm{M}$ phosphate buffer for one day. Afterwards, the brains were frozen and stored at $-75^{\circ} \mathrm{C}$ until further examination.

Brains were cut on a cryostat into 30 um free-floating sections through the whole hippo. campus. After being washed in $0.1 \mathrm{M}$ Tris-buffered saline (TBS), the free-floating sections were incubated for 30 minutes in $0.6 \% \mathrm{H} 2 \mathrm{O} 2$ at room temperature (RT). After this, the sections were incubated for 2 hours in $50 \%$ formamide at $65^{\circ} \mathrm{C}$. They were then rinsed in sodium citrate solution (0.3M NaCl, 0.03 M sodium citrate; Ph 7.0; RT) for 15 minutes, in $2 \mathrm{Mr}$ HCl for 30 minutes at $37^{\circ} \mathrm{C}$, in $0.1 \mathrm{M}$ borate buffer for 10 minutes ( $R T, p H 8.5$ ) and washed in TBS. Before incubating overnight with the BrdU antibody (Accurate Chemical \& Scientific Corporation, USA; $\left.1: 1000 ; 4^{\circ} \mathrm{C}\right)$, sections were blocked with TBS $++(3 \%$ donkey serum in TBS supplemented with $0.25 \%$ Triton-X100) for 60 minutes at RT. The next day, sections were washed in TBS, incubated with the biotinilated secondary antibody (Jackson Immunoresearch Laboratories, USA: 1:400) in TBS+ for 2 hours, washed in TBS, incubated with biotin streptavidin (ABC-kit, Vector Laboratories, USA), washed in TBS and reacted with a solution of diaminobenzidine, $0.09 \%$ $\mathrm{H}_{2} \mathrm{O} 2$ and $0.02 \%$ nickel chloride. After mounting the sections, the slides were counterstained with hematoxylin (Merck, Germany, $\mathbb{1}$ hour incubation), dehydrated, cleared and covered with a coverslip with Permount (Fisher scientific, USA). BrdU-positive cells through the whole DG were counted at a $40 \mathrm{X}$ magnification. At each level, cell counts were averaged for both groups and expressed as percentage of control. Finally data from the different levels were averaged.

\section{Statistics}

Birth weight data were evaluated with a two-way analysis of variance (ANOVA; experimental group $\times$ gender). Premweaning mortality was tested using the Fisher exact test. For the home cage emergence test, the data were not normally distributed since some rats remained in the home cage for the entire observation period. "Therefore, these data were transformed to rank scores. A repeated measurements analysis (experimental group $\times$ trials) was performed to study the effects over the trials. Data from P60 and P180-i.e., before and after the subsequent exposure to stress, respectively - were compared using a repeated measurement analysis as well (experimental group $\times$ age). In all other cases, the data were evaluated using a Student's $\mathrm{t}$-test. Statistical significance was assumed at $\mathrm{P}<0.05$. All statistics were carried out using SPSS software version 11.5 (SPSS Inc, USA). 


\section{Results}

\section{Litter size, birth weight and pre-weaning mortality}

There was no difference in litter size between the groups (9.8 and 9.2 pups/litter for controls and $\mathrm{PS}$, respectively). We found an overall reduction in birth weight of $\mathrm{PS}$ pups (PS effect: $-4.4 \% ; \mathrm{P}<0.001 ;$ see Fig. 1). In addition, male pups were heavier than femalle pups (gender effect: $4.6 \% ; \mathrm{P}<0.001$ ). There were no significant differences in pre-weaning mortality ( $6 \mathrm{pups}$ died, 2 control and 4 PS pups).

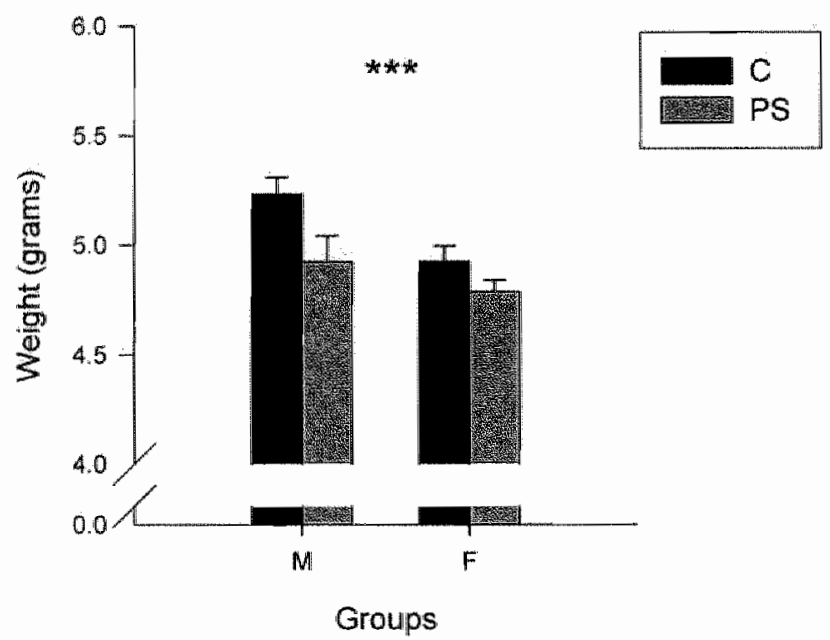

Fingure 1. Birth weights of both male (M) and female (F) prenatally-stressed (PS) and control (C) pups; n $=17-29$ per group. Bars represent meanis + S.E.M. Overall, PS birth weights were lower than the corresponding controls (PS effect: * P<0,001), Overall, males were heavier than females (gender effect: $\left.{ }^{p}<0.001\right)$.

\section{Somatic growth}

From $\mathrm{P} 21$ onwards, no significant differences in body weights were observed (data not shown).

\section{Open field test}

The effects of PS on performance in the open field test are depicted in Fig. 2. There was a significant experimental group $\times$ age interaction in total distance moved $(\mathrm{P}=0.032)$, with $\mathrm{PS}$ rats covering relatively less distance at an age of 2 months, but more at an age of 6 months compared with controls. A significant effect of age was seen in all parameters recorded $(P<0.001$ in all cases), with rats showing more anxiety-related behavior after the subsequent exposure to stress. No significant differences were observed in any of the other cases. 


\section{Home cage emergence test}

The escape latencies in the home cage emergence test are shown in Fig. 3. At an age of 2 months, there was a clear decrease in escape latency over the 3 trials (trial effect; $p<0.001$ ). At the first trial at an age of 6 months control animals took $40 \%$ more time to leave the home

\section{A: Center}

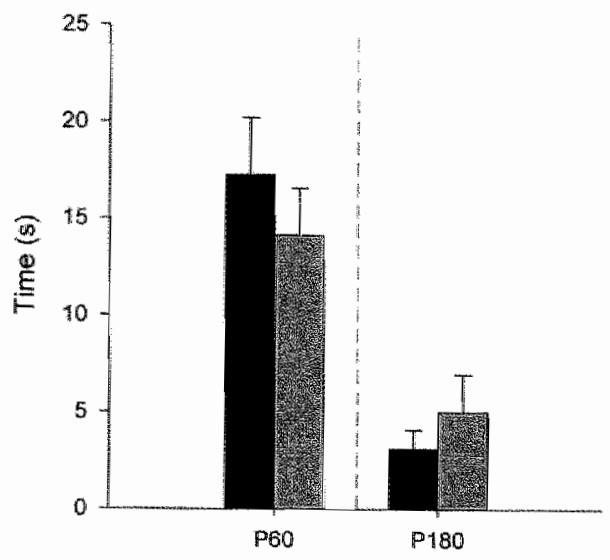

B: Walls

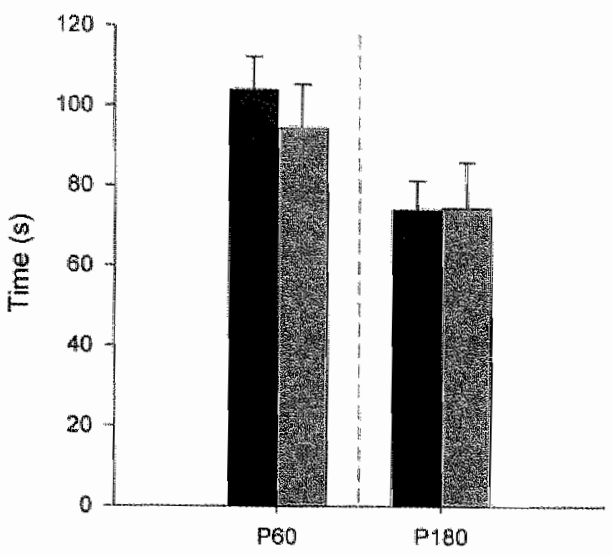

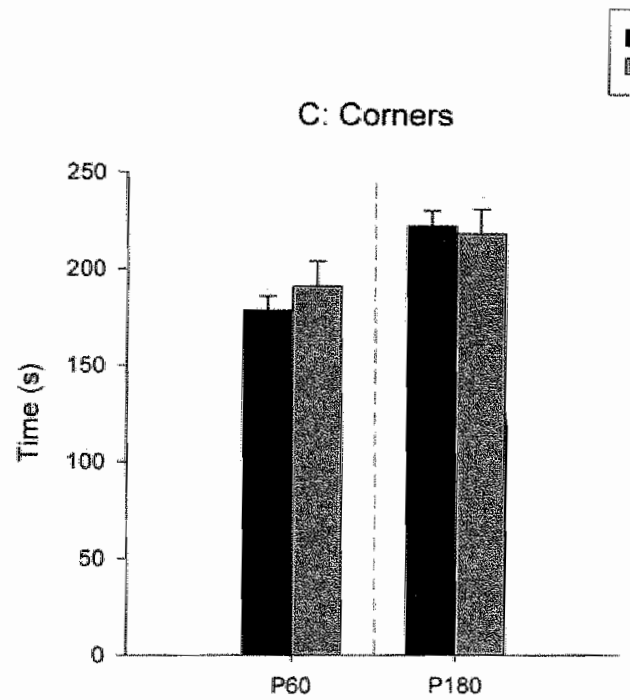

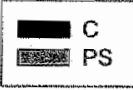

PS

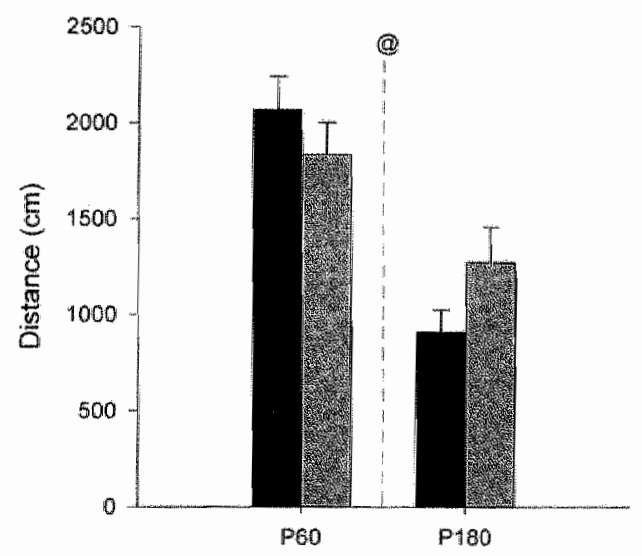

Figure 2. Effects of PS on open field betawior: time spent in the different zones of the open field (A.C) and total distance

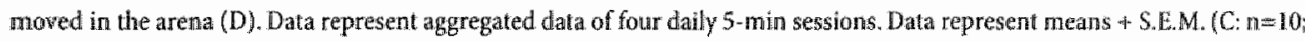
PS: $n=9$ ). A significant effect of age, i.e. more anxiety at an age of 6 months, was seen in all parameters recorded (P<0,001 in all cases). There was an experimental group $x$ age interaction effect in total distance moved $(@ P=0,032)$, with $P$ S rats covering relatively less distance at an age of 2 months, but more at an age of 6 months as compared with controls. No differences were observed in any of the other cases. 
cage as compared to PS offspring ( $\mathrm{t}-\mathrm{test}, \mathrm{P}=0.041$ ). Looking at the effect of the subsequent exposure to stress in more detail by focusing on the transition between the last trial at an age of 2 months and the first trial at an age of 6 months, an experimental group $\times$ age interaction $(\mathrm{P}<0,001)$ could be observed, with PS rats taking more time to escape at an age of 2 months, but relatively less at an age of 6 months. Further, a significant effect of age was observed, with both groups taking more time to escape after the subsequent exposure to stress $(P<0.001)$.

\section{Forced swim test}

The results of the forced swim test are depicted in Fig. 4. At an age of 2 months, PS rats showed $31 \%$ more immobility as compared to controls ( $t-t e s t ; P=0.043$ ). No differences were observed in immobility score at an age of 6 months. In adilition, no effect of age was observed.

\section{Stress-induced corticosterone secretion}

Both basal and stress-induced levels of corticosterone were not affected 6 months after PS, as shown in Fig. 5 .

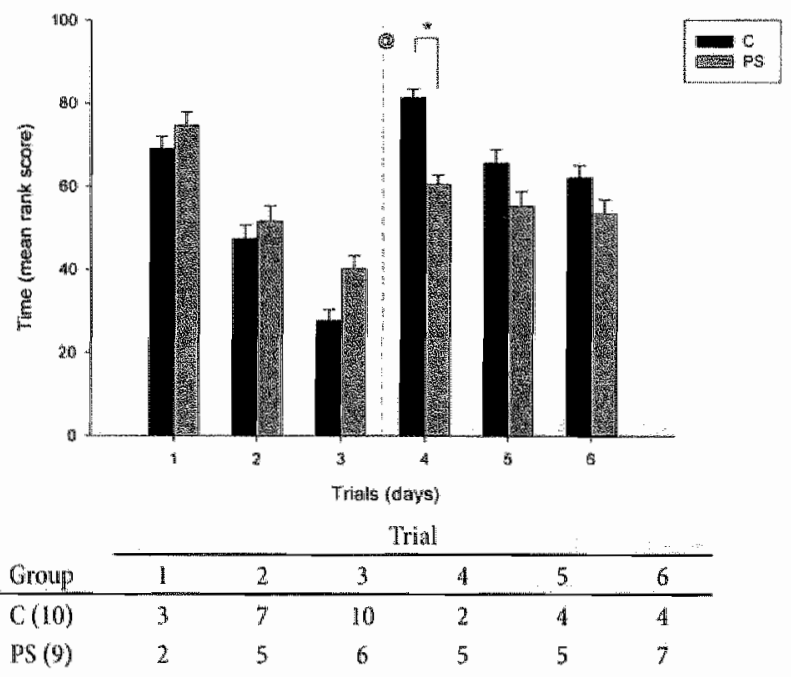

Figure 3. The effect of PS on escape behawion in the home cage emergence test. Bars represent mean rank scores + S.E.M.

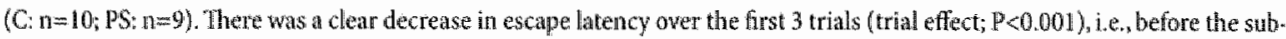
sequent exposure to stress, which is represented by the vertical gray line. Trials 4-6 were performed after the stress exposute During trial 4 . DS rats took significantly less time to lewe the home cage ( $t$-test; ${ }^{\prime}=0.041$ ). Looking at the shift between the last trial at an age of 2 months and the first trial at an age of 6 months, i.e. , trials 3 and 4 , we see a significant experimental group $x$ age interaction $(\odot \mathrm{P}<0.00$ ?), with PS rats taking more time to escape at an age of 2 months, but relatively less at an atge of 6 months. Highlighted in the table is the number of animals that escaped within 180 seconds columis represent the various trials/days. Notw aggin the shidt between trials 3 and 4. 


\section{BrdU immunohistochemistry}

The effect of PS on the number of BrdU positive cells in the hippocampal $D G$ is shown in Fig. 6. Numbers of BrdU-positive cells are expressed as percentage of control No difference between groups was observed.
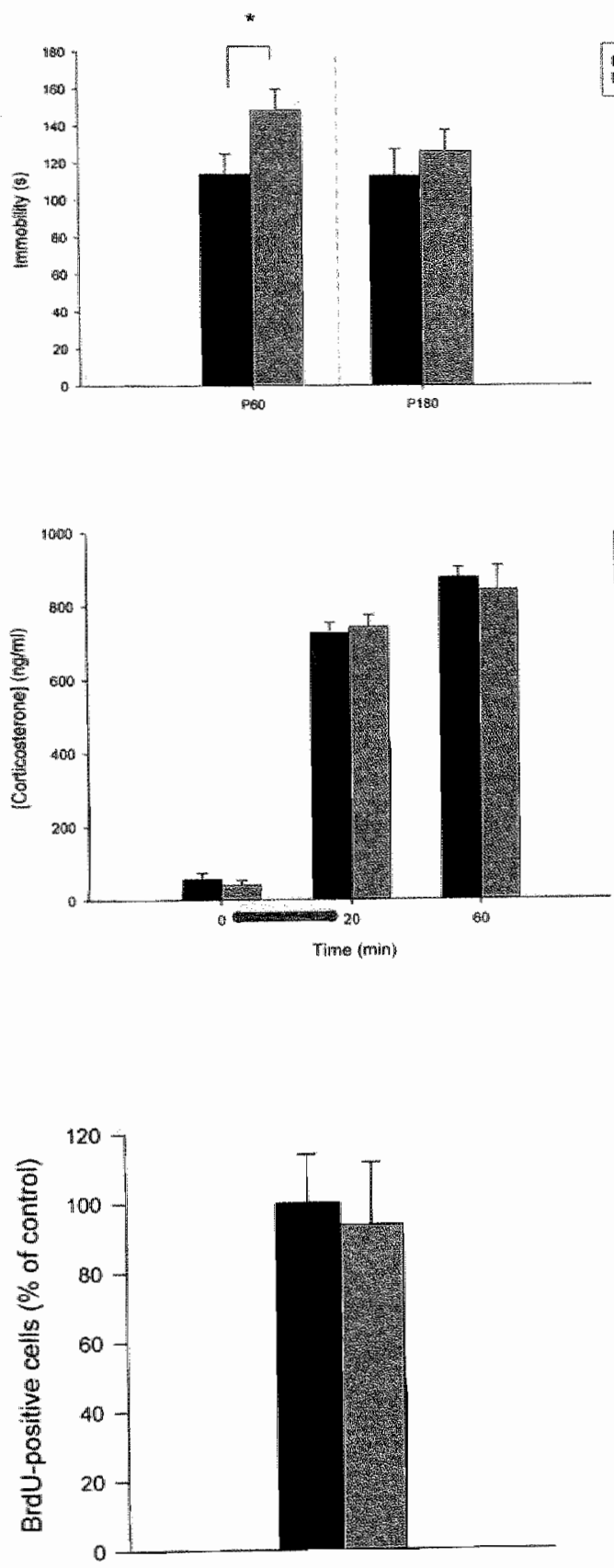

Figure 4. Eiffects of PS on the inmobility score in the forced swinming test. Values represent means + S.E.M. ( $\mathrm{C}, \mathrm{n}=10_{2}$ PS: nsm 9). Whemeas at an age of 2 months PS rats showed more inmobility compared to controll of ispring (t-test: $P=0.043)$, no difference was found between groups at an age of 6 months.

Figure 5. The effect of PS on stress induced. corthosterone secretion at an age of 6 months. Depicted are plasma corticosterone levels aither just before (Tìne $=0$ min; representing basal corticosterone level), immediately after a $20 \mathrm{~min}$ period of restraint stress (Time $=20$ mim) - represented by the horizontal gray bar-or 40 milu afker taking the rat ont of the restrainer tubue. Bars represent means + S.E.M. (C: $\left.n=10 ; \mathrm{PS}_{n} \mathrm{n}=9\right)$ ) No significant differences between groups were observed..

Figure 6. The effect of PS on cell prolifera tion within the hippocampal $D G$ at an ayge of 6 months. Shown are the number of BrdU-positive cells (expressed as \% of control). Bars represent means + 5. E.M. $(\mathrm{C}$ - $1=10 ; \mathrm{PS}: \mathrm{n}=9)$. No difference was observed between PS and control offspring. 


\section{Discussion}

In contrast to the majority of other PS-related investigations, the present study suggests that under certain circumstances PS may also have an adaptive effect in relation to stress coping in later life. Compared to control offspring, PS Fischer 344 rats performed relatively better, i.e., they were less anxious, in both the open field and home cage emergence task after a subsequent exposure to stress. Of note, all animals seemed to be more anxious at an age of 6 months. In addition, whereas PS animals initially exhibited more depression-related behavior, as measured using the forced swim test, this normalized after the subsequent exposure to stress.

PS is known to affect HPA axis (re-) activity in offspring, most likely by means of an enhanced release of maternal and placental stress hormones such as corticotropin-releasing factor (CRF) and cortisol/corticosterone, which enter the fetal circulation and affect fetal development (Weinstock, 2001, Huizink et al., 2004). Though the majority of PS-related investigations indicate that PS offspring are more responsive to stress (see review by Huizink et al., 2004), the present study suggests the opposite. PS Fischer 344 rats seem to perform relatively better in the anxiety-related tasks after the subsequent exposure to stress. In a previous study we reported that adult PS Fischer 344 rats which were subjected to intensive behavioral testing showed lower corticosterone levels after 20 minutes of restraint stress (Van den Hove et al., 2005). Taken together, these data suggest that PS may also have a relatively adaptive effect in relation to stress coping.

Genetic factors are likely to play a key role in this respect. Fischer 344 rats are considered to be relatively hyperresponsive to stress and to be more susceptible to a depressive-like state (Izumi et al., 1997, Stohr et al., 1998, Van den Hove et al., 2005). For instance, they are known for their increased CRF, adrenocorticotropic hormone (ACTH), and corticosterone release in response to a variety of stressful stimuli like open field and forced swim test exposure (Glowa et al., 1992, Sternberg et al., 1992). Considering the pivotal role of the HPA axis in the pathophysiology of PS-related disorders and its innate increased responsiveness in Fischer 344 rats, the HPA axis is likely to play an important role in the observed differences between control and PS Fischer 344 rats. However, the exact mechanisms behind the observed differences are still not clear. Evidently, the discrepancy between these observations and those in other PS-related studies stresses the significance of choice of strain in stress-related investigations.

According to the "predictive adaptive response' (PAR) hypothesis proposed recently (Gluckman and Hanson, 2004c, Gluckman and Hanson, 2004b), a growing fetus in the uterus tries to predict the environment it is likely to live in after birth -based upon mutritional and hormonal cues it receives from its mother - in order to give it an optimal chance of survival in adulthood. In doing so, the fetus adjusts its physiology, using developmentally plastic processes, based upon the current and therefore predicted conditions, (Gluckman and Hanson, $2004 \mathrm{c}$, Gluckman and Hanson, 2004b). If, however, the predicted and the actual environment later in life do not match, this is thought to lead to an increased risk of disease in later life. 
The fetal origims of adult disease" concept states that the risk of disease in adulthood partly depends upon variations in the prenatal environment (Barker, 1995), Fetal undernutrition, for example; resulting in impaired fetal growth and reduced birth weight, predisposes indwiduals to the development of e.g. cardiovascular disease and non-insulin-dependent (or type 2) diabetes mellitus in later life (Curhan et al., 1996. Barker et al., 2002). In wew of the PAR hypothesis, the relation between birth weight and disease risk in adulthood may be explained by a mismatch in pre- and postnatal nutritional status, i.e., fetal undernutrition and postnatal (western) high calorie, high fat diets (Gluckman and Hanson, 2004c). Of note, the 'fetal origins of adult disease' hypothesis only covers part of the PAR concept, i.e., a 'deprived' prenatal vs. a 'rich' postnatal environment.

In the present study, pups of dams exposed to stress during pregnancy weighed less at birth compared to control offspring. This impaired fetal growth may be explained by a reduced intake of food and water and/or an impaired conversion of dietary calories into maternal and fetal weight gain seen in reaction to stress (Ward and Wainwright, 1988, Hobel and Culhane, 2003). In addition, the placental transfer of maternal stress hormones, such. as CRF and corticosterone, and a reduction in uteroplacental blood flow, both of which are commonly observed in pregnancy stress, may affect fetal growth (Hobel and Culhane, 2003, Huizink et al., 2004). Though nutrition has neceived most focus, the PAR model may also be interpreted in a broader perspective, as already suggested by Gluckman and Hanson (2004a, 2004c). According to this concept, PS offspring should be able to better cope with stress in later life as compared to individuals that developed under "normal' prenatal conditions.

If we evaluate the data from both our previous behavioral study (Van den Hove et al., 2005) and the present investigation in light of the PAR concept, i.e., in terms of match and mismatch between pre- and postnatal conditions, we see a high degree of similarity with the hypothesized model. Whereas in the previous investigation PS rats that were left undisturbed after birth were more anxious at an age of 6 months as compared to controls, they responded less to stress after intensive behavioral testing with lower corticosterone levels following 20 minutes of restraint. Moreover, in the present study, PS rats initially performed worse in both anxiety-related tasks at an age of 2 months and relatively better after a subsequent exposure to stress as compared to control offspring. Finally, the significant effect found in the forced swim test at 2 months of age, i.e., more immobility after PS, disappeared after the subsequent exposure to stress. This latter finding may however also be age-related as we did not observe a difference between PS and control offspring in this specific task at an age of 6 months in our previous study (Van den Hove et al., 2005). Alternatively again, intensive behavioral testing may have played an important role. Altogether, these parallels suggest that the PAR hypothesis might provide a suitable explanation for the observed differences between PS and control rats in these 2 studies.

Recently, PS has also been shown to be able to reduce the process of neurogenesis within the hippocampal DG of adult rats (Lemaire et al.,2000, Koo et al., 2003) and juvenile nonhuman primates (Coe et al., 2003). Reduced neurogenesis within the adult DG has been linked. to the pathogenesis of depression (Duman et al, 2000, Jacobs et al, 2000), whereas the be- 
havioral effects of chronic antidepressants seem to be linked to the formation of new neurons in this brain region (Duman et al., 2001, Santarelli et al., 2003).

In the present study no difference between groups in the degree of cell proliferation within the hippocampal DG of male Fischer 344 rats was observed, which is in line with a previous study by our group (Van den Hove et al, 2005). Both the subsequent exposure to stress as well as the intensive behavioral testing acting upon a stress-sensitive genetic background may have played an important role in this respect. On the other hand, in line with these observations, Schmitz and colleagues (2002) did not find a reduced number of granule cells in the hippocampus of adult male Long-Evans rats after prenatal restraint stress, whereas female rats were affected in their study. Thus, gender differences might also play an important role. This awaits further research though.

In conclusion, the present data provide further evidence for the idea that PS, dependent upon the genetic background and history, may also have adaptive properties. Further, the PAR hypothesis appears to provide a suitable explanation for the observed differences between PS and control Fischer 344 rats. Finally, we once again underline the importance of choice of strain in stress-related investigations.

\section{References}

Barker, D. J., 1995. The fetal origins of adult disease. Proc R Soc Lond B Biol Sci. 262, 37-43.

Barker, D. J., Eriksson, J. G., Forsen, T. and Osmond, C., 2002 . Fetal origins of adult disease: strength of effects and biological basis. Int J Epidemiol. 31, 1235-1239.

Cameron, H. A, and McKay, R. D., 2001. Adult neurogenesis produces a large pool of new granule cells in the dentate gyrus. I Comp Neurol. 435, 406-417.

Chapman, R. H. and Stern, J. M., 1978. Maternal stress and pituitary-adrenal manipulations during pregnancy in rats: effects on morphology and sexual behavior of male offspring. I Comp Physiol Psychol. 92, 1074-1083.

Coe, C. L. Kramer, M., Czeh, B., Gould, E., Reeves, A. 1., Kirschbaum, C. and Fuchs, E., 2003. Prenatal stress diminishes neurogenesis in the dentate gyrus of juvenile rhesus monkeys. Biol Psychiatry. 54, 1025-1034.

Curhan, G. C., Willett, W. C., Rimm, E. B., Spiegelman, D., Ascherio, A. L. and Stampfer, M. J., 1996. Birth weight and adult typertension, diabetes mellitus, and obesity in US men. Circulation. 94, 3246-3250.

Duman, R. S., Malberg, J., Nakagawa, S. and D'Sa, C., 2000. Neuronal plasticity and survival in mood disorders. Biol Psychiatry $48,732-739$.

Duman, R. S., Nakagawa, S. and Malberg, I., 2001. Regulation of adult neurogenesis by antidepressant treatment. Neuropsychopharmacology. 25, 836-844.

Glowa, J. R., Stemberg, E. M. and Gold, P. W., 1992. Differential behavioral response in LEW/N and F344/N rats: effects of corticotropin releasing hormone. Prog Neuropsychopharmacol Biol Psychiatry. 16, 549-560.

Gluckman, P. D. and Hanson, M.A., 2004a. Developnental origins of disease paradigm: a mechanistic and evolutionary perspective. Pediatr Res. 56, 311-317.

Gluckman, P. D. and Hanson, M.A., 2004b. The developmental origins of the metabolic syndrome. Trends Endocrinol Metab, 15, 183-187.

Gluckman, P. D. and Hanson, M. A., 2004c. Living with the past: evolution, development, and patterns of disease. Science. $305,1733-1736$.

Hobel, C. and Culhane, I., 2003. Role of psychosocial and nutritional stress on poor pregnancy outcome. I Nutr. 133, $17095 \cdot 17175$

Huizink, A. C., Mulder, E. J. and Buitelaar, I. K., 2004. Prenatal stress and risk for psychopathology: specific effects or induction of general susceptibility? Psychol Bull, 130, 115-142. 


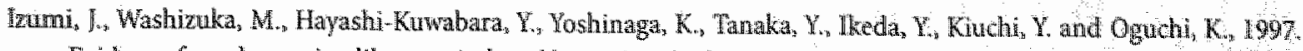
Evidence for depressive-like state induced by repeated saline injections in Fischer 344 rats phamacol Biodhem Behaw. $57,883-888$.

Jacobs, B. L, Prag, H. and Gage, F. H. 2000. Adul brain neurogenesis and psychatry. a novel theory of depression. Mot Psychiatiry. $5,262-269$.

Koo, I. W, Park C. H., Choi, S. H, Km, N. J. Kim, H. S, Choe, I. C. and Suh, Y. H., 2003. The postnatal environment can counteract prenatal effects on cognitive ability, cell proliferation, and symaptic protein expression. Faseb $) .17$, $1556-1558$.

Lemaire, V., Koeh, M., Le Moal, M. and Abrous, D. N., 2000. Prenatal stress produces learning deficits associatted with an inhibition of aeurogenesis in the hippocampus. Proc Natl Acad Sci U S A. 97, 11032-11037.

Ossenkopp; K. P. and Mazmanian, D. S, 1985. The measurement and integration of behavional variables: aggregation and complexity as important issues. Neurobehav Toxicol Teratol 7, 95-100.

Porsolt, R. D.,Anton, $G_{\text {. }}$ Blavet, N. and Jalfe, M., 1978. Behavioural despair in ratts: a new model sensitive to antidepressant treatments. Eur / Pharmacol. 47, 379-391.

Prickaerts, I., Koopmans, G., Blokland, A. and Scheepens, A., 2004. Learning and adult nevrogenesis: survival with or without proliferation? Neurobiol Learn Mem. $81,1-11$.

Prickaerts, J., Raajmakers, W. and Blokland, A., 1996 . Effects of myocandial infarction and captopril therapy on anxiety-related behaviors in the rat. Physiol Behav, 60,43-50.

Santarelli, L., Saxe, M., Gross, C., Surget, A., Battaglia, F. Dulawa, S, Weisstaub, N., Lee, J., Duman, R., Arancio, O. Belzung, C. and Hen, R., 2003. Requirement of hippocampal neurogenesis for the behavioral effects of antidepres. sants. Science. 301,805-809.

Schmitz, C., Rhodes, M.E., Bludau, M., Kaplan, S., Ong, P., Uefing, I., Vehoff, I., Korr, H. and Frye, C. A., 2002. Depression: reduced number of granule cells in the hippocampus of femalle, but not male, rats due to prenatal restraint stress. Mol Psychiatry, $7,810-813$.

Sternberg, E. M., Glowa, Jn R., Smith, M. A, Calogero, A. E., Listwak, S. I., Aksentijevich, S., Chrousos, G. P. Wilder, R. L. and Gold, P.W, 1992. Corticotropin releasing hormone related behavioral and neuroendocrine responses to stress in Lewis and Fischer rats. Brain Res. 570, 54-60.

Stohr, T., Schulte Wermeling, D, Szuran, T, Pliska, V., Domeney, A., Welzl, H, Weiner, I. and Feldon, J., 1998. Diflerential. effects of prenatal stress in two inbred strains of rats. Pharmacol Biochen Behav. 59, 799-805.

Stulon, J., Demey-Ponsart, L, Beauduin, F. and Sodoyez, J. C., 1978. Radioimnaunoassay of corticosterone, cortisol and cortisone: their application to human cord and maternal plasma. I Steroid Biochem. 9,671-676.

Van den Hove, D. L., Blanco C. E. Aendekerk, B., Desbonnet, L., Bruschettini, M., Steimbusch, H. P., Prickaerts, J. and Steinbusch, H. W., 2005. Prenatal restraint stress and long-term affective consequences. Dev Weurosci. 27, 313320.

Ward, G. R. and Wanwright, P.E, 1988. Reductions in maternal food and water intake account for prenatal stress effects on neurobehavioral dewelopment in B6D2F2 mice. Physiology \& Behawior. 44,781-786.

Ward, L. L and Weisz, J., 1984. Differential effects of maternal stress on circulating levels of corticosterone, progesterone, and testosterone in male and female rat fetuses and their mothers. Endocrinology. 114, 1635-1644.

Weinstock, M., 2001. Alterations induced by gestational stress in brain morphology and behaviout of the oftspring. Prog Neurobiol. 65,427-451. 


\section{Chapter 7}

\section{Prenatal stress produces anxiety- and depression-related behavior particularly in male Sprague-Dawley rats}

Van den Hove DLA ${ }^{1 / 2}$, Prickaerts $\Gamma^{2}$, Steinbusch $\mathrm{HWM}^{2}$, Van Donkelaar $\mathrm{EL}^{2}$, Bruschettini $\mathrm{M}^{2}$, Scheepens $\mathrm{A}^{1 / 3}$, Blanco $\mathrm{CE}^{1}$

'Department of Pediatrics, Maastricht Uniwersity,

Maastricht, The Netherlands.

Department of Psychiatry and Neuropsychology, Maastricht: University.

Maastricht, "The Netherlands.

${ }^{3}$ Liggins Institute, University of Auckland, Auckland, New Zealand.

In Preparation 


\section{Abstract}

Adverse life events experienced by the pregnant mother may be reflected upon the develloping fetus, predisposing prenatally stressed offspring to the development of psychopathology in later life. In the present study we examined the effects of prenatal stress on anxiety-and depression-related behavior in both male and female Sprague-Dawley rats at 4 months of age. Prenatal stress was associated with a clear increase in anxiety-related behavior in male, but not female offspring, as evaluated in the elevated zero maze and the home cage emergence test. Likewise, depression-related behavior in the forced swim test was increased in male prenatally stressed rats only. Male prenatally stressed offspring further showed increased basal plasma corticosterone levels, whereas both prenatally stressed males and females failed to show an adequate response to stress with lower stress-induced corticosterone levels as compared to controls. Female hippocampal weight was relatively higher after prenatal stress, which may explain the absence of clear behavioral effects of prenatal stress in this gender. In addition, male birth weight was a predictive marker both for performance in the forced swim test, as well as for plasma corticosterone levels in adulthood.

In conclusion, prenatal stress resulted in increased anxiety-and depression-related behavior particularly in male Sprague-Dawley rats.

\section{Introduction}

Prenatal maternal stress has been related to various learning, behavioral, and mood disorders like anxiety and depression in later life (Weinstock, 2001, Huizink et al., 2004). In rats, prenatal stress. (PS) has been associated with disturbances in the hypothalamo-pituitary-adrenal (HPA) axis (see review by Weinstock, 2005), paradoxical sleep alterations (Dugovic et $\mathrm{al}_{*}$, 1999, Rao et al., 1999), and increased anxiety- and depression-related behavior (Fride and Weinstock, 1988, Wakshlak and Weinstock, 1990, Vallee et al, 1997, Secoli and Teixeira, 1998, Griffin et al., 2003, Rimondini et al., 2003, Dickerson et al., 2005, Estanislau and Morato, 2005). In addition, anxiety-and depression-related effects of PS could be counteracted by treating PS offspring with various kinds of antidepressants (Alonso et al., 1999, Morley-Fletcher et al., 2003a, Morley-Fletcher et al., 2004, Poltyrev et al., 2005). For these reasons, PS in rats may be a suitable animal model for mood disorders.

However, outcome may vary and not all rat strains may be suitable in this respect. In previous investigations by our group using Fischer 344 rats, behavioral effects in PS offspring were not straightforward, as discussed in Chapters 5 and 6 . In the present study we examined the effects of PS in both male and female Sprague-Dawley rats. Adult anxiety-and depression-related behavior was studied using the elevated zero maze test, the home cage emergence test, the forced swim test, and the sucrose intake test. Further, basal and stress-induced activity of the HPA axis was studied. Animals were weighted at birth to determine whether birth weight may be used as a predictive marker for adult performance. 


\section{Experimental procedures}

\section{Animals and procedures}

The animal studies were all approved by the Animal Ethics Board of the University of Maas. tricht, The Netherlands. Acclimatized pregnant normal Sprague-Dawley rats (Charles River, The Netherlands) were used. The animals were housed individually within temperature-controlled environment $\left(21 \pm 1^{\circ} \mathrm{C}\right.$ ) with a $12 \mathrm{hr}$ light/12hr dark cycle (lights on from $7.00-19.00 \mathrm{~h}$ ) and had access to standard rat chow and water ad libitum. Pregnancy was determined by observation of vaginal plugs (embryonic day 0 - E0). Restraint stress was performed daily during the last week of pregnancy (E14-E21). Pregnant female rats ( $n=8$ ) were individually restrained 3 times a day (at approximately $9.00,13.00$, and $17.00 \mathrm{~h}$ ) for 45 minutes in transparent plastic cylinders while at the same time being exposed to bright light (Ward and Weisz, 1984). Control (C) pregnant females $(n=8)$ were left undisturbed in their home cages. Within an hour after the last pup of a litter had been born, pups were individually labeled by means of toe cut, gender (based on anogenital distance) and individual body weights were determined. Only litters of 8 or more pups were included in this study. Litters were culled to 8 pups (if necessary).

At postnatal day 21 (P21), pups were weaned and housed together (2 male or 2 female rats/cage; $n=14$ rats per experimental condition per gender) for further examination. Rats were kept at a reversed day-night cycle from this point onwards (lights on from 17.00-5.00 h). Body weights of the offspring were measured at P0 (birth), P21 (weaning), P60, P90, and P140. Anxiety- and depression-related behavior of the rats was analyzed from P100 onwards. At P150, the animals were killed by quick decapitation, after which the brains were taken out. The prefrontal cortex and hippocampus were dissected out, weighed and quickly snap frozen in liquid nitrogen after which they were stored at $-75^{\circ} \mathrm{C}$ until further analysis. A maximum of 2 male and female pups per litter were examined to prevent litter effects (Chapman and Stern, 1978).

\section{Anxiety- and depression-related behavior}

\section{Elevated Zero Maze test (EZM)}

The EZM introduced by Shepherd and colleagues (1994) consisted of a circular alley (diameter of $100 \mathrm{~cm}$; path width $10 \mathrm{~cm}$ ) made from black plastic material that was transparent for infrared light and elevated $20 \mathrm{~cm}$ above the floor. The maze was divided in four parts, i.e., two opposite open parts and two opposite closed parts with sidewalls $30 \mathrm{~cm}$ height. The open parts had borders with a height of $5 \mathrm{~mm}$ to prevent the rat from stepping down from the apparatus. For the test, the rat was placed into one of the open parts facing the closed part of the apparatus. After five minutes the rat was removed from the apparatus and the maze was cleaned with ethanol and water and dried thoroughly. The movements of the rat were scored automatically under dark conditions with a computerized system using an infrared video 
camera (Ethovision Pro, Noldus, The Netherlands). Time spent in each part of the maze and total distance traveled and were determined.

\section{Home Cage Emergence test (HCE)}

The rat's home cage (opened) was placed in the center of an open field $\left(1 \mathrm{~m}^{2}\right)$ and the rat was allowed to leave its cage via a grid walkway. The latency to emerge from the home cage (ie., four paws on the grid) was scored. If the rat did not emerge from its home cage within $300 \mathrm{sec}$; the session was ended, the home cage was closed again and the rat was given a score of 300 sec. This test was carried out on 3 consecutive days under low light conditions (Prickaerts et al, 1996).

\section{Forced Swimming test (FS)}

In the FS test originally designed by Porsolt and colleagues (1978) four cylindrical glass tanks $\left(50 \mathrm{~cm}\right.$ tall, $20 \mathrm{~cm}$ in diameter) were filled to a height of $30 \mathrm{~cm}$ with $25^{\circ} \mathrm{C}$ water. The movements of the rat were scored automatically with a computerized system (Ethovision Pro, Noldus, The Netherlands) during a 5 min session under low light conditions. Scored were "immobility which reflects no movement at all and/or minor movements necessary to keep the nose above the water) and 'strong mobility' reflecting 'escape behavior' (e.g. climbing against the walls and diving). Settings within Ethovision were adjusted based on manually recorded sessions and were attuned for each gender separately (immobility/mobility threshold: 12 and 20; mobility/strong mobility threshold: 16.5 and 23.9 for males and females, respectively).

\section{Sucrose Intake test (SI)}

Rats were allowed to acclimatize to a $1 \%$ sucrose solution 2 days before the actual experiment was started. At 5.00 h on the test day just before the start of the dark phase, rats were deprived of food and water for $14 \mathrm{~h}$. At $19.00 \mathrm{~h}$, i.e., $2 \mathrm{~h}$ after the lights had turned on, a $1 \%$ sucrose solution was offered. After 1 hour sucrose consumption was measured (Willner et al., 1992). Intake was expressed as $\mathrm{ml} 1 \%$ sucrose $/ \mathrm{kg}$ body weight consumed.

\section{Corticosterone response and radioimmuno assay}

To test the responsiveness of the HPA axis the rats were individually placed in a type II (mouse) cage filled with $500 \mathrm{ml} 25^{\circ} \mathrm{C}$ water. Experiments were performed in an isolated room between 13.00 and 15.00 h. Immediately after taking the rat from its home cage a first blood sample was collected via a saphenous vein puncture representing the basal corticosterone level. Immediately after this first sample was taken the rat was put in the water cage for 20 minutes after which a second blood sample was taken. Afterwards, it was returned to their home cage and left undisturbed for 40 minutes after which a third and final blood sample was taken. Blood samples were kept on ice and subsequently centrifuged at $5000 \mathrm{rpm}$ for $10 \mathrm{~min}$ utes at $4^{\circ} \mathrm{C}$ after which the plasma was frozen down to $-75^{\circ} \mathrm{C}$ for subsequent determination (in duplicate). For this purpose, $50 \mathrm{ml}$ of plasma was extracted with $3 \mathrm{ml}$ dichloromethane 
and vortexed for 1 minute. Corticosterone was subsequently measured directy on 1 ml dried

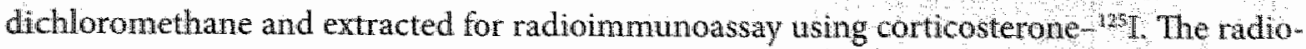
immunological reaction was performed overnight at $4^{\circ} \mathrm{C}$, after which a second antibody system was used to separate bound and unbound steroid as previously described in detail (Sulon et al., 1978).

\section{Statistics}

Body weights of both dams and offspring over time were analyzed using a repeated measurements ANOVA (experimental condition $x$ time) and also independently at the various time points using a $t$-test. Because of expected sex and experimental condition interactions, parameters studied in the offspring were analyzed for each gender separately using a $t$-test. For the home cage emergence test, the data were not normally distributed since sonne rats remained in the home cage for the entire observation period. Therefore, these data were transformed to rank scores, after which average escape latencies were compared between groups. Plasma corticosterone levels were analyzed by a repeated measures ANOVA (experimental condition $x$ time) and also independently at the different time points using a t-test. Corticosterone values were $\mathrm{In}$ transformed to normality. Correlation analysis was performed using Pearson's correlation coefficient $\left(r_{p}\right)$. Of note, sucrose intake was not included in correlation analysis, since consumption was examined per cage (two rats together) and not for each rat individu. ally (to avoid stress related to separate housing). Statistical significance was assumed to exist at $\mathrm{P}<0.05$. All statistics were carried out using SPSS software version 12,0.1 (SPSS Inc, USA).

\section{Results}

\section{Dam weight}

Dam weight over time is depicted in Table 1 . A within-subjects effect was observed for time $(\mathbb{P}<0.001)$. Further, over time, an effect of maternal stress was observed $(P=0.027)$. At E21 stressed dams had lower body weights as compared to controls (stress effect: $-8.9 \%, \mathrm{P}=0.002$ ). At P21 dams from the PS group still showed reduced body weight as compared to controls (stress effect: $-9.2 \%, \mathrm{P}=0.031$ ).

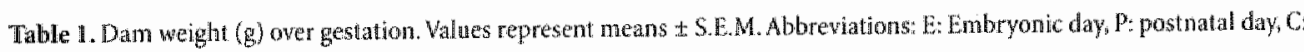
nontrol, PS: prenatal stress group; * $\mathrm{p}<0.05{ }^{*} * \mathrm{p}<0.01(\mathrm{t}-\mathrm{tes})$

\begin{tabular}{cccc} 
Group & E0 & E21 & P21 \\
\hline C & $270.7 \pm 3.7$ & $431.4 \pm 6.1$ & $349.9 \pm 3.0$ \\
PS & $268.3 \pm 3.1$ & $393.0 \pm 7.5^{* *}$ & $317.4 \pm 11.3^{*}$
\end{tabular}




\section{Litter size, pre-weaning mortality}

No differences were observed in litter size (13.6 \pm 0.9 and $14.1 \pm 0.5$ pups per litter for control and PS, respectively) or pre-weaning mortality (no pups died in either group after litters had been culled to 8 pups).

\section{Body weight}

The effect of PS on offspring body weight is shown in Table 2. PS male rats weighted less at birth as compared to controls (PS effect: $-12.9 \%, \mathrm{P}<0.001$ ). Similarly, PS females were lighter than control females (PS effect: $-11.6 \%, P=0.001$ ). After P21 the difference between PS and control rats seemed to fade, whereas at P140, following the behavioral tests body weights of both groups diverged once more (Table 2).

Table 2. Ofispring body weight (g) ower time. Values represent means I S.E.M. Abbreviations: P: postnatal day, C: control, PS: prenatal stress; $* 00.05 * * 0.01, * * \mathbb{P}<0.001, * 0.05<\mathrm{P}<0.10$ (t-test).

\begin{tabular}{ccccccc} 
Gender & Group & P0 & P21 & P60 & P90 & P140 \\
\hline \multirow{2}{*}{ Males } & C & $7.0 \pm 0.2$ & $63.8 \pm 1.1$ & $356.0 \pm 9.6$ & $452.0 \pm 12.2$ & $539.3 \pm 13.8$ \\
& PS & $6.1 \pm 0.2^{* * *}$ & $55.8 \pm 1.1^{* * *}$ & $348.2 \pm 5.6$ & $438.6 \pm 9.4$ & $508.6 \pm 9.7^{*}$ \\
\cline { 2 - 7 } Females & C & $6.6 \pm 0.1$ & $60.5 \pm 1.2$ & $226.7 \pm 6.4$ & $275.9 \pm 9.4$ & $304.4 \pm 8.9$ \\
& PS & $5.9 \pm 0.2^{* * *}$ & $55.2 \pm 1.1^{* *}$ & $214.4 \pm 2.0^{*}$ & $259.3 \pm 5.0$ & $276.4 \pm 4.1^{* *}$
\end{tabular}

\section{Anxiety- and depression-related behavior}

\section{$E Z M$}

Time spent in the open and closed arms of EZM as well as distance covered in the EZM are depicted in Figure 1. PS male rats spent less time in the open and more time in the closed arms of the EZM as compared to control males (PS effect: $-34.4 \%, \mathrm{p}=0.011$ ). In addition, male PS rats covered less distance during the $5 \mathrm{~min}$ trial as compared to control males (PS effect: $-25.3 \%, \mathrm{P}=0.035$ ). No differences were observed between PS and control females.

\section{HCE}

The average escape latencies in the home cage emergence test are shown in Figure 2. Over the three trials, male PS rats took more time to leave the home cage as compared to controls (PS effect: $25.3 \%, \mathrm{P}=0.037$ ). A similar pattern was observed in female offspring, though this did not reach statistical significance (PS effect: $33.7 \%, \mathrm{P}=0.095$ ). 
患

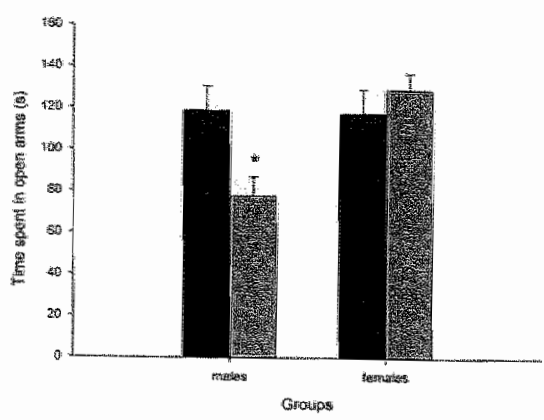

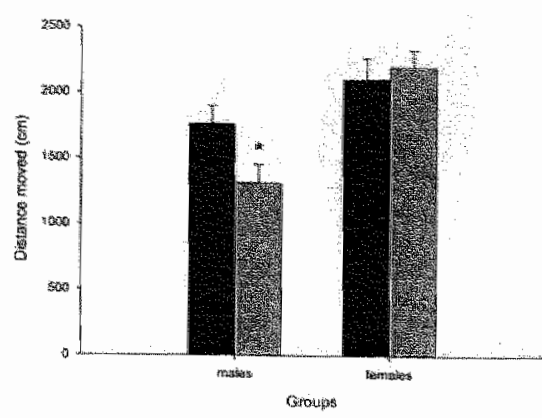

Figure 1. Tinse (s) spent in the open arms of (A) and total distance moved in (B) the Elevated Zero Mate (BizM) test Values Fepresent means + S.E.M. Male prenatally stressed (PS) rats spent less time in. the open arms of the EZM as compared to control (C) males. Further, male PS rats covered less distance during the 5 min trial as compared to control males. No differences were observed between PS and control females. *P<0.05 (t-test).

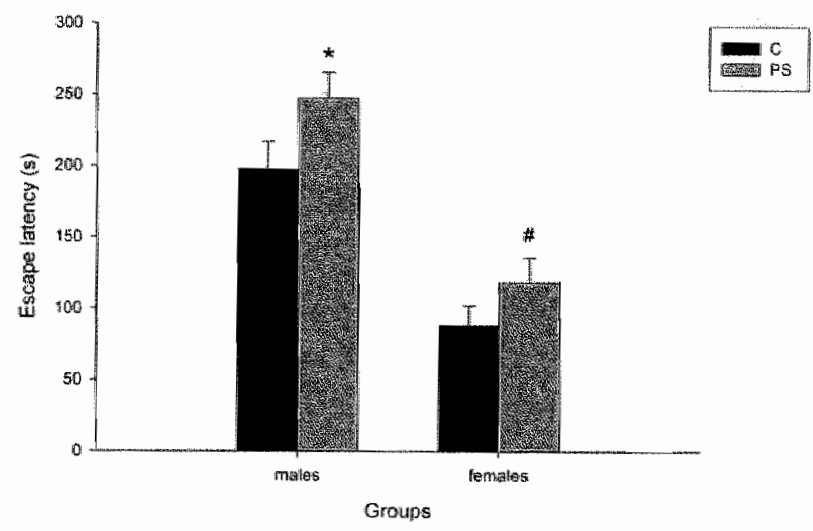

Figure 2. Average escape latencies (s) in the Home Cage fimergence (HCE) test. Valtes represent means $+5 \mathrm{EM}$. Oke the Whee trials, male prenatally stressed (PS) rats took more time to leawe the home adge as compared to controls (C). A similar

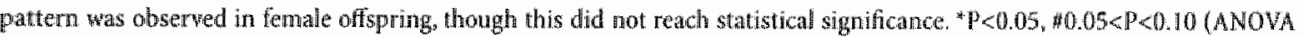
basted on ranks).

\section{FS}

Results from the FS are shown in Figure 3. Whereas no differences between groups were observed in time spent immobile, PS in males resulted in less strong mobility as compared to controls (PS effect: $-21.7 \%, \mathrm{P}=0.049$ ). No differences in were obserwed in females in immobility or strong mobility. 

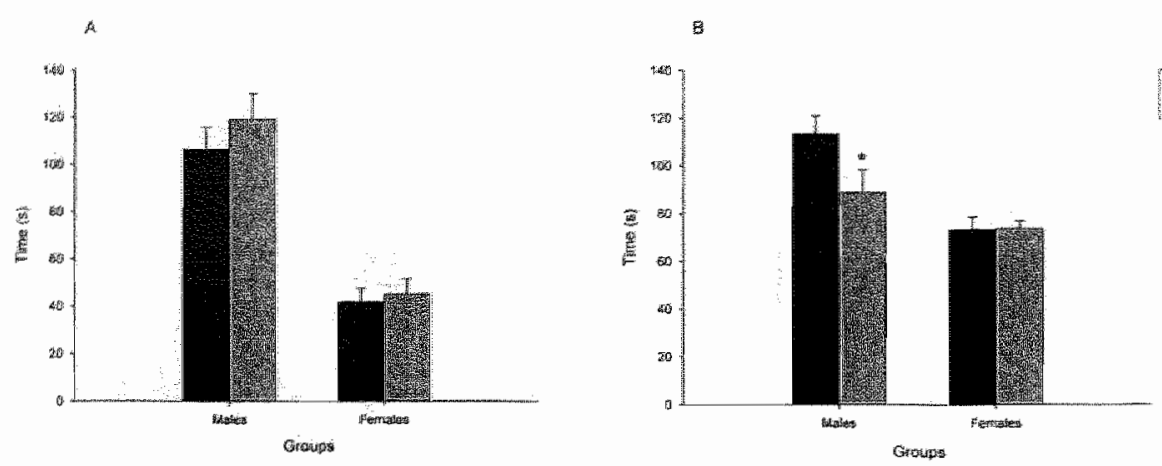

Figure 3. Immobility (A) and strong mobility (B) in the Forced Swim (FS) test Values represent means (s) + S.E.M. Whereas no differences between grotps were observed in time spent immobile, prenatal stress (PS) in malles resulted in less strong mobilty as compared to controls (C). No differerices in were observed in females, ${ }^{*}<0.05$ (t-test).

\section{SI}

No differences in SI were observed between PS and control offspring (Table 3).

Tablle 3. Sucrose Intake (milkg body weight). Wallues represent means 1 S.E.M. Abbreviations: C: control, PS: prenatal stress. No significant differences between experimental groups were observed.

\begin{tabular}{ccc} 
Gender & Group & Sucrose Intake \\
\hline \multirow{2}{*}{ Males } & C & $39.5 \pm 4.7$ \\
& PS & $45.1 \pm 5.4$ \\
\cline { 2 - 3 } Females & C & $56.6 \pm 6.8$ \\
& PS & $70.1 \pm 7.6$
\end{tabular}

\section{Corticosterone response}

Plasma corticosterone levels under basal conditions, immediately after 20 min of restraint stress, or 40 minutes after being placed back into the home cage, are depicted in Figure 4.

Within males, a significant within-subjects effect was observed both for time $(P<0.001)$ and experimental group $\times$ time $(P=0.002)$. Over time, a significant effect of $P S$ was observed $(\mathrm{P}=0.036)$. Male PS rats showed higher basal plasma corticosterone levels as compared to controls (PS effect: $108.7 \%, \mathrm{P}=0.002$ ). Stress - induced corticosterone levels were again lower in male PS rats (PS effect: $-21.9 \%, P=0.004$ ). No difference between groups was observed after 40 minutes of recovery.

In females, a significant within-subjects effect was observed time only $(\mathrm{P}<0.001)$ Further, only stress-induced plasma corticosterone levels differed between groups, with PS females showing lower corticosterone levels as compared to controls (PS effect: $-21.6 \%, \mathrm{P}=0.039$ ). 


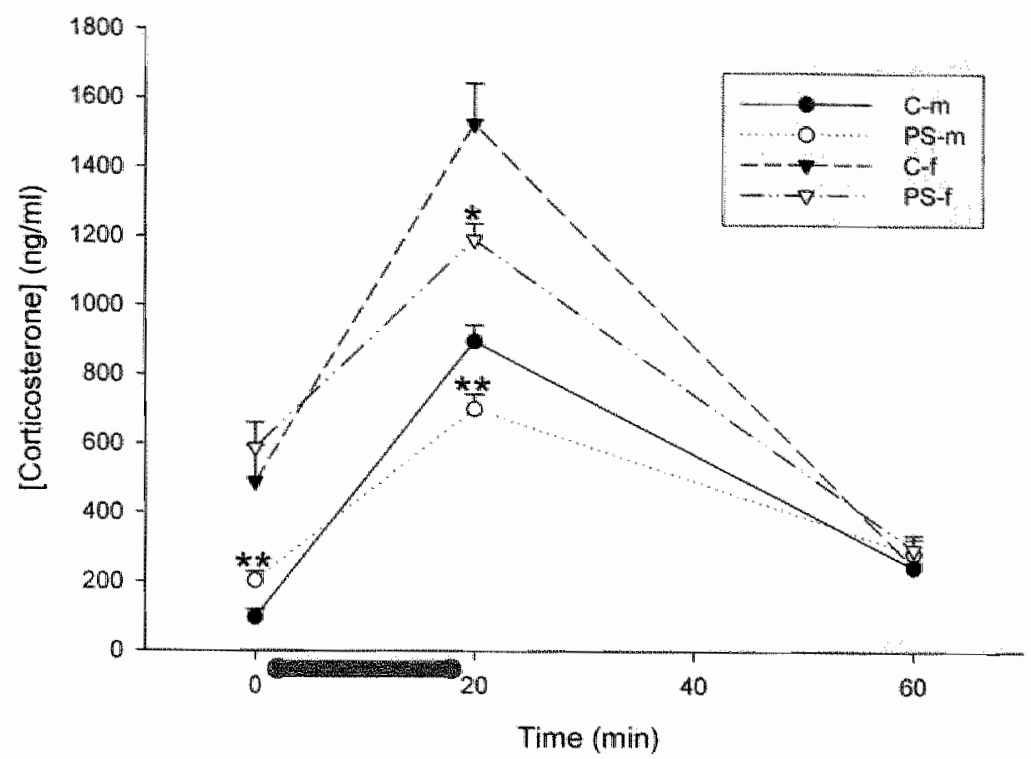

Figure 4. Stress-induced corticosterone secretion. Values represent means (s) + S.E.M. ${ }^{*}$ P 60.05 (one-Way ANOWA). Male prenatally stressed (PS) rats showed higher basal plasma corticosterone levels as compared to controls (C). Stress-induced conticosterone levels the grey bar represents a 20 min period of stress) were lower in both male and female PS offspring. No difference between groups was observed 40 minutes after placing the animals back into their home cage, $* 00,05, * *<<0.01$ (t-lest: PS versus control).

\section{Brain region weights}

Weight data of the prefrontal cortex and hippocampus are listed in Table 4. Relative hippocampal weight was higher in PS females as compared to control females (PS effect: $13.2 \%$, $P=0.015)$. No difference between groups was observed in any other case.

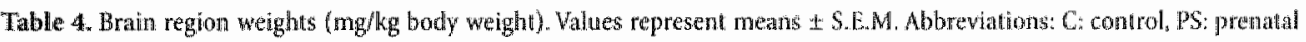
stress, PFC: prefrontal cortex, HIP: hippocampus; * P<0.05 (t-test).

\begin{tabular}{cccc} 
Gender & Group & PFC & HIP \\
\hline \multirow{2}{*}{ Males } & C & $79.2 \pm 4.7$ & $302.9 \pm 9.8$ \\
& PS & $95.4 \pm 6.4$ & $299.4 \pm 9.8$ \\
\cline { 2 - 4 } Females & $C$ & $147.1 \pm 5.6$ & $485.9 \pm 14.5$ \\
& PS & $164.6 \pm 15.1$ & $550.1 \pm 19.8^{*}$
\end{tabular}




\section{Correlations}

Correlations between the different parameters are depicted in Table 5 .

Table 5, Correlations between the different parameters studied in males (A) and females (B). Depicted are Pearson's correlathon woeffients (i) representing the associations between the warious Abbreviations: BW: birth weight, EZM-OA: elewated zeromaze; time spent in open arms, EZM-MD: elevated zero maze; distance moved, HCE-EL home cage emergence; escape latency. FS-M forced swim test; immability, IS-SM: forced swim test; strong mobility, CORT-B: basal plasma corticasterone lewels, CoxT-S: stress-induced plasma corticosterane levels, CORT-R: plasma corticosterone levels after 40 minutes of recor-

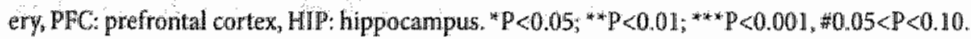

\section{A: males}

BW EZM-OAEZMWDM HCE-EL FS-IM FS-SM CORT-B CORT-S CORT-R PFC HIP

\begin{tabular}{|c|c|c|c|c|c|c|c|c|c|c|c|}
\hline BW & & - & - & - & - & $.48^{*}$ & $-46^{*}$ & $.55^{* * *}$ & $-.35^{p}$ & - & - \\
\hline$E Z M-O A$ & - & & $.45^{\circ}$ & $.48^{15}$ & - & - & - & 48 & - & - & - \\
\hline WZM-DM & - & $.45^{*}$ & & $-35^{m}$ & - & - & - & $.59^{* *}$ & - & - & - \\
\hline $\mathrm{HCL}-\mathrm{BL}$ & - & $-.48^{*}$ & $-.35^{\circ}$ & & - & - & - & $-466^{*}$ & - & - & - \\
\hline FS-IM & - & - & - & - & & $-.72 * *$ & - & - & $.38^{\circ}$ & - & - \\
\hline FS SM & $48 *$ & - & - & - & $-.72^{* * *}$ & & $.43^{*}$ & $399 \times$ & $-.34^{*}$ & - & 42 \\
\hline $\operatorname{COR}^{\alpha}-1 B$ & $-.46^{x}$ & - & - & - & - & $-.43^{\text {*n }}$ & & $-.39 *$ & - & - & - \\
\hline CORT $-S$ & $.55^{* *}$ & $.48^{*}$ & $.59 * *$ & $-46^{x}$ & - & $.39^{*}$ & $-.39^{\circ}$ & & - & - & - \\
\hline CORT-R & $-35^{*}$ & - & - & - & $.38^{i}$ & $-.34^{x}$ & - & - & & - & - \\
\hline $\mathrm{PHC}$ & - & - & - & - & - & - & - & - & - & & $.45^{*}$ \\
\hline HIP & - & - & - & - & - & $42^{*}$ & - & - & - & $.45^{\text {pi }}$ & \\
\hline
\end{tabular}

\section{B: females}

BW IZZM-OAEZM-DM HCE-EL ES-IM RS-SM CORT-B CORT-S CORT-R PFC HP

\begin{tabular}{|c|c|c|c|c|c|c|c|c|c|c|c|}
\hline$B W$ & & - & $-33^{\prime \prime}$ & - & - & - & $\ldots$ & - & - & - & - \\
\hline $\mathrm{ELM}-O \mathrm{~A}$ & - & & $36^{*}$ & $\cdots$ & - & - & - & - & - & - & - \\
\hline EZM-DM & $-33^{1}$ & $36^{\prime}$ & & - & - & - & - & - & - & - & - \\
\hline HCE-EL & - & - & - & & - & - & - & - & - & - & - \\
\hline FS M & - & - & - & - & & $-59^{* * *}$ & - & - & - & - & - \\
\hline FS-SM & $\cdots$ & - & - & - & $-59 *$ & & - & - & - & - & - \\
\hline CORT-B & - & - & - & - & - & - & & - & - & - & - \\
\hline CORTS & - & - & - & - & - & - & - & & - & $-m$ & - \\
\hline CORT $R$ & - & - & - & - & - & - & - & - & & - & - \\
\hline $\mathrm{PFC}$ & - & - & - & - & - & $\cdots$ & $\cdots$ & - & - & & - \\
\hline HIP & - & - & - & - & - & - & - & - & - & - & \\
\hline
\end{tabular}




\section{Discussion}

In the present study, PS was associated with impaired fetal growth in both genders. Further, PS resulted in a significant increase in anxiety- and depression-related behavior in male Sprague-Dawley offspring. Behavior in females was largely unaffected. In addition, only male PS offspring showed clear increased basal plasma corticosterone levels, whereas PS offspring from both genders failed to show an adequate response to a $20 \mathrm{~min}$ period of stress. Further; male birth weight was a predictive marker both for depression-related behavior in the FS,

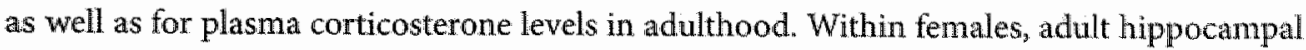
weight was relatively increased after PS.

\section{Prenatal maternal stress as an animal model for depression}

Previous research on PS within our group using Fischer 344 rats did not yield clear-cut results regarding anxiety-and depression-related behavior (see Chapters 5, 6, and 9). Since rats from the Fischer 344 strain are relatively susceptible to a depressive-like state, control offspring may reach this state easily as well (Sternberg et al., 1992, Dhabhar et al., 1997, Izumi et al., 1997). For this reason, in this investigation, Sprague-Dawley rats were selected. In this latter rat strain behavioral effects of PS are both well-characterized and persistent (Dugovic et al., 1999, Morley-Fletcher et al., 2003a, Morley-Fletcher et al., 2003b, Morley-Fletcher et al., 2004). Likewise, in the present study, PS was associated with an increase in anxiety-and depression-related behavior in male Sprague-Dawley offspring. Moreover, depression-related effects of PS were counteracted in this rat strain by treating offspring with various kinds of antidepressants (Alonso et al., 1999, Morley-Fletcher et al., 2003a, Morley-Fletcher et al.s 2004, Poltyrev et al., 2005). Altogether, this suggests that PS in male Sprague-Dawley rats may be a suitable animal model of depression.

\section{Sucrose intake}

No effects were observed in the SI test, which has been designed to measure loss of interest or pleasure (anhedonia), one of the core symptoms of depression (Willner et al., 1992). Conversely, sucrose consumption tended to be higher in PS offspring as compared to controls. In support of this idea, a comparable study by Jezova and colleagues (2002) demonstrated a tendency to a higher sucrose preference in males prenatally stressed by maternal food restriction. Perhaps increased sugar consumption plays a mediatory role in the relation between prenatal maternal stress associated with fetal undernutrition and e.g. non-insulin-dependent (type 2) diabetes mellitus in later life (Curhan et al., 1996, Barker et al, 2002), as discussed below. Yet, this is purely speculative and awaits further research. 


\section{HPA axis (re-) activity}

Male, but not female, Sprague-Dawley rats of 4 months of age showed significantly elevated basal plasma corticostterone levels after PS. In addition, stress-induced corticosterone secretion was impaired in both genders. Interestingly, the pattern of stress-induced corticosterone secretion was different from that of other studies using the same PS model and rat strain. In a study by Morley-Fletcher and colleagues (2003a) using male Sprague-Dawley rats of 3 months of age no effect of PS on either basal or stress-induced plasma corticosterone levels was found. In that study, however, recovery after 20 minutes of restraint stress was weaker after PS. In two other comparable studies by the same group using male Sprague-Dawley rats of 2 months of age, both stress-induced plasma corticosterone levels as well as levels after recovery were higher in PS animals (Dugovic et al., 1999, Morley-Fletcher et al., 2003b).

An age-dependent relationship between early-life experience, i.e., maternal deprivation, and HPA axis (re-) activity was suggested by De Kloet and Oitzl (2003). Maybe a comparable phenomenon is involved in HPA axis (re-) activity after PS.

We therefore believe that not necessarily HPA axis hyperactivity in particular, but alterations in HPA axis (re-) activity per se, are of importance in PS. Interestingly, within males, stress-induced corticosterone values, which were actually lower after PS, were correlated to performance in the various behavioral tasks.

\section{Birth weight: a suitable predictive marker?}

The 'developmental origins of health and disease' (DOHaD) concept (Gillman, 2005) states that the risk of disease in adulthood partly depends upon variations in the prenatal environment, which is often reflected in body weight at birth, also referred to as the 'Barker' hypothesis (Barker, 1995). Fetal undernutrition, for example, resulting in impaired fetal growth and reduced weight at birth, predisposes individuals to the development of cardiovascular disease and type 2 diabetes mellitus in later life (Curhan et al., 1996, Barker et al., 2002). Further. reduced birth weight has been linked to an increased susceptibility to stress (Nilsson et al., 2001) and depression in later life (Thompson et al., 2001, Gale and Martyn, 2004). Interest. ingly, in the present study, a significant positive correlation between male fetal growth and strong mobility in the FS test was observed. In addition, male birth weight was correlated negatively to basal, and positively to stress-induced plasma corticosterone levels in adulthood. This suggests that male birth weight may be useful as a predictive marker in PS-related investigations.

Of note, the relationship between fetal growth and disease risk in later life reflects the sensitivity of fetal growth to adverse intrauterine influences and does not imply a contributory role of being born small (Gluckman and Hanson, 2004). In this respect, birth weight is a rough integrated measure of many fetal processes and various intrauterine adverse events may have independent effects on fetal growth while in parallel also having long-term pathological consequences. 
The observed reduction in birth weight in PS pups in the present study nay be explained by a reduction in food and water intake and an impared conversion of dietary calones into maternal weight gain as seen in reaction to stress (Ward and Wainwright, 1988, Hobel and Culhane, 2003). In support of this idea, maternal weight gain over gestation was reduced by restraint stress. Further, the transplacental transport of maternal corticotrophin-releasing factor (CRF) and corticosterone, and excess sympatho-adrenal activation resulting in a reduction in uteroplacental blood How, commonly observed in stress during pregnancy, may impair fetal growth (Aghajafari et al., 2002, Hobel and Culhane, 2003, Huizink et al, 2004).

Of note, the difference in weight between PS and C offspring diminished gradually over the first three months of life, whereas behavioral testing made groups diverge again. This may be due to a different reaction to stress related to behavioral testing as illustrated by the altered HPA axis regulation in PS offspring.

In conclusion, the present study shows that prenatal maternal stress in Sprague-Dawley rats is associated with clearly increased anxiety-and depression-related behavior in adult male, but not female offspring. Male PS offspring further showed increased basal plasma corticosterone levels, whereas both PS males and females failed to show an adequate response to stress with lower stress-induced corticosterone levels as compared to controls. Female hippocampal weight was relatively higher after $\mathrm{PS}_{\mathrm{x}}$ which may in one way or another relate to the lack of behavioral effects of PS in this gender. Finally, male birth weight was predictive both for performance in the forced swim test, as well as for plasma corticosterone levels in adulthood, which suggests that birth weight may be useful as a predictive marker in PS-related investigations.

\section{References}

Aghaiafari, F, Murphy, K., Matthews, S., Ohlsson, A., Amankwah, K. and Hannah, M., 2002. Repeated doset of antenatal corticosteroids in animals; as systematic review. An J Obstet Gynecol. 186, 843-849.

Allonso, S. I. Castellano, M. A., Quintero, M. and Nawarro, E., 1999. Action of antidepressant drugg on maternal stressinduced hypoactivity in female rats. Methods Find Exp Clin Pharmacol. 21,291-295.

Barker D. J, 1995. The fetal origins of adult disease. Proc R Soc Lond B Biol Sci. 262, 37-43.

Barker, D. J., Eriksson, I. G., Forsen, T. and Osmond, C., 2002. Fetal origins of adult disease: strength of eftects and biological basis. Int J Epidemiol. 31, 1235-1239.

Chapman, R. H. and Stern, J. M., 1978. Maternal stress and pituitary-adrenal manipulations during pregnancy in rats: effects on morphology and sexual behavior of male offspring. / Comp Physiol Psychol. 92, 1074-1083.

Curhan, G. C., Willett, W. C.. Rimn, E. B., Spiegelman, D., Ascherio, A. L. and Stampfer, M. 1.s 1996. Birth weight and adult hypertension, diabetes mellitus, and obesity in US men. Circulation. 94, 3246-3250.

De Kloet, E. R. and Oitzl, M. S., 2003. Who cares for a stressed brain? The mother, the kid or both? Neurobiol Aging. 24 Suppl 1, S61-65; discussion S67-68.

Dhabhar, F. S., MCEwen, B. S. and Spencer, R. L., 1997. Adaptation to prolonged or repeated stress--comparison between rat strains showing intrinsic differences in reactivity to acute stress. Neuroendocrinology. 65, 360-368.

Dickerson, P.A., Lally, B. E., Gunnel, E., Birkle, D. L. and Salm, A. K., 2005. Early emergence of increased fearful behawior in prenatally stressed rats. Physsiol Behaw. 
Dugovic, C., Maccari, S., Weibel, L. Turek, E. W. and Van Reeth, O., 1999. High corticosterone lewels in prenatally stressed rats predict persistent paradoxical slece alterations.) Neurosci. 19,8656-8664.

Estanislau; C. and Morato, 5., 2005. Prenatal stress produces more behavioral alterations than maternal separation in the elevated plus-maze and in the elevated T-maze. Behar Brain Res. 163, 70-77.

Fride $E$. and Weinstock, M. 1988. Prenatal stress increases anxiety related behavior and alters cerebral lateralization of dopamime activity Life Sci. 42, 1059-1065.

Gale, C. R. and Martyn, C. N. 2004. Birth weight and later risk of depression in a national birth cohort. Br J Psychiatry. $184,28-33$

Gillman, M. W., 2005. Developmental origins of health and disease. N Engl J Med. 353, 18.48-1850.

Gluckman, P. D. and Hanson, M. A.,2004. Living with the past: evolution, development, and patterns of disease. Science. $305,1733-1736$

Griffin, W. C., Jrd, Skinner, H. D., Salm, A. K. and Birkle, D. L., 2003. Mild prenatal stress in rats is associated with enhanced conditioned fear. Physiol Behay. 79, 209-215.

Hobel, $C$. and Culhane, J., 2003. Role of psychosocial and nutritional stress on poor pregnancy outcome. J Nutr. 133, $17095-1717 \mathrm{~S}$,

Huizink, A. C. Mulder, E. J. and Buitelaar, J. K., 2004. Prenatal stress and risk for psychopathology: specific effects or induction of general susceptibility? Psychol Bull. 130, 115-142.

izumi, J., Washizuka, M., Hayashi-Kuwabara, Y, Yoshinaga, K., Tanaka, Y., Ikeda, Y., Kiuchi, Y. and Oguchi, K., 1997. Evidence for a depressive-like state induced by repeated saline injections in Fischer 344 rats. Pharmacol Biochem Behav. 57, 883-888.

Jezova, D., Skultetyova, I, Makatsori, A.s Moncek, F. and Duncko, R., 2002. Hypothalamo-pituitary-adrenocortical axis function and hedonic behavior in adult male and female rats prenatally stressed by maternal food restriction. Stress. 5, 177-183.

Morley-Fletcher, S. Darnaudery, M., Kaehl, M., Casolini, P., Van Reeth, O. and Maccari, S., 2003a. Prenatal stress in rats predicts inmobility behavior in the forced swim test. Effects of a chronic treatment with tianeptine. Brain Res. $989,246-251$.

Morley -Fletcher, S., Darnaudery, M., Macaer, E, Froger, N., Lanfumey, L., Laviola, G., Casolini, P., Zuena, A. R., Mar* zano, L., Hamon, M. and Maccari, S., 2004. Chronic treatment with imipramine reverses immobility behaviour, hippocampal corticosteroid receptors and cortical 5-HT(1A) receptor mRNA in prenatally stressed rats. Neuropharmacollogy. 47, 841-847.

Morley-wletcher, S, Rea, M., Maccari, S. and Laviola, G., 2003b. Environmental enrichment during adolescence reverses the effects of prenatal stress on play behaviour and HPA axis reactivity in rats. Eur J Neurosci. 18, 3367-3374

Nilsson, P. M., Nyberg, P. and Ostergren, P.-O., 2001. Increased susceptibility to stress at a psychollogical assessment of stress talerance is associated with impaired fetal growth. Int J Epidemiol. 30, 75-80.

Poltyrev, T., Gorodetsky, E, Bejar, C., Schorer-Apelbaum, D. and Weinstock, $M_{s}$ 2005. Effect of chronic treatment with ladostigil (TV-3326) on anxiogenic and depressive-like behaviour and on activity of the hypothalamic pituitaryadrenal axis in male and female prenatally stressed rats. Psychopharmacology (Berl). 181, 118-125.

Porsolt, R. D., Anton, G., Blavet, N. and Jalfre, M., 1978. Behavioural despair in rats: a new model sensitive to antidepressant treatments. Eur ] Pharmacol. 47,379-391.

Prickaerts, J., Raajimakers, W. and Bloklland, A., 1996. Effects of myocardial infarction and captopril therapy on anxiety-related behaviors in the rat. Physiol Behav, 60,43-50.

Rao, U., McGinty, D. 1. Shinde, A., McCracken, I. T. and Poland, R. E., 1999. Prenatal stress is associated with depression-related electroencephalographic sleep changes in adult male rats: a preliminary report. Prog Neuropsychopharmacol Biol Psychiatry. 23,929-939.

Rimondìn, R. Agren, G., Borjesson, S., Sommer, W. and Heilig, M., 2003. Persistent behavioral and autonomic supersensitivity to stress following prenatial stress exposure in rats. Behav Brain Res. 140,75-80.

Secoli, S. R. and Teixeira, N. A., 1998. Chronic prenatal stress affects development and behavioral depression in rats. Stress, 2, 273-280.

Shepherd, J. K., Grewal S. S. Fletcher, A., Bill, D. J. and Dourish, C. T., 1994. Behavioural and pharmacological characterisation of the elevated "zero-maze" as an animal model of anxiety. Psychopharmacology (Berl). 116, 56-64.

Sternberg, E. M., Glowa, J. R., Smith, M. A., Calogero, A. E., Listwak, S. J., Aksentijevich, S., Chrousos, G. P., Wilder, R. L. and Gold, P. W. 1992. Corticotropin releasing hormone related behavioral and neuroendocrine responses to stress in Lewis and Fischer rats. Brain Res. 570, 54-60. 


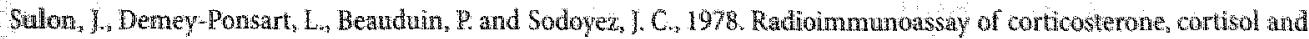
cortisone: their application to human cond and maternal plasma.. Steroid Biochem. $9.671-676$.

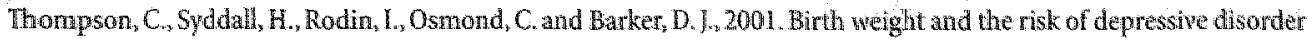
in late life. Br J Psychiatry. $179,450-455$.

Walee, M., Mayo, W. Dellu, F. Le Mod, M., Smon, H. and Maccari, S., 1997 . Prenatal stress induces hight anxiety and postnatal handling induces low anxiety in adult offpring: correlation with stress-induced conticosterone sectetion. N Neurosci. 17, 2626-2636.

Wakshlak, A. and Weinstock, M., 1990. Neonatal handling reverses behavional abnormalities induced in rats by prenatal stress. Physiol Behav, $48,289-292$.

Ward, G. R. and Wainwight, P.E., 1988. Reductions in maternal food and water intake accoun for prenatal stress eftects on neurobehavioral development in B6D2F2 mice. Physiology \& Behavior. 44, 781 - 786.

Ward, I. L. and Weisz, J, 1984. Differential effects of maternal stress on circulating levels of corticosterone, progesteronc, and testosterone in male and female rat fetuses and their mothers. Endocrinology. 114,1635 -1644.

Weinstock, M., 2001. Alterations induced by gestational stress in brain morphology and behaviour of the offspring. Prog Neurobiol. 65, $427-451$.

Weinstock, M., 2005. The potential influence of maternal stress hormones on development and mental health of the offspring Brain Behav Immun. 19,296-308.

Willner, P, Muscat, R, and Papp, M, 1992. Chronic mild stress-induced anhedonia: a realistic animal model of depression. Neurosci Biobehav Rev. 16, 525-534. 


\section{Chapter 8}

\section{Maternal paroxetine treatment and neonatal mortality in the rat; a preliminary investigation}

Van den Hove DLA ${ }^{\mathrm{l} / 2}$, Blanco $\mathrm{CE}^{1}$, Desbonnet $\mathrm{L}^{2 / 3}$, Myint $\mathrm{AM}^{2}$, Bruschettini $\mathrm{M}^{2}$, Prickaerts $\mathrm{J}^{2}$, Leonard $\mathrm{BE}^{2}$, Scheepens $\mathrm{A}^{1 / 4}$, Steinbusch $\mathrm{HWM}^{2}$

'Department of Pediatrics, Maastricht University, Maastricht, The Netherlands.

${ }^{2}$ Department of Psychiatry and Neuropsychology, Maastricht University, Maastricht, The Netherlands.

"Department of Psychiatry, University College Cork, Cork, Ireland.

${ }^{4}$ Liggins Institute, University of Auckland, Auckland, New Zealand.

Human Psychopharmacology (short communication), Submitted 


\section{Abstract}

In this preliminary study we examined the effects of daily exposure to maternal restraint stress and paroxetine $(10 \mathrm{mg} / \mathrm{kg}$; p.o.) throughout the last week of gestation in Fischer 344 rats. Maternal paroxetine treatment led to a shortened gestational length, reduced birth weight, and a considerable rise in neonatal mortality. This increased mortality may be associated with withdrawal symptoms and serotonin toxicity in the offspring. The present study suggest that paroxetine should be administered with great caution in pregnant or reproductive-aged women.

\section{Introduction}

Exposure of a pregnant woman to excessive stress may affect her offspring by promoting the development of learning, behavioral and mood disorders, including anxiety and depression in later life (Huizink et al., 2004). The serotonergic (5-hydroxytryptaminergic; 5 -HT) system is known to play an important role in the etiology of mood disorders (Porter et al, 2004). Several studies performed in the last two decades have shown that prenatal stress. (PS) can induce long-lasting alterations in the 5- $\mathrm{HT}^{\mathrm{T}}$ system in PS rat offspring (Huizink et al., 2004).

Depression and anxiety disorders affect $13.5 \%$ and $4.7 \%$ of reproductive-aged women, respectively (Robins and Regier, 1991, Kessler et al., 1993) and selective serotonin reuptake inhibitors (SSRIs), like paroxetine, are commonly prescribed. SSRIs inhibit 5-HT reuptake from the synaptic cleft into the presynaptic serotonergic neuron. "This leads to more postsynaptic 5-HT receptor activation thereby increasing the level of 5-HT signal transduction, thought to be impaired in depressed patients. Paroxetine has been shown to be able to cross the placental barrier (Hendrick et al., 2003) thereby possibly affecting the perinatal and longterm outcome of offspring exposed to this drug during pregnancy.

The aim of this study was to investigate the effects of maternal paroxetine treatment on a background of maternal stress. We initially hypothesized that paroxetine may beneficially alter neuropsychological outcome of PS offspring. Further, this study allowed us to study possible side-effects of prenatal treatment with this particular SSRI on both the dams and their offspring.

\section{Experimental procedures}

\section{Animals and procedures}

These animal studies were all approved by the Animal Ethics Board of the University of Maastricht, The Netherlands. Acclimatized pregnant Fischer 344 rats (Charles River, The Netherlands) were used. The animals were housed individually within a temperature-con- 
trolled enwironment $\left(21 \pm 1^{\circ} \mathrm{C}\right)$ with a $12 \mathrm{hr}$ light/12hr dark cycle (lights on from $\left.7.00-19.00 \mathrm{~h}\right)$ and had access to standard rat chow and water ad libitum pregnancy was determined by observation of vaginal plugs (embryonic day 0-EO). Restraint stress was performed daily during the last week of pregnancy (E14-E21). Pregnant female rats were individually restrained 3 times a day (at approximately $9.00,13.00$, and $17.00 \mathrm{~h}$ ) for 45 minutes in transparent plastic cylinders while at the same time being exposed to bright light (Ward and Weisz, 1984). Control pregnant females were left undisturbed in their home cages. In addition, both control and PS groups received an oral administration (gavage) of either paroxetine (Seroxat, GlaxoSmithKline, Zeist, The Netherlands; $10 \mathrm{mg} / \mathrm{kg} ; 2 \mathrm{ml} / \mathrm{kg}$ p.o.) or vehicle (normal drinking water; $2 \mathrm{ml} / \mathrm{kg} \mathrm{p}$.0), daily during the last week of gestation (E14-E21; at $8: 30 \mathrm{~h}$ ). In this way, four groups of offspring were produced: prenatally stressed rats with (PS+) and without (PS-) maternal paroxetine treatment and the corresponding controls ( $\mathrm{C}+$ and $\mathrm{C}$-). Dam weight was studied at E0 and E21. Only litters of 8 or more pups were included in this study. As soon as the last pup of a litter had been born, litter size and pup gender was defined (based on anogenital distance) and individual body weights were determined.

\section{Statistics}

Differences in dam weight, gestational length, litter size, and pre-weaning mortality were evaluated with a 2-way ANOVA (experimental group $\times$ treatment). Birth weight data were analyzed with a 3 -way ANOVA (experimental group $\times$ treatment $\times$ gender). Statistical significance was assumed to exist at $\mathrm{P}<0.05$. Correlation analysis was performed using Pearson's correlation coefficient $\left(r_{p}\right)$. Effects were analyzed in more detail using Bonferroni post hoc tests. All statistics were carried out using SPSS software version 12.0.1 (SPSS Inc, USA).

\section{Results}

The effects of prenatal maternal stress and paroxetine treatment on dam weight, gestational length, birth weight, and pre-weaning mortality is depicted in the table. Most striking is the finding that paroxetine treatment resulted in a 10-fold increase in mortality during the preweaning period (treatment effect: $1003.44 \% ; \mathrm{P}<0.001$ ). It was noted that the majority of these pups died within a few days of birth. Further, no significant correlations between any of the parameters were observed in any of the cases. 
Table. Whe ellect of prenatal maternal stress and paroxetne treatment on dam weight oner gestation (A), gestational length $(B)$, birth weigh (C) and pre-weaning mortality (D). A) Overall, ps was associated with less weight gan ower gestation (dif

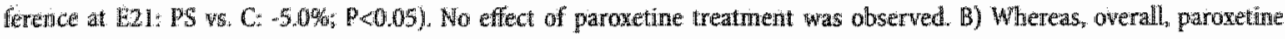
treatment resulted in a decrease in gestational length ( $\mathrm{P}<0.001)$. No effect of PS was obserwed. C) Overall, both PS (P<0.001) and parowetine (P C0.001) were associated with lower birth weights as compared to their correxponding controls. In atdition. overall, male pups were heavie as compared to females (P<0.001). D) Overall, paroxetine treatment was associated with a

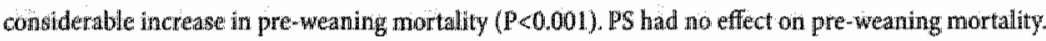

\begin{tabular}{|c|c|c|c|c|c|}
\hline Parameter & Group & C- & PS - & $\mathrm{C}+$ & PSt \\
\hline \multirow[t]{2}{*}{ A) Dam Weight (g) } & EO & $184.5 \pm 2.0$ & $182.4 \pm 2.0$ & $187.6 \pm 0.8$ & $182.6 \pm 2.4$ \\
\hline & E21. & $250.7 \pm 2.2$ & $240.4 \pm 5.1$ & $249.8 \pm 4.7$ & $235.1 \pm 4.0$ \\
\hline B) Gestational Length (days) & & $21.8 \pm 0.1^{*}$ & $21.6 \pm 0.2$ & $21.1 \pm 0.1^{4}$ & $21.3 \pm 0.2$ \\
\hline \multirow[t]{2}{*}{ C) Birth Weight (g) } & M & $5.46 \pm 0.05^{*}$ & $5.09 \pm 0.07^{* .4}$ & $4.66 \pm 0.06^{\natural, t}$ & $4.61 \pm 0.07^{+.4}$ \\
\hline & $\mathrm{F}$ & $5.06 \pm 0.05^{* 4.5}$ & $4.78 \pm 0.04^{*+10^{4}}$ & $4.37 \pm 0.07^{\mathfrak{p}, \mathrm{s}}$ & $4.38 \pm 0.06^{\ddagger}$ \\
\hline D) Pre-weaning Mortality (\%) & & $4.0 \pm 2.1^{\dagger}$ & $12.9 \pm 8.9^{*}$ & $95.8 \pm 4.2$ & $91.00 \pm 7.2^{1}$ \\
\hline
\end{tabular}

Numbers represent means \pm S.E.M. Abbrevations/symbols: C: control; PS: prenatal stress; $(+)$; paroxeline wreated; $(\alpha)$ vehicletreated. Ex embryonic day; $M$ : nale; $\mathrm{F}$ : female. * P $<0.05$ (Bonferroni), $C$ versus $P S ;+P<0.05$ (Bionferroni), vehicle (-) versus paroxetine (*); $* 0.05$ (Bonferroni), M versus $\mathbb{E}$ :

\section{Discussion}

The present study shows that paroxetine treatment of pregnant rats leads to a shortened gestational length, reduced birth weight and a significant rise in neonatal mortality. Prenatal restraint stress resulted in reduced weight gain over gestation as well as reduced birth weight of the pups.

To our surprise, both groups of offspring treated antenatally with paroxetine showed a very high level of mortality during the first few postnatal days, whereas mortality was low in the untreated groups. At first sight paroxetine treated offspring appeared much less active from birth onwards (personal observations). Since not all animals delivered in the same week, we were able to perform a small cross fostering experiment to find out whether the observed neonatal mortality was due to the mother, the pup or both. For this purpose, 2 $\mathrm{C}+$ pups were placed with a $\mathrm{C}$ - mother within 3 hours after birth. Likewise, $2 \mathrm{C}$ - pups were placed with a $\mathrm{C}+$ mother. All pups died, suggesting that maternal paroxetine treatment was affecting both mother and pups".

1 GlaxoSmithkline thenselves now report of an increase in pup mortality during the first 4 days of lactation when dosing (1 $\mathrm{mg} / \mathrm{kg} / \mathrm{day}$ ) occurred during the last week of gestation. In contrast to our investigation, maternal paroxethe treatment was contunued throughout lactation in this study, ruling oul maternal withdrawal effects (see Paxil prescribing information at wwwgskicom) 
Though probably less severe as in adults, it is now believed that withdrawal effects of SSRIs do exist in human neonates (Sanz et al, 2005). Neonatal withdrawal symptoms of paroxetine include irritability, crying, inability to feed and sleep, respiratory distress, increased tonus, shivering, neonatal convulsions, hypoglycemia, and increased vascular fragility. This is also referred to as 'the neonatal withdrawal syndrome', or the 'SRI-related, Le, SSRI and SNRI (selective noradrenergic reuptake inhibitor)-related neonatal syndrome (Moses-Kolko et al. 2005, Sanz et al., 2005). In addition, severe serotonin toxicity, also referred to as the serotonin syndrome, resulting from an excess of synaptic 5-HT, may also play an important role in causing (part of) these neonatal symptoms (Haddad et al., 2005).

In clinical practice, neonates tend to recover within a few weeks from most of these acute symptoms. Less is known however about the long-term effects of antenatal SSRI treatment. Based on the neonatal complications Sanz and colleagues (2005) recently concluded that SSRIs, especially paroxetine, should be cautiously managed in the treatment of psychiatric disorders in pregnant women.

In conclusion, the results of this study suggest that the increased neonatal mortality in offspring of dams that had been treated with paroxetine during the last week of gestation is probably associated with withdrawal effects and serotonin toxicity. Altogether, we suggest that paroxetine should be cautiously managed in the treatment of mood disorders in pregnant women. Furthermore, there is a need for further experimental studies on both the short- and long-term effects of SSRI treatment during gestation.

\section{References}

Haddad, P. M, Pal, B. R., Clarke, P., Wheck, A. and Sridhiran, S., 2005. Neonatal symptoms following maternal paroxetine treatment serotonin toxicity or paroxetine discontinuation syndrome? J Psychopharmacol. 19, 554-557.

Hendrick, V., Stowe, Z. N., Altshuler, L. L., Hwang, S., Lee, E. and Haynes, D., 2003. Placertal Passage of Antidepressant Medications. Am J Psychiatry, 160,953-996.

Huizink, A. C. Mulder, E J. and Buitelarar, J. K. 2004. Prenatal stress and risk for psychopathology: specific effects or induction of general susceptibility? Psychol Bull. 130,115-142.

Kessler, R. C., McGonagle, K. A., Swartz, M., Blazer, D. G. and Nelson, C. B., 1993. Sex and depression in the National Comorbidity Survey. I: Lifetime prevalence, chronicity and recurrence. J Affect Disord. 29,85-96.

Moses-Kolko, E. L, Bogen, D., Perel, J., Bregar, A. Uhl, K., Levin, B. and Wisner, K. L., 2005. Neonatal Signs After Late lin Utero Exposure to Serotonin Reuptake Inhibitors: literature Review and Implications for Clinical Applications. JAMA. 293, 2372-2383.

Porter, R. J., Gallagher, P. Watson, $S_{\mathrm{s}}$ and Young, A. H., 2004. Corticosteroid-serotonin interactions in diepression: a review of the human evidence. Psychopharmacology (Berl) 173,1-17.

Robins, L. N. and Regier, D. A. 1991 eds. Psychiatric disorders in America: the Epidemiologic Catchnent Area Study. The Free Press, New York.

Sanz, E. J., De-las-Cuevas, C., Kiura, A., Bate, A. and Edwards, R., 2005 . Selective serotonin reuptake inbibitors in pregnant women and neonatal withdrawall syndrome: if database analysis. The Lancet. 365,482 .

Ward, I. L. and Weisz, I., 1984. Differential effects of maternal stress on circulating levels of corticosterone, progesterone, and testosterone in malle and fenale rat fetuses and their mothers. Endocrinology. 114, 1635-1644. 


\section{Chapter 9}

\section{General Discussion}

\section{Prenatal stress and adult psychopathology}

Van den Hove DLA 
Increasing evidence has suggested that adverse life events experienced by the pregnant mother may be reflected upon the developing fetus, resulting in an increased risk for (psycho-) pathology in later life. The work described in this thesis shows that PS may have significant short and long-term consequences on offspring development. The major findings reported in this thesis are:

- PS rat offspring show lower birth weights, increased basal and stress-induced plasma levels of corticosterone just after birth, and an aberrant pattern of neonatal brain development, with lower levels of hippocampal cell proliferation and of the neurotrophic factors BDNF and S100B. We also found an increased activity of hippocampal caspase-3, a protease involved in the key steps of apoptosis (Chapters 2 and 3). Processes like these may contribute to an increased risk for disease in adulthood.

- Further, PS resulted in lower 5-HT, receptor binding in the ventral hippocampus, which is related to emotional processing, whereas the dorsal hippocampus was not affected. In addition, hippocampal $5-\mathrm{HT}_{2 \mathrm{~A}}$ receptor binding was not changed after PS (Chapter 4).

- In adulthood, PS was associated with an increase in anxiety-and depression-rellated behavior in male Fischer 344 rats. Females were not included in this study (Chapters 5 and 6).

- However, behavioral results within Fischer 344 rats were not always straightforward. Under stressful conditions PS male Fischer 344 rats seemed to perform relatively better, i.e., less worse, with lower stress-induced plasma corticosterone levels and less anxious behavior as compared to control offspring. These latter findings are in line with the "predictive adaptive response (PAR) hypothesis proposed recently (Chapters 5 and 6 ).

- In adult male Sprague-Dawley rats, PS was associated with a clear increase in anxiety. and depression-related behavior. Females were largely unaffected. Male PS offspring further showed increased basal plasma corticosterone levels, whereas both PS males and femalles failed to show an adequate response to stress with lower stress-induced. corticosterone levels as compared to controls. Female hippocampal weight was relatively higher after PS, which may explain the clear absence of behavioral effects of PS in this gender. In addition, male birth weight seemed to be a useful predictive marker for adult psychological functioning (Chapter 7).

- Of a different nature were the effects of maternal paroxetine treatment. Although paroxetine was initially administered in order to reduce the effects of prenatal maternal stress, it induced massive neonatal mortality most likely due to drug withdrawal effects and serotonin toxicity (Chapter 8 ). 


\section{Methodological considerations}

\section{Rat brain development}

Though human beings are born in a relatively immature neurological state, the human brain is rather developed at birth as compared to that of the rat. After birth, it takes the rat brain approximately 2 weeks to reach the developmental age of that of a term human (Clancy et al., 2001). Rats, like most rodents, are altricial and their eyes do not open until about two weeks after birth. During this period they fully depend on their mother. In our experiments restraint stress was performed from E14-E21, during which time the hippocampus, important in emotional processing and the pathophysiology of mood disorders, is at a critical point in its development (Clancy et al., 2001).

\section{Gestational stress and the HPA axis}

The role of the placenta in relation to the interplay between the maternal and fetal HPA axis differs significantly between humans and rats. In contrast to the situation in rodents, the human placenta provides an additional source of CRF: PCRF. Placental CRF is known to play an important role in the communication between the maternal and fetal HPA axis in humans (Weinstock, 2005). In this regard pCRF plays a key role in the effects of maternal stress in humans. In rodents, however, processes like the transplacental transport of maternal stress hormones as well as a more direct stimulation of the fetal HPA axis are more important. In addition, abnormalities in the levels of $11-\beta-\mathrm{HSD}-2$, which converts and inactivates cortisol/ corticosterone, may result in increased fetal cortisol and corticosterone levels in humans and rodents, respectively (Weinstock, 2005).

\section{Breeding conditions}

Obtaining pregnant rats from an external company or institution, coinciding with e.g. stress induced by transport and exposure to a novel environment may, in some cases, mask the effects of the actual PS procedure. In this situation the control group suffers from a substantial. amount of stress during pregnancy making experimental interpretation difficult. Except for the control experiment performed as discussed in Chapter 2, we therefore ran the breeding program at our own animal facilities, using male and female rats that were habituated to their surroundings.

\section{Chronic restraint stress}

The nature, timing, frequency, and duration of the prenatal stress exposure are very important in relation to outcome in the offspring (Huizink et al., 2004). The maternal restraint stress model used by our group, i.e., restraint stress, three times 45 minutes dailly, from E14-E21. is 
a chronic, but predictable stress model. This means that the pregnant dams may habituate to the stress procedure over time. Even so, the effects of this widely used procedure are evident. Of note, in addition to the effects observed in the offspring, stressed dams displayed reduced mobility in the forced swim test at P21 (weaning) as compared to controls (unpublished observations).

\section{Strain differences}

Various rat strains differ considerably in terms of stress responsivity. For the purpose of our studies, we initially used Fischer 344 rats, an inbred strain known for its low heterogeneity and its relative susceptibility to a depressive-like state (Sternberg et al., 1992, Dhabhar et al., 1997, Izumi et al., 1997). However, behavioral differences between Fischer 344 exposed to prenatal maternal stress or not were not persistent, as discussed in Chapters 5 and 6 . We therefore switched to Sprague-Dawley rats (see Chapter 7). In the latter rat strain the behavioral effects of PS have been well-characterized and are persistent (Dugovic et al., 1999, Morley-Fletcher et al., 2003a, Morley-Fletcher et all, 2003b, Morley-Fletcher et al., 2004). In addition, depression-related effects of PS in this rat strain could be counteracted by treating PS offspring with various antidepressants (Alonso et al., 1999, Morley-Fletcher et al., 2003a, Morley-Fletcher et al,, 2004, Poltyrev et al., 2005).

These results emphasize the importance of choice of strain in stress- and in particular PS-related research; a choice that depends on the nature of the research question. For example, when using PS as an animal model for anxiety/depression, i.e., in order to study the efficacy of antidepressants, Sprague-Dawley rats seem most suitable.

\section{Age-dependent HPA axis (re-) activity}

Surprisingly, basal plasma corticosterone levels in both 1-day-old Fischer 344 pups were higher as compared to those after 1 hour of maternal deprivation, a well-known stressor (Chapter 2). Why basal corticosterone levels were higher as compared to those after maternal deprivation is not clear at the moment. Though purely speculative, maybe a physiological mechanism related to parturition is involved, reflecting the start of the stress-hyporesponsive period. Clearly, this awaits further research.

In terms of adult HPA axis (re-) activity, male Sprague-Dawley rats at 4 months of age showed elevated basal plasma corticasterone levels, while stress-induced corticosterone secretion was impaired after PS (Chapter 7). Another study on PS using the same PS model and male Sprague-Dawley rats of 3 months of age did not find an effect of PS on either basal or stress-induced plasma corticosterone levels (Morley-Fletcher et al., 2003a). In that study, however, recovery after 20 minutes of restraint stress was weaker after PS. In two other comparable studies by the same group using male Sprague-Dawley rats of 2 months of age, both stress-induced plasma corticosterone levels as well as levels after recovery were higher in PS animals (Dugovic et al., 1999, Morley-Fletcher et al., 2003b). 
An age-dependent relation between early-life experience and HPA axis (re-) activity has already been suggested by De Kloet and Oitzl (2003). Probably a comparable phenomenon is involved in HPA axis (re-) activity after PS. We therefore believe that not HPA. axis hyperactivity in particular, but alterations in HPA axis (re-) activity per se, are of importance in PS.

\section{The role of gender}

Though PS has a clear effect on both genders, it seems to have a different impact on male and female offspring, which is probably related to the different timing of relevant developmental processes over gestation in both sexes in relation to the timing of the stress exposure (e.g. Owen and Matthews, 2003).

\section{Anxiety and depression}

Although the overall prevalence of mood disorders is higher in females as compared to males (Blehar, 1995), this gender difference is not so well defined in relation to PS. For example, male offspring of pregnant women exposed to psychological stress during preg. nancy as a result of a severe earthquake showed a higher proportion of severe depression in adulthood as compared to controls, whereas prenatally exposed women did not significantly differ from women in the control group (Watson et al., 1999). Regarding our data, most prominently, as reported in Chapter 7 , onlly male Sprague-Dawley rats showed a clear increase in anxiety- and depression-related behavior after PS whereas females remained largely unaffected.

\section{HPA axis alterations}

Male, but not female, Sprague-Dawley rats of 4 months of age showed elevated basal plasma corticosterone levels after PS, whereas stress-induced corticosterone secretion was again impaired in both genders (Chapter 7). Male HPA axis (re-) activity was also altered after PS in other investigations using the same PS model and rat strain (Dugovic et al., 1999, Morley-Fletcher et al., 2003a, Morley-Fletcher et al., 2003b, Poltyrev et al., 2005). Other studies using different PS models and rat strains that compared HPA axis (re-) activity in offspring of both genders found significant differences in basal and stress-induced plasma levels of ACTH and corticosterone in PS females only (Takahashi et al., 1988, Weinstock et al., 1992, Szuran et al, 2000). In the latter two studies, only female offspring born to PS mothers showed significantly fewer hippocampal GR binding sites, which may be related to the sex-specific development of brain GR and MR (Owen and Matthews, 2003). In yet another study, PS significantly increased both plasma ACTH and corticosterone levels after restraint stress only in female offspring (McCormick et al., 1995). Both the rat strain used, and the nature, timing and duration of the maternal stress exposure may be important in this respect. In addition, also the nature and timing of the acute stressor used to evoke a corticosterone response in the offspring may explain differences (De Kloet and Oitzl, 2003). 


\section{Birth weight - depression}

Interestingly, the relationship between birth weight and the incidence of depression in adulthood is also sexually divergent. Women and not men, with low birth weight had an increased risk of depression at age 26 years. (Galle and Martyn, 2004), whereas men and not women, with Low birth weight showed an increased risk of depression at age 68 (Thompson et al., 2001). Interestingly, in the study described in Chapter 7 , a significant correlation between male birth weight and strong mobility in the forced swim test was observed (see below).

Altogether, mood disorders that have a fetal/developmental origin may represent different forms as compared to those that develop as a result of adult life-events only (which show a higher prevalence in females). The exact role of gender in relation to PS remains to be elucidated though.

\section{Developmental origins of adult health and disease}

Repeatedly, it was shown that prenatal restraint stress resulted in impaired fetal growth (Chapters 2, 5, 6,7, and 8). The "developmental origins of health and disease" (DOHaD) concept (Gillman, 2005) states that the risk of disease in adulthood partly depends upon variations in the prenatal environment, which are often reflected in body weight at birth (Barker, 1995). Low birth weight subjects have an increased risk for adult (psycho-) pathology.

The observed reduction in birth weight in PS pups may be explained by a reduction in food and water intake and/or an impaired conversion of dietary calories into maternal weight gain as seen in reaction to stress (Ward and Wainwright, 1988, Hobel and Culhane, 2003). Indeed, maternal weight gain over gestation was reduced by restraint stress (Chapters 2 and 7). Of note, however, though the importance of maternal nutritional status is evident, fetal nutrition is not always simply a reflection of maternal nutrition. In addition, the transplacental transfer of maternal stress hormones, i.e., CRF and corticosterone, excess pCRF production, and excess sympatho-adrenal activation resulting in a reduction in uteroplacental blood flow, all phenomena commonly observed in gestational stress, may affect fetal growth (Aghajafari et al., 2002. Hobel and Culhane, 2003, Huizink et al., 2004).

We found a significant correlation between fetal growth and adult performance in the forced swim test, with low birth weight male offspring showing more depression-related behaviour in this behavioral task (Chapter 7). In addition, male birth weight was predictive for adult basal and stress-induced plasma corticosterone levels. This suggests that male birth weight may be useful as a predictive marker in PS-related investigations.

Of note, the relationship between fetal growth and disease risk in later life reflects the sensitivity of fetal growth to adverse intrauterine influences and does not imply a causal role of being born small. That is, birth weight is a rough integrated measure of many fetal processes and intrauterine adverse events may have independent effects on birth weight/size and in parallel also have long-term pathological consequences. Moreover, many adverse events that 
affect the fetus and have long-term pathological consequences yet have no effect on birth size (Givckman and Hanson, 2004b, Gluckman and Hanson, 2004a).

\section{PAR concept: epigenetics}

Prenatal gene-environment interactions may play a crucial role in detemining the postnatal phenotype (Gluckman and Hanson, 2005). In this respect PARs may primarily provide immediate survival advantage or anticipation. However, long-term performance may also be favored by a relatively unfavorable intratterine environment, as survival conditions may be tough in adult life (Chapter 1).

Part of our findings in Fischer 344 rats supports this idea. On the one hand male PS offspring show lower birth weights, increased basal and stress-induced plasma levels of corticosterone just after birth, an aberrant pattern of neonatal brain development, lower $5-\mathrm{HT}_{\mathrm{AA}}$ receptor levels in the ventral hippocampus and an increase in anxiety- and depression-related behavior in adulthood. On the other hand adult PS Fischer 344 rats seem to perform relatively better under stressful conditions with lower stress-induced plasma corticosterone levels and less anxious behavior. We therefore believe that PS may indeed have adaptive effects in relation to stress coping in later life, dependent on the genetic background. One should bear in mind though that these adaptive effects have a relative charac ter, since stress in later life had a negative effect on both PS and control offspring. In other words, PS offspring seemed to perform better as compared to control offspring. Clearly, the concept of predictive adaptive responses in relation to prenatal maternal stress requires more research.

\section{Paroxetine treatment during gestation}

The paroxetine study was principally designed to investigate potential beneficial effects of maternal SSRI treatment in relation to prenatal maternal stress. The actual implications of this investigation were of a completely different nature. We show that maternal paroxetine treatment in Fischer 344. rats led to a high degree of neonatal mortality in both PS and control offispring likely due to severe neonatal drug withdrawal effects and severe serotonin. toxicity. Because of these withdrawal effects, it has recently been suggested that SSRIs, and. especially paroxetine, should be cautiously managed in the treatment of psychiatric disorders in pregnant women (Sanz et al, 2005)'. In addition, the long-tern effects of SSRI treatment during pregnancy await further research. Conversely, inadequate treatment of maternal depression or anxiety would also compromise fetal health. This further stresses the need of a careful risk-benefit assessment, primarily directed towards treating maternal depression or anxiety.

\footnotetext{
"At December $3^{\text {th }} 2005$ the Food and Drug Administration (FDA) warned pregnant women and their doctors away from the
} antidepressant paroxetine because of an increased risk of heart defects in newborns. 


\section{Future perspectives}

Several retrospective clinical studies showed an increased incidence of behavioral abnormalities in offspring exposed to PS (Stott, 1973, Huttunen and Niskanen, 1978, Meijer, 1985, Watson et al., 1999). Further, depression and anxiety disorders affect approximately $14 \%$ and $5 \%$ of reproductive-aged women, respectively (Robins and Regier, 1991, Kessler et al., 1993). In another study among 1734 pregnant Swedish women, $14.1 \%$ of the women were suffering from psychiatric disorders, of which the majority was undiagnosed and only $5.5 \%$ received some form of treatment (Andersson et al., 2003). In a comparable study by Marcus and colleagues (2003), $20 \%$ of 3472 pregnant women screened were diagnosed as depressed, whereas only $13.8 \%$ of those women received any form of treatment for depression. This illustrates the clinical relevance of prenatal maternal stress.

\section{"An ounce of prevention is worth a pound of cure..."}

In the case of prenatal maternal depression and/or anxiety it seems practically applicable to at least reduce the impact of maternal stress on the offspring. An effective psychotherapeutical and/or pharmaceutical approach will have a positive effect on the emotional well-being of the pregnant woman which in turn will have a more indirect positive effect on the fetus. Evidently, in case of a pharmaceutical approach, the drug in question should have limited, or preferably, no (in-)direct, harmful, effects on the developing fetus, like with SSRIs as discussed in Chapter 8 . The maternal HPA axis is a likely target in this respect. For example, studying the effects of CRF (1) antagonist administration during gestation may be a first step (Weinstock, 2005). In cases of (unexpected) and stressful life events during pregnancy psychological support should be of primary concern. Seen in the light of the Barker hypothesis an adequate nutrient supply, i.e, a combined micronutrient supplementation, has been suggested (Hininger et al., 2004). Of note, in PS offspring suffering from mood disorders, both psychological support and pharmaceutical intervention are a good option.

\section{"From clinic to bench and back again, eventually"}

First of all, clinical practice should become more aware of the importance of prenatal life and the consequences of prenatal maternal stress in particular. Clinicians should aim at systematic screening for maternal stress and/or mood disorders in pregnant women using questionnaires as a first step in determining which women may require further support or treatment. Purther, genetic profiling of women vulnerable to mood disorders may lead to the discovery of vulnerability genes. Knowledge regarding genetic vulnerability may in turn be used in animal models on depression/anxiety and prenatal maternal stress in particular to study possible mechanisms. Conversely, studying gene-expression in our prenatal maternal restraint stress model may also lead to the discovery of potential therapeutical targets. 
However, until suitable pharmacological therapies have been designed, after having been tested thoroughly for both their efficacy and possible harmful short-and long-term side-effects, GPS should focus on the preservation of an optimal intrauterine environment devoid of severe stress. Primary concern should be directed towards an adequate nutrient supply and psychosocial support to the pregnant woman.

\section{PARs}

The role of PARs in PS also remains intriguing; especially in conditions where serious life events act upon on a background of PS. The genetic background of the species or strain imvestigated clearly plays an important role in this respect. What exact mechanisms form the basis of 'PARs' and the 'DOHaD' in general, and those of PS in particular, remains to be determined. Epigenetics provides a likely candidate and opens windows for future research regarding PS. The role of gender in relation to PS and adult life events is also intriguing in this regard.

\section{In conclusion}

Adverse life events or mood disorders experienced by preguant women may be reflected upon the developing fetus, generally resulting in an increased risk for pathology in later life. Altogether, the present work stresses the importance of the fetal environment in relation to adult health and disease, more specific in relation to mood disorders. Clinical practice should become more aware of this phenomenon. Besides the development of proper effective pharmaceutical strategies, an adequate nutrient supply and psychosocial support to the pregnant woman are of importance. SSRIs, and especially paroxetine, should be cautiously managed in the treatment of mood disorders in pregnant and reproductive-aged women.

\section{References}

Aghajafari, E, Murphy, K, Matthews, S., Ohlsson, A., Amankwah, K. and Hannah, M. 2002. Repeated soses of antenalta! conticosteroids in animals: a systematic review. Am J Obstet Gynecol. 186, 843-849.

Alonso, S. 1., Castellano, M. A., Quintero, M. and Navarro, E., 1999. Action of antidepressant druggs on maternal stressinduced hypoactivity in female rats. Methods find Exp Clim Pharmacol, 21, 291-295.

Andersson, L., Sundstrom-Poromaa, I., Bixo, M., Wulf, M., Bondestam, K and aStrom, M., 2003. Point prevallence of psychiatric disorders during the second trimester of pregnancy: a population-based study. Am J Obstet Gynecol. 189. 148-154.

Barker, D. J., 1995. The fetal origins of adult disease. Proc R Soc Lond B Biol Sci.262, 37-43.

Blehar, M. C., 1995. Gender differences in risk factors for mood and anxiety disorders: implications for clinical treatment research. Psychopharmacol Bull. 31.,687-691.

Clancy, B., Darlington, R. B. and Finlay, B. L., 2001. Translating dewelopmental time across mammalian species. Neuroscience. 105,7 . 
De Edoet; E. R. and Oital, M. S., 2003. Who cares for a siressed brain? The mother, the kid or both? Neurobiol Aging. 24 Suppl $1, \$ 61-65 ;$ discussion $\$ 67-68$.

Dhablar, E S., Mc Ewen, B.S. and Spencer, K. L., 1997 , Adaptation to prolonged or repeated stress--comparison between rat strains showing intrinsic differences in reactiwity to acute stress. Neuroendocrinology. 65, 360-368.

Dugovic, C, Maccari, S., Weibel, L., Iurek, E. W. and Van Reeth, 0., 1999. High corticosterone levels in prenatally stressed rats predict persistent paradoxical sleep alterations. I Neurosci. 19, 8656-8664.

Gale, C. R, and Martyn, C. N., 2004. Birth weight and later risk of depression in a national birth cohort. Br I Psychiatry. 184. $28-33$.

Gillman, M. W., 2005. Developmental origins of health and disease. N Engl J Med. 353, 1848-1850.

Giluckman, P. D. and Hanson, M.A., 2004a. Developmental origins of disease paradigm: a mechanistic and evolutionary perspective. Pediatr Res, 56,311-317.

Gluckman, P. D. and Hanson, M. A., 2004b. Living with the past: evolution ${ }_{n}$ development, and patterns of disease. Science. 305; 1733-1736.

Gunckman ${ }_{0}$ P. D. and Hanson, M.A., 2005. The Fetal Matrix: Evolution, Development and Disease. Cambridge University Press, Cambridge.

Hininger, I., Favier, M., Arnaud, J., Faure, H., Thoulon, J. M., Hariveau, E., Favier, A. and Roussel, A. M., 2004. Effects of a combined micronutrient supplementation on maternal biological status and newborn anthropometrics measurements: a randomized double-blind, placebo-controlled trial in apparently healthy pregnant women. Eur I Clin Nutr. 58, 52-59.

Hobel, $\mathrm{C}$ and Culhane, J., 2003. Role of psychosocial and nutritional stress on poor pregnancy outcome. I Nutr. 133, 17095-1717S.

Huixink, A. C. Mulder, E. I. and Buitelaar, I. K., 2004. Prenatal stress and risk for psychopathology: specific effects or induction of general susceptibility? Psychol Bull. 130, 115-142.

Huttunem, M. O. and Niskanen, P., 1978. Prenatal loss of father and psychiatric disorders. Arch Gen Psychiatry. 35, $429-431$.

Izumi, J., Washizuka, M., Hayashi-Kuwabara, Y., Yoshinaga, K., Tanaka, Y., Ikeda, Y., Kiuchi, Y. and Oguchi, K., 1997. Evidence for a depressive-like state induced by repeated saline injections in Fischer 344 rats. Pharmacol Biochem Behav. 57, 883-888.

Kessler, R. C., McGonagle, K. A., Swartz, M., Blazer, D. G. and Nelson, C. B., 1993. Sex and depression in the National Comorbidity Survey. I: Lifetime prevalence, chronicity and recurrence. J Affect Disord. 29,85-96.

Marcus, S. M., Flynn, H.A., Blow, E.C. and Barry, K. L., 2003. Depressive symptoms among pregnant women screened in obstetrics settings. I Womens. Health (Larchmt). 12, 373-380.

McCormick, C. M., Smythe, J. W., Sharma, S. and Meaney, M. J., 1995. Sex-specific effects of prenatal stress on hypothalamic-pituitary-adrenal responses to stress and brain glucocorticoid receptor density in adult rats. Brain Res Dev Brain Res. $84,55-61$.

Meijer, A., 1985. Child psychiatric sequelae of maternal war stress. Acta Psychiatr Scand. 72, 505-511.

Morley-lletcher, S., Darnaudery, M. Kaethl, M., Casolini, P., Van Reeth, O, and Maccari, S., 2003a. Prenatal stress in rats predicts immobility behavior in the forced swim test. Effects of a chronic treatment with tianeptine. Brain Res. $989 ; 246-251$.

Morley-Fletcher, S., Darnaudery, M., Mocaer, E., Froger, N., Lanfumey, L., Laviola, G., Casolini, P., Zuema, A. R., Marzano, L., Hamon, M. and Maccari, S., 2004. Chronic treatment with imipramine reverses immobility behaviour, hippocampal corticosteroid receptors and cortical 5-HT(1A) receptor mRNA in prenatally stressed rats. Neuropharmacology, $47,841-847$.

Morley - Fletcher, S., Rea, M., Maccari, S. and Laviola, G., 2003b. Environmental enrichnent during adolescence reverses the effects of prenatal stress on play behaviour and HPA axis reactivity in rats. Eur I Nenrosci. 18, 3367-3374.

Owen, D. and Matthews, S. G., 2003. Glucocorticoids and sex-dependent development of brain glucocorticoid and mineralocorticoid receptors. Endocrinology. 144, 2775-2784.

Poltyrev, T., Gorodetsky, E., Bejar, C., Schorer-Apelbaum, D, and Weinstock, M., 2005. Effect of chronic treatment with ladostigil (TV-3326) on anxiogenic and depressive-like behaviour and on activity of the hypothalamic-pituitary-adrenal axis in male and female prenatally stressed rats. Psychopharmacology (Berl). 181, 118-125.

Robins, L. N. and Regier, D. A., 1991. eds. Psychiatric disorders in America: the Epidemiologic Catchment Area Study. . The Free Press, New York. 
Sanz, E. J., De-las-Cuevas, C. Kiuru, A.,Bate,A, and Edwards, R. 2005. Selective serotonin reuptake inhibions in pregnant women and neonatal withdrawal syndrome: database walysis. The Lancet. 365,48 .

Sternberg, E. M., Glowa, J. R., Smith, M. A. Calogero, A. E., Histwak, S. I. Aksentijevich, S, Chrousos, G. P. Wilter, R. L. and Gold, P. W., 1992. Corticotropin releasing hormone related behavioral and neuroendocrine responses to stress in Lewis and Fischer rats. Bratin Res. $570,54-60$.

Stot, D. H. 1973. Follow-up study from birth of the effects of prenatal stresses. Dev Med Child Neurol. 15,770)-787.

Szuran, T. F, Pliska, V. Pokorny, J and Welzl, H., 2000, Prenatal stress in rats! eftects on plasma corticosterone, hippocanapal glucocorticoid receptors, and maze performance. Physiol Bethav, $71,353-362$.

Takahashi, L. K., Kalin, N. H., Barksdale, C. M., Vanden Burgt, J. A. and Brownfeld, M. S., 1988. Stressor controllability during pregnancy influences pituitary-adrenal hormone concentrations ind analgesic responsiveness in offspring. Physiol Behav. 42, 323-329.

Thompson, $\mathrm{C}$, Syddall, H., Rodin, $\mathrm{L}_{*} \mathrm{O}$ smond ${ }_{4} \mathrm{C}$ and Barker, D. I., 2001 . Birth weight and the risk of depressive disorder in late life. Br I Psychiatry. 179, 450 455.

Ward, G. R. and Wainwright, P. E., 1988. Reductions in maternal food and water intake account for prenatal stress effects on neurobehavioral development in B6D2F2 mice. Physiology \& Behavior. $44,781-786$.

Wattson, J. B., Mednick, S.A., Huttunen, M. and Wang, X, 1999. Prenatal teratogens and the development of adul mental illness. Dev Psychopathol. 11,457-466.

Weinstock, M., 2005. The potential influence of maternal stress hormones on devalopment and mental health of the offspring. Brain Behaw Immun. 19, 296-308.

Weinstock, M., Matlina, E., Maor, G. I., Rosen, H. and MclEwen, B.S., 1992. Prenatal stress selectively alters the reactivity of the hypothalamic-pituitary adrenal system in the female rat. Brain Res, 595, 195-200. 


$$
8
$$




\section{Summary}

A growing body of evidence indicates that alterations in the fetal environment can have longterm consequences on metabolic and endocrine functioning in postnatal life. Accordingly, adverse life events or mood disorders experienced by pregnant women may be reflected upon the developing fetus, generally resulting in an increased risk for psychopathology in later life. However, the exact mechanisms accounting for the effects of prenatal stress (PS) are still unclear. Consequently, an appropriate strategy for attenuating the impact of prenatal maternal stress is lacking. By exposing pregnant rats to restraint stress during the last week of gestation we showed that PS has significant short-and long-term consequences on offspring development.

PS Fischer 344 offspring showed lower birth weights as well as increased basal and stress-induced plasma levels of corticosterone soon after birth, and a disrupted neonatal brain development. For example, PS was associated with impaired brain cell proliferation and increased caspase-3-like activity within the neonatal hippocampus. In addition, hippocampal BDNF and S100B (neurotrophic factor) levels were reduced just after birth. Developmental alterations like these may contribute to an increased risk for psychopathology in adulthood (Chapters 2 and 3 ).

Further, PS in Fischer 344 rats resulted in lower $5-\mathrm{HT}_{1 \mathrm{~A}}$ receptor binding in the wentral hippocampus, and area related to emotional processing, whereas the dorsal hippocampus, responsible mainly for learning and memory processes, was not affected. In addition, thippocampal 5-HT $\mathrm{HA}_{2 \mathrm{~A}}$ receptor binding was not altered by PS (Chapter 4 ).

In adult male Sprague-Dawley rats, PS was associated with an increase in anxiety-and depression-related behavior, whereas females were largely unaffected. Male PS offspring also exhibited increased basal plasma corticosterone levels, whereas PS offspring of either gender failed to show an adequate response to stress, with lower stress-induced corticosterone levels as compared to controls. Interestingly, male birth weight seemed to be a useful predictive marker for adult psychopathology (Chapter 7).

Behavioral effects of PS were not always clear cut in adult male Fischer 344 rats. If left undisturbed after birth, PS males demonstrated increased anxiety- and depression-related behavior. Conversely, PS males showed lower stress-induced plasma corticosterone levels and exhibited less anxious behavior as compared to control offspring after a short period of postnatal stress. "These findings are in line with the "predictive adaptive response' (PAR) 
hypothesis, which postulates that a growing fetus tries to predict the environment it is likely to be born into in order to have an optimal chance of survival in that environment (Chapters 5 and 6 ).

Of a different nature, were the effects of maternal paroxetine treatment. The antidepressant paroxetine was administered in order to reduce the effects of prenatal maternal stress, through a positive effect on the pregnant dam. Unexpectently, it induced neonatal mortality in the vast majority of newborn pups, most likely due to neonatal withdrawal eflects and serotonin toxicity (Chapter 8 ).

In conclusion, the present work stresses the importance of the fetal environment in relation to adult psychological health, and specifically in relation to mood disorders. Clinical practice should become more aware of this phenomenon. Until proper pharmaceutical strategies have been designed, an adequate nutrient supply and psychosocial support to the pregnant woman are advisable. SSRIs, and especially paroxetine, should be cautiously used in the treatment of mood disorders in pregnant women. 


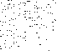

.

.

.

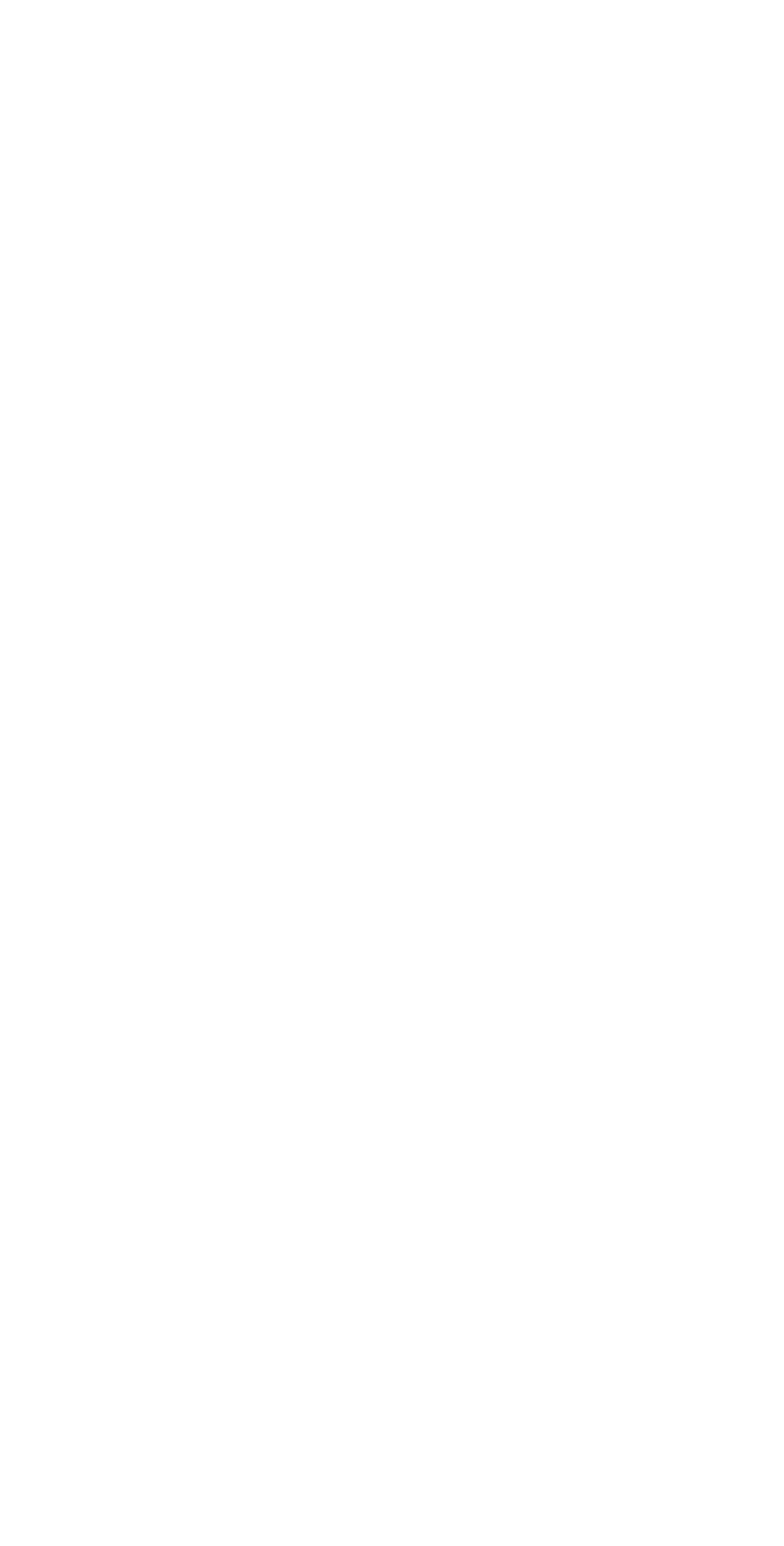





\section{Samenvatting}

Veranderingen in de foetale leefomgeving kunnen verstrekkende gevolgen hebben op het metabole en endocriene functioneren in het postnatale leven. Zo is aangetoond dat ingripende gebeurtenissen of stemmingsstoornissen bij zwangere vrouwen hun invloed kunnen uitoefenen op de zich ontwikkelende foetus, daarbij resulterend in een verhoogde vatbaarheid voor psychopathologie in het latere leven. De exacte mechanismen verantwoordelijk voor de effecten van prenatale stress. (PS) op adult functioneren zijn echter nog steeds onbekend. Dit met als gevolg dat een geschikte behandelwijze voor het tegengaan wan de effecten van PS ontbreekt. Onze studies, waarbij zwangere ratten in kleine plastic buizen (restraners) werden geplaatst tijdens de laatste week van de zwangerschap (drie maall daags 45 minuten), toonden aan dat PS resulteert in verscheidene korte en lange termijn effecten bij het nageslacht.

PS Fischer 344 nakomelingen vertoonden een verlaagd gewicht bij de geboorte, toegenomen basale en stressgeinduceerde plasma corticosteronwaarden één dag na de geboorte en een verstoorde ontwikkeling van het neonatale brein. Zo was PS bijvoorbeeld gerelateerd aan een afname in celproliferatie binnen het neonatale brein. Binnen de neonatale hippocampus werd verder een toename in caspase-3 activiteit en een afname in de niveau's van de neurotrofe factoren BDNF en $\$ 100 B$ waargenomen. Dergelijke veranderingen tijdens de vroege ontwikkeling dragen mogelijk bij aan een verhoogd risico voor psychopathologie op volwassen leeftijd (Hoofdstukken 2 en 3).

PS in Fischer 344 ratten resulteerde verder in een afname in $5-\mathrm{HT}^{*}$ receptor binding binnen de ventrale hippocampus, een gebied betrokken bij de regulatie van emotioneel gedrag. $5-\mathrm{HT}_{\text {iA }}$ binding binnen de dorsale hippocampus, een gebied voornamelijk betrokken bij leren en geheugen, was niet aangedaan, evenals hippocampale $5-\mathrm{H}^{2} \mathrm{~T}_{2 \mathrm{~A}}$ receptor binding (Hoofdstuk 4).

Volwassen mannelijke PS Sprague--Dawley ratten vertoonden een toename in angst-en depressiegerelateerd gedrag. Daarentegen was het gedrag van vrouwelijke PS Sprague-Dawley ratten nauwelijks an verandering onderhevig. PS mannetjes hadden verder toegenomen basale plasma corticosteron waarden, terwijl PS nakomelingen van beide geslachten een inadequate stressgeinduceerde corticosteron respons vertoonden in vergelijking met nakomelingen van moeders die tijdens de zwangerschap met rust waren gelaten. Het geboortegewicht bij manneties bleek binnen deze studie overigens een bruikbare predictieve marker te zijn voor psychopathologie op volwassen leeftijd (Hoofdstuk 7). 
De gedragmatige effecten van PS waren niet zo eenduidig in volwassen Fischer 344 mannetjes. Hoewel, indien na de geboorte met rust gelaten, PS mannetjes een toename in angst- en depressiegerelateerd gedrag vertoonden, leken deze dieren beter (lees: minder slecht) opgewassen tegen stress vergeleken met controle nakomelingen. Zo vertoonden PS mannetjes bijyoorbeeld lagere stressgeinduceerde plasma corticosteronwaarden en relatief minder angstgerelateerd gedrag in vergelijking met controle dieren na een korte periode van postnatale stress. Deze bevindingen sluiten aan bij de "predictive adaptive response" (PAR) hypothese, die verondersteld dat een zich ontwikkelende foetus zijn toekomstige leefomgeving tracht te voorspellen om zo een optimale kans te hebben hierin te overleven (Hoofdstukken 5 en 6).

Anders van aard waren de effecten van maternale behandeling met paroxetine, een veelgebruikte SSRI. Dit antidepressiva werd toegediend met als doel de effecten van prenatale maternale stress tegen te gaan wia een positief effect op de zwangere rat. Geheel onverwacht resulteerde deze behandeling in een massale sterfte van jonge pups, waarschijnlijk als gevolg van ontwenningsverschijnselen en serotonerge toxiciteit (Hoofdstuk 8).

Al met al benadrukt dit onderzoek het belang van het foetale leven in relatie tot psychopathologie op volwassen leeftijd, meer specifiek in relatie tot stemmingstoornissen. Totdat er geschikte farmaceutische therapieën zijin ontwikkeld, dient men te zorgen voor een adequate voedselvoorziening en psychologische steun voor de zwangere vrouw waar nodig. Het gebruik van SSRIs, en in het bijzonder paroxetine, tijdens de zwangerschap, moet vermeden worden (Hoofdstuk 9). 



\section{Curriculum vitae}

Daniël van den Howe was born on October 7 th 1978 in Maastricht, where he also grew up. After his Gymnasium-beta graduation at the Trichter College in Maastricht he left for Amsterdam in 1997 to study Medical Biology at the University of Amsterdam (UvA). He specialized in neurobiology and did an internship at the Swammerdam Institute for Life Sciences (SILS) in Amsterdam under the superwision of Professor Marian Joëls. After he had graduated cum laude in 2001, he came back to Maastricht, as a biology teacher at his former secondary school. In 2002 he started as a Ph. D. student at the Department of Pediatrics (supervisor Professor Carlos E. Blanco) and the Department of Psychiatry and Neuropsychology (supervisor Professor Harry W.M. Steinbusch) at Maastricht University (UM), the work of which is described in this thesis. During this project he also visited the lab of Professor Jean M. Lauder of the Department of Cell and Developmental Biology at the University of North Carolina (UNC) in the USA in 2004 for three months with a grant awarded by the Netherlands Organization for Scientific Research (NWO), Further, he was recently awarded a Kootstra Fellowship for talented aspirant postdocs by the UM.

Daniël van den Howe werd geboren op 7 oktober 1978 te Maastricht, waar hij ook opgroeide. Na het behalen van zijn Gymnasium diploma aan het Trichter College in Maastricht vertrok hij in 1997 naar Amsterdam om aldaar Medische Biologie te gaan studeren aan de Universiteit van Amsterdam (UVA). Hij specialiseerde zich in de neurobiologie en volgde o.a. een stage aan het Swammerdam Institute for Life Sciences (SILS) in Ansterdam onder supervisie van Professor Marian Joëls. Nadat hij in $2001 \mathrm{cum}$ laude afgestudeerd was keerde hij terug naar Maastricht, als leraar biologie op zijn voormalige middelbare school. In 2002 begon hij als promovendus binnen de afdelingen Kindergeeskunde (o.L.v. Professor Carlos E. Blanco) en Psychiatrie en Neuropsychologie (o.l.w. Professor Harry W.M. Steinbusch) aan de Universiteit Maastricht (UM). Het resultaat is dit proefschrift. Tijdens dit promotieonderzoek bezocht hij) in 2004 ook het lab van Professor Jean M. Lauder van de afdeling Cell and Developmental Biology aan de Universiteit van North Carolina (UNC) in de VS voor drie maanden m.b.v. een beurs toegekend door de Nederlandse Organisatie voor Wetenschappelijk Onderzoek (NWO). Verder ontving hij recentelijk een Kootstra Fellowship, een beurs voor talentvolle aspirant postdocs, van de UM. 



\section{Acknowledgements/Dankwoord}

Ik weet het, het is een cliché, maar toch, een promotieonderzoek doe je niet alleen. Bij deze wil ik dan ook iedereen bedanken die op enigerwijs heeft bijgedragen aan het voltooien van dit proefschrift! Hierbij will ik echter graag van de gelegenheid gebruik maken een aantal mensen in het bijzonder te bedanken.

Allereerst mijn beide promotoren: Prof. Dr. H.W.M. Steinbusch, Harry, en Prof. Dr. C.E. Blanco, Carlos. Bedankt voor jullie steun, in welke vorm dan ook, gedurende de afgelopen 4 jaar. Zonder jullie had ik hier niet gestaan. Jullie zijn ieder op jullie eigen manier van onschatbare waarde geweest. Jullie hebben me verder aanvankelijk goed kort aan de lijn gehouden en me op het juiste moment 'losgelaten'. Dit heeft mij wetenschappelijk maar zeker ook persoonlijk gevormd. Ik zou het achteraf bekeken niet anders hebben gewild. Bedankt ook voor de geboden mogelijkheden wat netwerken en buitenlandervaring betreft. Dat we nog lang mogen blijven samenwerken.

Veel dank ben ik ook verschuldigd aan mijn co-promotoren 'Wieckse White' Arjan Scheepens en Jos 'broodje frikadel' Prickaerts. Arjan, Jij hebt mij 4 jaar terug geholpen het project op te starten en ik kon altijd terecht bij je met wat dan ook. Ik heb enorm veel van je geleerd. Ik ben ervan overtuigd dat onze wegen zich nog zullen kruisen. Jos, jij hebt mijn project altijd maar weer nieuw leven ingeblazen met interessante discussies en het nodige kraswerk bij mijn drafts hield me scherp en alert. Mede dankzij jou is eigenlijk alles rondom dit project in een stroomversnelling geraakt. Nu aan de slag met NEWMOOD.

Wilma, intussen moeder, Van de Berg, ook jij was een motor achter dit project. Zonder jouw hulp bij aanvang, had ik hier zeker weten niet gestaan.

Prof. Marian Joëls, Henk Karst en medewerkers van het Swammerdam Institute for Life Sciences-Center for Neurosciences. Bij jullie is het allemaal begonnen! Bedankt voor de mooie tijd en het enthousiasme voor de wetenschap dat jullie op me hebben overgebracht.

De docenten Biologie aan het toenmalige Trichter College te Maastricht; in het bijzonder Dhr. Slots. Bedankt voor de levenservaring en zeker voor het flexibele lesrooster, dat het combineren van beide banen mogelijk maakte. Ik vond het geweldig!

A special word of thanks to Prof. Dr. Jean Lauder and colleagues/friends (Ann, Hans, Derrick \& family, Gennady and Lyuda, Gail, Victoria and Corinne) from the Department of Cell and Developmental Biology (University of North Carolina, Chapel Hill, NC, USA) who 
made my stay in the States possible. The visit to Chapell Hill was one of the best experiences of my life. Mainly thanks to you:

Prof Brian Leonard. You, Mu Myint and the students from Ireland, in particular Lieve Desbonnet, thank you for your contribution. Brainstorming with you is always great. Brian, you are a true inspiration to me!

Dr. Diego 'Pepuzz' Gazzolo..., thank you for your contribution! We'll meet again, I'm sure!

De paranimfen: Allereerst Dominique Gilissen, mijn boezemvriend. Ik heb ongelooflijk veel van je geleerd, waaronder alles uit het leven te halen wat er in zit en volop te genieten, hier en nu. Je beschikt over ongelooflijk veel talenten, vergeet dat niet. Matteo 'Pepuzz' Bruschettini. Gedurende een groot deel van mijn promotietijd mijn kamergenoot en daarnaast een echte vriend, mag ik wel zeggen. Sbrigati! Capisco? Daccordo? Grazie... Je bent een voorbeeld voor velen.

Zijn "opvolgster" Eva "5e" van. Donkelaar. We maken er wat moois van de komende tijd! Succes met promoveren. Is het nu $5 \mathbb{E}$ btw?

Gunter Kenis, ook jij was en bent nog steeds een 'rolle model' voor me, als wetenschapper en als mens. Je bent de drijvende kracht achter zoveel wetenschap!

Dat zelfde geldt voor Jan. Hoewel je nooit direct bij mijn project betrokken bent geweest, heb je mij toch weten te inspireren, bedankt (ook voor de prachtige cover).

Arjan Blokland: bedankt voor je inspirerende inbreng en tegengas waar nodig ;-).

De 'labwachters' Hellen Steinbusch en Marjanne Markerink-Van Ittersum, velen malen dank voor jullie bijdrage, van 'talkie-talkie' tot de onmisbare hulp op de werkwloer. Waar zouden we zijn zonder jullie?

Iedereen bij P\&N en Kindergeneeskunde, bedankt! In het bijzonder Ronald 'Ronnie' Deumens, a.k.a. Sjors, Sjarel, Sjaac (mijn eerste echte maat op de werkvloer), Wiell Honig (bedankt voor je hulp met mijn PC en Fischer-vrienden), Guido 'Sportman van het jaar' Koopmans, Bert 'Captain Scrabble' loosten: we hebben wat afgelachen de afgelopen jaren. Brenda Aendekerk en de stagiaires Bart Boosten en Lucia Kooiman: ook jullie erg bedankt? Niet te vergeten, het secretariaat P\&N met Lilian Swaen, Akke Spauwen, Nicole Senden en Mirèse Willems. Het secretariaat wan de afdeling Kindergeneeskunde met Tamara Smits en Marleen Rosbak. Allen bedankt!

Mensen van de verschillende discussieplatformen (o.a. Mood Disorder), bedankt voor het heerlijke brainstormen.

Medewerkers van het RNIL en CPV: bedankt voor al jullie hulp.

Niet te vergeten, Esther, die gedurende mijn eerste twee jaar heel wat heeft moeten doorstann als ik bijvoorbeeld met de feestdagen weer eens met mijn ratten bezig was in plaats van met haar... Ik heb ongelooflijk veel yan je geleerd, bedankt.

Mijn familie, in het bijzonder mam, pap, Manon, Dave en mijn petekindje Laura, die me hebben gemaakt tot wat ik nu ben en me van kinds af aan (mam en pap dan) hebben. gestimuleerd het beste uit mezelf te halen, zonder daarbij te vergeten te genieten van het leven. Het kan immers morgen voorbij zijn. Je werkt met name om te leven en niet andersom, toch? Laura, je eeuwige lach heeft me, daar waar nodig, de juiste afleiding bezorgd ;-) 
Misschien nog wel het allerbelangrijkste, mijn vrienden. De zinnen verzetten met jullie heeft mijn AlO-tijd tot een top-tijd gemaakt. Unne groete mercil Van de Raod vaan 11 tot de "Wicksers' en alles dat daar tussenin zit!" Teveel namen om op te noemen...

Een leven zonder liefde is als een landschap zonder zon. Als er geen schaduwen zijn, dan zijn er ook geen grote lichten.

Rene de Masny 



\section{Publications and Presentations}

\section{Journal articles}

DLA Van den Hove, JM Lauder, A Scheepens, I Prickaerts, CE Blanco, HWM Steinbusch (2006) Prenatal stress in the rat alters hippocampal $5-\mathrm{HT}_{1 A}$, but not $5-\mathrm{HT}_{2 A}$ receptor expression! Brain Res (In Press).

M Bruschettini, DLA Van den Howe, D Gazzolo, HWM Steinbusch, CE Blanoo (2006) Lowering the dose of antenatal steroids: the effects of a single course of betamethasone on somatic growth and brain cell proliferation in the rat. Am J Obstet Gynecol (In Press).

J Prickaerts, DLA Van den Hove, FLP Fierens, HK Kia, I Lenaerts, T Steckler (2006) Chronic corticosterone manipulations in mice affect brain cell proliferation rates, but only partly affect BDNF protein levels. Neurosci Lett 396: 12-16.

DLA Van den Hove, CE Blanco, B Aendekerk, L Desbonnet L, M Bruschettini, HP Steinbusch HP, I Prickaerts, HWM Steinbusch (2005) Prenatal restraint stress and long-term affective consequences. Dev Neurosci $27: 313-20$.

DLA Van den Hove, HWM Steinbusch, A Scheepens, WDJ Van de Berg, LAM Kooiman, BJG Boosten, I Prickaerts, CE Blanco (2006) Prenatal stress and neonatal rat brain development. Neurosci 137:145-55.

M Bruschettini, DLA Van den Hove, D Gazzolo, P Bruschettini, CE Blanco, HWM Steinbusch (2005) A single course of antenatal betamethasone reduces neurotrophic factor $\$ 100 \mathrm{~B}$ concentration in the hippocampus and serum in the neonatal rat. Dev Brain Res 159:113-18.

A Scheepens, DLA Van den Hove, $M$ van de Waarenburg and CE Blanco (2003) A single course of prenatal betamethasone in the rat alters postnatal brain cell proliferation but not apoptosis. J Physiol 552: 163-75.

'This work was supported by a grant from the Netherlands Organization for Scientific Reseanch (NWO). 


\section{Submitted}

DLA Van den Hove, HWM Steinbusch, L Desbonnet, M Bruschettini, HP Steinbusch, A Scheepens; ] Prickaerts, CE Blanco. Prenatal restraint stress and behavior; the implications of a subsequent exposure to stress. Am / Obstet Gynecol.

DLA Van den Hove, HWM Steinbusch, M Bruschettini, D Gazzolo, R Frulio, A Scheepens, J Prickaerts $\mathrm{CE} \mathrm{Blanco}$ Prenatal stress reduces $\mathrm{SIOOB}$ in the neonatal rat hippocampus. Neuroreport.

DLA Van den Hove, $\mathrm{CE}$ Blanco, L Desbonnet, AM Myint, M Bruschettini, I Prickaerts, BE Leonard, A Scheepens, HWM Steinbusch. Maternal paroxetine treatment and neonatal mortality in the rat; a preliminary investigation. Human Psychopharm.

M Bruschettini, DLA Van den Hove, D Gazzolo, P Bruschettini, CE Blanco, HWM Steinbusch. Cognition- and anxiety-related behavior, synaptophysin- and MAP2-immunoreactivity in the adult rat treated with a single course of antenatal betamethasone. Ped Res.

\section{Posters (most relevant)}

DLA Van den Hove, CE Blanco, L Desbonnet, M Bruschettini, HP Steinbusch, I Prickaerts, HWM Steinbusch (2005) Prenatal restraint stress and behavior; the implications of a subsequent exposure to stress. Neuroscience meeting 2005 (Washington DC, USA).

DLAA Van den Hove, CE Blanco, L Desbonnet, M Bruschettini, HP Steinbusch, J Prickaerts, HWM Steinbusch (2005) Prenatal restraint stress and behavior; the implications of a subsequent exposure to stress. Endo-Neuro-Psycho (ENP) meeting 2005 (Doorwerth, The Netherlands).

DLA Van den Hove, HWM Steinbusch, B Aendekerk, L Desbonnet, M Bruschettini, H Stein" busch, J Prickaerts $\mathrm{CE}$ Blanco (2005) Prenatal stress and subsequent exposure to stress: behavioral consequences. Pediatric Academic Societies ${ }^{3}$ (PAS) meeting 2005 (Washington).

DLA Van den Hove, A Scheepens, WDJ Van de Berg, BJG Boosten, LAM Kooiman, HWM Steinbusch, CE Blanco (2004) The Effect of Prenatal Stress on Birth Weight, Brain Cell Proliferation, Apoptosis and Brain Derived Neurotrophic Factor Content. Pediatric Academic Societies" (PAS) meeting 2004 (San Francisco).

DLA Van den Hove, A Scheepens, WDJ Van de Berg, BJG Boosten, CE Blanco, HWM Steinbusch (2003) The effect of gestational stress on dam weight, birth weight and developmental cell proliferation. Endo-Neuro-Psycho (ENP) meeting 2003 (Doorwerth, The Netherlands). 


\section{Presentations (most relevant)}

DLA Van den Hove (2006) Prenatal stress produces anxiety-and depression-related behavior particularly in male Sprague-Dawley rats. Invited lecture at the Department of Cellular Animal Physiology, Radboud University Nijmegen (Nijmegen, The Netherlands).

DLA Van den Hove (2006) Prenatal stress and adult psychopathology. Institutes Day Brain \& Behavior 2006 (Maastricht, The Netherlands).

DLA Van den Hove (2005) Prenatal stress and adult psychopathology. GROW Science Day 2005 (Vaals, The Netherlands).

DLA Van den Hove (2005) Prenatal stress and neonatal brain development in the rat. Invited lecture at the Neonatal Research Unit of the Karolinska Institute (Stockholm, Sweden).

DLA Van den Hove, CE Blanco, L Desbonnet, M Bruschettini, HP Steinbusch, J Prickaerts, HWM Steinbusch (2005) Prenatal Restraint Stress and Behavior in Fischer 344 Rats; the Implications of a Subsequent Exposure to Stress. Developmental Origins of Adults Health and Disease (DOHaD) meeting 2005 (Toronto, Canada). Pediatr Res 58 (5): 1025 D O-059.

DLA Van den Hove (2005) Prenatal stress and neonatal brain devellopment. Invited lecture at the Department of Maternal Fetal and Neonatal Health, Garibaldi Hospital (Catania, Italy).

DLA Van den Hove, JM Lauder, J Prickaerts, CE Blanco, HWM Steinbusch (2005) Prenatal stress in the rat alters hippocampal 5-HT1A, but not 5-HT2A receptor expression. European Graduate School for Neuroscience (EURON) psychopharmacology meeting 2005 (Kerkrade, The Netherlands).

DLA Van den Hove (2004) Prenatal stress and neonatal brain development. Invited lecture at the Department of Cell and Developmental Biology, University of North Carolina (Chapel Hill, USA).

DLA Van den Hove (2003) The effect of prenatal stress on birth weight, developmental cell proliferation, apoptosis and brain derived neurotrophic factor. European Graduate School for Neuroscience (EURON) Psychopharmacology meeting: from laboratory to Clinic 2003 (Maastricht, The Netherlands).

DLA Van den Hove (2002) Prenatal stress and depression. GROW Science Day 2002 (Vaals, The Netherlands). 